
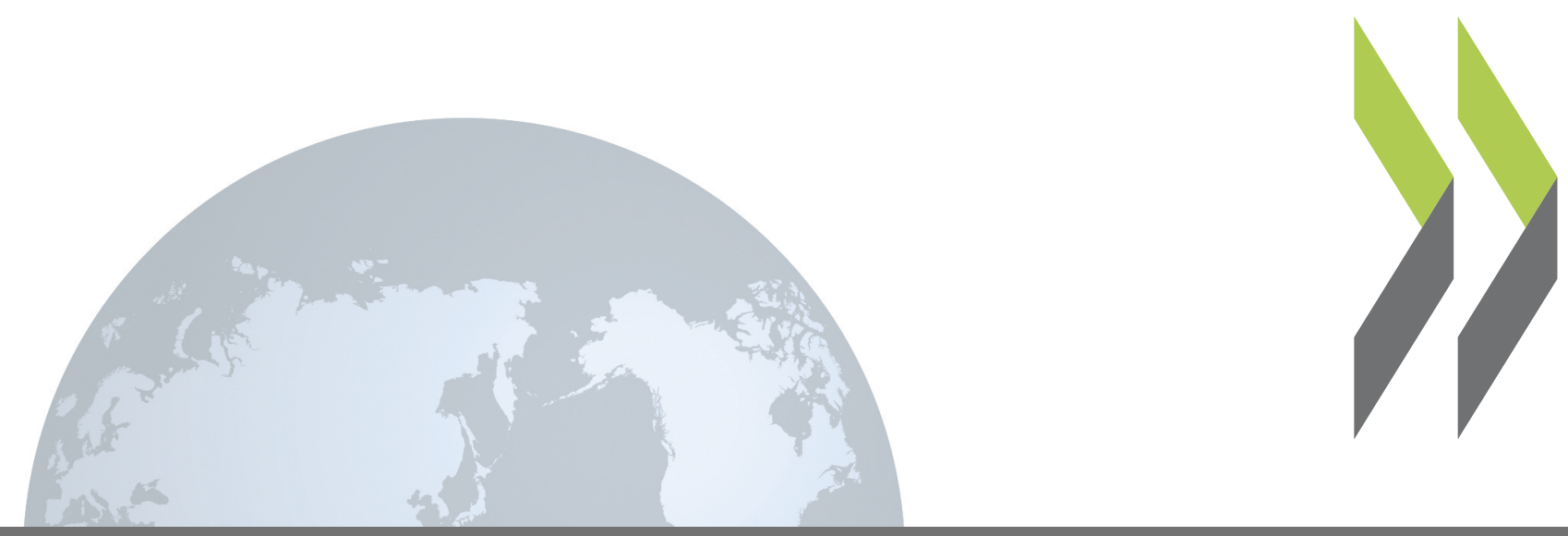

OECD Economics Department Working Papers No. 50

\title{
Private Consumption, Inflation and the "Debt
}

Neutrality Hypothesis": The Giuseppe Nicoletti Case of Eight OECD
Countries 


\section{OECD \\ DEPARTMENT \\ OF ECONOMICS AND STATISTICS}

\section{WORKING PAPERS}

No.50 PRIVATE CONSUMPTION, INFLATION AND THE "DEBT NEUTRALITY HYPOTHESIS" : THE CASE OF EIGHT OECD COUNTRIES

Giuseppe Nicoletti

Monetary and Fiscal Policy Division

January 1988

ㅇD로

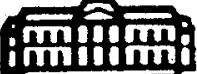

OEED 


\title{
ECONOMICS AND STATISTICS DEPARTMENT
}

\section{WORKING PAPERS}

\begin{abstract}
This series of Working Papers is designed to make available, to a wider readership, selected studies which the Department has prepared for use within OECD. Authorship is generally collective, but main individual authors are named. The Papers are generally available in their original language, English or French, with a summary in the other.

Comment on the Papers is invited, and may be sent to OECD, Department of Economics and Statistics, 2 rue André Pascal, 75775 Paris Cedex 16, France. Additional copies of the Papers on a limited basis can be forwarded on request.
\end{abstract}

ORGANISATION FOR ECONOMIC CO-OPERATION AND DEVELOPMENT

Copyright OECD 1986

WP. 931, 932

10808 
This paper examines the empirical basis for the debt-neutrality hypothesis in an international cross-section of eight major OECD countries over the period 1961-85. The analysis uses a dynamic demand system for durable and non-durable goods derived from individual optimizing behaviour. The model nests three specifications corresponding to different degrees of consumer rationality: the traditional life-cycle consumption model, the case of inflation-adjustment of disposable income (no money illusion) and the case of full "tax discounting" (no fiscal illusion). In addition, the model incorporates explicitly the role of a variable interest rate and substitution between public and private consumption. The model is estimated using three different consumption aggregates at the single-country level and over the pooled data set. Estimates of the inflation-adjustment and fiscal illusion parameters are provided and specification tests opposing the three versions of the model are performed. The evidence supports the inflation-adjustment of disposable income but rejects, in most instances, the hypothesis of full debt neutrality. Interestingly, however, a comparison of the results across countries suggests that the degree of fiscal illusion is low precisely in the countries where the growth of public debt is explosive.

Cette étude analyse, de façon empirique, l'hypothèse de neutralité de la dette publique, à partír de données internationales couvrant huit pays de l'OCDE et portant sur la période 1961-85. L'analyse se base sur un modèle dynamique de demande de biens durables et non durables, fondé sur un comportement de maximisation des consommateurs. Le modèle inclut trois spécifications correspondant à divers degrés de rationalité des consommateurs : le cas traditionnel de cycle de vie, le cas où le revenu disponible est corrigé des effets d'érosion dûs à l'inflation (absence d'illusion monétaire) et le cas où les consommateurs prévoient les taxes futures associées au service de la dette publique (absence d'illusion fiscale). Le modèle introduit explicitement $l^{\prime}$ influence du taux d'intérêt réel et la possibilité d'une substitution entre consommation publique et privée. Les estimations utilisent trois agrégats différents pour la consommation et sont effectuées pour chacun des pays et sur l'ensemble des séries de données temporelles et transversales. Les paramètres exprimant les degrés de correction pour l'inflation et d'illusion fiscale sont estimés et les trois spécifications concurrentes du modèle sont testées l'une par rapport à l'autre. Les résultats sont favorables à l'hypothèse de correction pour l'inflation mais rejètent, en général, celle de complète neutralité de la dette publique. L'examen comparé des résultats pour les différents pays suggère cependant que le degré d'illusion fiscale est faible précisément dans les pays où la croissance de la dette publique est explosive. 
PRIVATE CONSUMPTION, INFLATION AND THE "DEBT NEUTRALITY HYPOTHESIS" : THE CASE OF EIGHT OECD COUNTRIES

by

Giuseppe Nicoletti*

Monetary and Fiscal Policy Division

This paper was written while the author was a consultant in the Monetary and Fiscal Policy Division of the Department of Economics and Statistics at OECD. Thanks are due to Bruce Montador for his support and advice throughout this work and to Luca Barbone for his helpful suggestions. Partial funding from the Consiglio Nazionale delle Ricerche (Progetto Finalizzato CNR, "Struttura et evoluzione dell'economia italiana", U.0. M. Pagano-III/5/c-Contr. 8601349.53) is also acknowledged. The author is particularly indebted to Nicola Rossi for his most useful comments. 
I. INTRODUCTION

II. AN OVERVIEH OF THE THEORETICAL ISSUES

III. AN OVERVIEW OP THE EMPIRICAL EVIDENCE 10

A. Models and results

B. Limitations of the models

IV. A MODEL OF CONSUMPTION BEHAVIOUR

A. The model

B. Nesting the Basic Model and the Barro Model

C. The estimable model and its properties

V. EMPIRICAL ANALYSIS

A. The data

B. Debts, deficits and saving in eight OECD countries

C. Estimation and tests

VI. SUMMARY AND CONCLUSIONS

ANNBX $\quad 41$

NOTES $\quad 46$

$\begin{array}{lr}\text { TABLES AND CHARTS } & 54\end{array}$

$\begin{array}{ll}\text { REPERENCES } & 91\end{array}$ 
WP. $931 . s r$

\section{INTRODUCTION}

Over the last fifteen years, the fiscal position of many OECD countries has been dominated by the growing financing needs of the government sector. Notwithstanding recent improvements in the budget balances of some Member countries, in most cases the outlook for the long-run sustainability of current fiscal policies remains worrisome. Generally, abnormally high government deficits were the result of expansionary fiscal policies, of a lasting slack of economic activity and, more recently, of the high level of real interest rates partly induced by the firm anti-inflationary stand of most monetary authorities. The combination of these factors produced an upward trend of debt/GNP ratios in many OECD countries. High debt levels and sustained government deficits have increased awareness among economists and the general public of the necessity of budgetary adjustments designed to bring these variables under control in the medium term.

In an economic environment where the concern about the sustainability of fiscal policies is deepening, the private sector consumption behaviour can be expected to be influenced by anticipations about future fiscal events. The idea that the private sector can, under certain conditions, "pierce the government veil" and perceive correctly the constraints faced by the public sector is recurrent in economic theory and is known as the hypothesis of "ultrarationality" of agents. Recently, the most influential attempt to introduce ultrarationality and "fiscal expectations" into a forward-looking model of private sector behaviour was made in a paper by Barro (1974) who showed that, under rather stringent assumptions, the private sector correct anticipation of the future taxes associated with government debt service implies that the choice between tax and debt finance is irrelevant. If valid, this proposition would have important policy consequences, since it implies that only government direct absorption of goods and services can "crowd out" private resources. This line of reasoning has been dismissed by many economists as requiring excessively prescient consumers and unrealistic assumptions about markets and the structure of taxation. However, a complete divorce between probable future developments and current behaviour seems inconsistent with fundamental economic reasoning, at least in the context of the forward-looking theory of consumption that underlies much of the analysis of and prescriptions for economic policy. In particular, if private agents add a reaction function of the fiscal authorities to the set of constraints under which consumption decisions are taken, the effects of current and planned budgetary policies may differ substantially from those traditionally predicted by macro-economic theory.

Most of the theoretical and empirical debate about the economic scope of the "fiscal expectations" hypothesis has scrutinized the "debt neutrality" proposition put forth by Barro. To date, however, formal tests of this proposition have not been able to deliver unambiguous answers. In general empirical analyses of this proposition concentrate on its rejection (or non-rejection) but pay little attention to the economic and econometric meaning of intermediate results. While Barro's extreme view of a one-to-one substitutability between private and public saving is usually rejected, it is not possible to rule out, on the basis of the available evidence, some degree 
of "tax discounting" by agents. More generally, the significance of fiscal variables in the estimation of consumption models suggests that traditional models, by ignoring fiscal expectations, may be mis-specified.

The purpose of this paper is to present a new empirical analysis of the "fiscal expectations" issue in the context of a cross-country sample of eight OECD countries. To date, cross-country analyses of the tax-discounting hypothesis have been very few, although comparing the impact of different experiences of debt and deficits on private consumption seems a most promising avenue for research (1). Moreover, past analyses merely pooled international data sets, without taking a comparative approach. Finally this literature is frequently marred by the use of ad hoc consumption models and by the omission of important variables, making the results difficult to interpret.

The analysis undertaken in this paper is novel in several respects. A life-cycle demand system for durables and non durables is derived from individual optimizing behaviour using Theil's differential approach to demand analysis (also known as the "Rotterdam model"). The main advantage of this flexible functional form approach is that the implied consumption equations are general enough to nest many alternative hypotheses about consumers' behaviour. Under appropriate parameter restrictions, the model is consistent with both "random walk" and "error correction" models of consumption. The estimation of equations for durables and non durables makes it possible to check the model specification by imposing parameter restrictions within and across equations. In addition, it permits to control for the impact of the choice of the dependent variable on the results. In the past, both model specification and the choice of the dependent variable have proven to affect in important ways the results of tests of the "tax-discounting" hypothesis. Finally, the model nests, through an appropriate definition of the current and future components of intertemporal wealth, the traditional life-cycle model and the augmented specifications deriving from the "fiscal expectations" hypothesis.

Attempts are also made to control for the effects of a number of variables often ignored in the empirical "tax-discounting" literature. These include inflation adjustment of disposable income, interest rate variability and direct substitutability between private and public consumption. With the exception of the recent studies by Modigliani et al. (1985) and Modigliani \& Jappelli (1986), studies of the tax-discounting hypothesis using disposable income as a proxy for intertemporal wealth usually ignore inflation adjustment. The omission of inflation adjustment is equivalent to assuming that agents consider the inflation-premium component of interest payments as part of their real income. However, this appears to be an inappropriate framework for testing the tax-discounting hypothesis, since agents who foresee future taxes should not be affected by this kind of money illusion. Following Modigliani et al. this paper estimates the parameter of "tax discounting" together with the so-called "Hicksian-correction" factor, measuring the degree of ex ante inflation adjustment of disposable income. Two other important variables usually omitted in tests of the tax-discounting hypothesis are the real interest rate and government consumption. Estimates of consumption sensitivity to these variables are interesting in their own right, but controlling for them is particularly important in measuring the impact of government deficits on private consumption. On the one hand deficits and real rates were highly correlated in the last decade; on the 
other hand, substitutability (or complementarity) of private and public consumption can be a direct "crowding out" (or "crowding in") channel that operates independently of the "tax-discounting" effect. By ignoring these variables, many of the models used to test the tax-discounting hypothesis are poorly specified.

Another interesting aspect of the empirical investigation is the nature of the data set used. Inferences are based on cross-section and time-series data relative to eight major OECD countries in the period 1961-1985. For each of these countries, a life-cycle consumption model is estimated, including proxies for current and future wealth among the regressors. The "nested" definitions of anticipated and unanticipated components of future human wealth are approximated using the historical series of OECD income and government consumption forecasts. In a second stage of the analysis, data are pooled using the dummy-variable approach. The advantages of a cross-section and time-series analysis are obvious. First, it can help reduce multicollinearity among variables, which usually plagues tests of the "debt neutrality" proposition. Second it increases the degrees of freedom, which are usually limited by the lack of long time series for wealth stocks and government finance variables. Finally, by comparing estimates of the inflation-correction and tax-discounting parameters across countries one can try to relate agents' behaviour to the different historical developments in inflation, deficits and debts. The results of the analysis show that countries in which inflation was historically higher and where the dynamics of public debt and deficits appear to be explosive provide higher estimates of the inflation-correction and tax-discounting parameters. This may be interpreted as an indication that the private sector "learns with time" and that the public concern over the necessity of fiscal restraint has repercussions on agents' saving behaviour.

The plan of the paper is as follows. The next section briefly outlines the conflicting models and the theoretical rationale for the introduction of fiscal variables in life-cycle consumption functions. Section III reviews some of the empirical evidence concerning the "ultrarational" behaviour of agents. Section IV derives the consumption model that is the basis of our analysis. Section $V$ describes the data and discusses the results of our estimations. Estimation results are supplemented by a set of nested and non-nested "rationality tests" that oppose three competing rationality hypotheses: the traditional model, with no inflation-correction and no tax-discounting (labelled the "basic" model); the model with full inflation-correction and no tax-discounting (labelled the "Hicks" model); and the model with full tax-discounting (labelled the "Barro" model). A summary of the findings concludes the paper.

\section{AN OVERVIBW OF THE THEORETICAL ISSUES}

The conventional consumption function, derived from the Life Cycle or Permanent Income Hypotheses and embodied in most existing econometric models, relates consumption to various proxies for the private sector's intertemporal wealth. These usually include current (and/or lagged) disposable income and the stock of the private sector's financial and, possibly, fixed assets. This widely accepted model of consumption behaviour, which, henceforth, will be 
called "Basic Model", deals in a rather asymmetric way with the influence of fiscal variables on consumption. Current taxes, government transfers (including interest payments) and government debt creation are accounted for by relating consumption to disposable income and by including the stock of monetary and interest-bearing debt in the private sector's stock of wealth. However, the effects on consumption of future taxes and transfers, as well as the effects of current and future government consumption, are usually ignored, which is strange for a theory that embodies a strong intertemporal element. In addition, while the theory imposes heavy informational requirements on agents, who are sometimes supposed to be able to "pierce the corporate veil", no allowance is usually made for the ability of agents to foresee the current and future constraints faced by the government and the implications of inflation for the real value of their stock of financial assets.

The policy implications of the Basic Model are well known. An increase in government debt financing causes, at least in the long run, a crowding out of private saving and, hence, of capital accumulation that shifts the burden of the debt on future generations (2). These conclusions rest on the proposition that private saving, being controlled by life cycle considerations of "selfish" generations, is largely independent of government's current and future budget stance.

The asymmetries of the Basic Model, first noticed by Bailey (1962), were addressed in what has come to be known as the "ultrarational" or Consolidated Approach (CA) (3). In the CA, agents are assumed to incorporate the intertemporal constraint of the government into their own budget constraints and to evaluate fully the consequences of government activities for their own welfare levels. A fundamental insight of this approach is the possibility of a direct crowding out of private expenditure by government-related activities. This can occur either through a substitution of public for private consumption or through a substitution of public for private savings. The first effect derives in a straightforward way from the assumption that government consumption yields utility to individuals (4). The second depends on the so-called "tax-discounting hypothesis", namely the idea that individual agents foresee the future tax liabilities associated with current and future deficit financing of government expenditures and take account of them in their present behaviour.

The implications of the $C A$ have been pursued on different levels. The extreme view, mostly stemming from the work of Barro (1974), is based on the so-called "dynastic model". The dynastic model subsumes the aggregate behaviour of different (overlapping) generations of finitely-lived consumers in the behaviour of a single infinitely-lived representative consumer. The combination of the $\mathrm{CA}$ and of the dynastic model can be shown to have drastic implications. First, the consumption behaviour of agents depends on total resources available to the economy -- i.e. national income net of government absorption -- rather than on disposable income. Second, government debt ceases to be considered net wealth by the private sector since its current value is exactly offset by the discounted value of the future taxes necessary to finance the stream of interest payments that it implies. In other words, the stock of government debt does not affect consumption levels since it leaves agents' lifetime wealth unaffected. Given the level of public spending, agents respond to every government bond issue with a dollar-for-dollar increase of private saving. Third, there is no replacement 
of government debt for private assets in agents' portfolios (entailing a debt burden for future generations in terms of reduced capital accumulation) because agents can maintain the pre-debt optimal allocation of resources across generations by altering the level of private bequests.

From a policy point of view, the implications of this hypothesis are far-reaching. Since agents are completely aware of future taxes and will offset any undesired intergenerational redistribution of resources, whether government chooses to finance a given stream of expenditures through taxes or debt has an equivalent effect on the economy. It follows that, in this model (henceforth called the "Barro" model), debt-financed tax cuts have no effect at all on the economy and no crowding-out effects should be expected from the accumulation of government debt. These results, often referred to as the Ricardian Equivalence Proposition (REP) (5), are clearly at odds with the implications of the Basic Model.

While Barro's formal results are interesting from a theoretical point of view, their empirical relevance can be questioned, given the extremely restrictive assumptions necessary for the REP to hold. These assumptions concern the nature of individual preferences and of government policies as well as the configuration of markets. In particular, the validity of the REP requires:

a) the existence of operative intergenerational transfers (bequests or gifts) motivated by the altruistic nature of individual preferences (6);

b) certainty about agents' lifetimes (7);

c) the absence of capital market imperfections (8);

d) the absence of distortionary taxation.

In addition the kind of consolidation between public and private accounts which leads to the REP implicitly requires:

e) that the intertemporal budget constraint of the government is binding, i.e. that the government is solvent in the long-run (9), and

f) that the long-run financing regime of the government consists only of taxation (10).

Income taxation, monetisation of deficits, liquidity constraints and imperfections in intergenerational transfers, among many other features of real world economies, suggest that the Barro Model has little empirical content. But the probable failure of many of the above assumptions does not prevent the CA from providing a less restrictive depiction of reality than the one put . forth by the Basic Model. While it seems clear that the tax-discounting hypothesis does not hold in its strongest presentation, direct crowding out of private expenditure and expectations about future tax increases (or spending cuts) could be important factors in determining the impact of current fiscal policies and the effects of planned budgetary adjustments. For instance, if concern about future taxes is strong and substitutability between private and public consumption is high, current deficits depress private spending while the announcements of future budget restrictions stimulate it. If, on the contrary, tax discounting is negligible and public consumption does not substitute for private consumption, current deficits stimulate consumption while spending cuts or tax increases depress it. 
This kind of considerations makes it desirable to design and test models of consumption embedding elements of the CA. Ideally, models of this kind should explicitly account for the reaction function of the fiscal authorities and the features of the economy (such as the myopia of agents or market imperfections) that violate the assumptions of the Barro Model (11). This modelling strategy, coupled with the assumption of rational expectations would stress the signalling role of current and past fiscal behaviour, leading to an analysis of the effects of fiscal policy richer in implications than the traditional one. This line of research, termed the Extended Life Cycle Hypothesis by Modigliani \& Sterling (1986) and the Fiscal Expectations Hypothesis by Feldstein (1982), is still in its infancy stage. While no attempt is made in this study to fill this gap in the theoretical literature, it is important to keep in mind when interpreting the estimates of the tax-discounting parameter that the latter should be related to a complex set of interactions between the characteristics of agents' preferences, the constraints that they face and their perception of the fiscal authorities' reaction function.

With the exception of the recent studies by Modigliani \& Sterling (1986) and Leiderman \& Razin (1986), the prevailing empirical approach has been to test life-cycle consumption functions under the null hypothesis of the Barro Model. With few exceptions, studies of this kind have been quite vague about the microfoundations of the models tested. Consequently, a variety of ad hoc specifications have been employed. The next section reviews some of the empirical evidence on the tax-discounting hypothesis provided by these econometric investigations (12).

\section{AN OVERVIEW OF THE EMPIRICAL EVIDENCE}

A. Models and results

Empirical analyses of tax-discounting behaviour are usually based on models relating consumption to various components of current wealth and income. In general these models "nest" the Basic and the Barro Models by including the stock of government debt and the government surplus (or government consumption, if the income variable is Net National Product) as separate regressors in the consumption equation. According to the sign and the magnitude of the estimated coefficients, the definitions of private wealth and disposable income change, including or excluding part of the government debt and of the government surplus (or, alternatively, of government consumption). The Basic Model is obtained by imposing zero restrictions on the coefficients of these fiscal variables and the Barro Model is obtained by setting their coefficients equal to the inverse of the propensities to consume out of wealth and disposable income (13). However, these restrictions are seldom tested jointly: most authors claim acceptance or rejection of the tax-discounting hypothesis on the basis of the signs, the magnitudes and the significance of single coefficients. As a result partisans and opponents of this hypothesis base their assessments on different grounds. The former find evidence of tax-discounting behaviour in the rejection of any of the zero restrictions that lead to the Basic Model, namely the significance of the debt and/or tax variables and the irrelevance of the deficit or government consumption variables. The latter base the rejection of the tax-discounting 
hypothesis on the violation of any one of the restrictions leading to the Barro Model (14).

Tables 1-3 summarize the results obtained for three commonly used consumption specifications. The three specifications and the restrictions characterizing the Barro Model are shown at the bottom of the page. Each table reports the coefficient estimates of the various components of income and wealth, their significance, the other variables introduced as regressors, the estimation method used, the restrictions actually tested and the claim of the author(s) as to the rejection or the acceptance of the tax-discounting hypothesis.

The evidence brought up by Tables $1-3$ is ambiguous. On the one hand there is strong evidence that the implications of the pure Barro Model are violated: the relevant restrictions, when tested jointly, hold in only one case (Seater \& Mariano, 1985) and government transfers always have a significant positive effect on consumption. On the other hand, a number of statistical results suggest that conventional consumption functions are mis-specified: it is surprisingly difficult to obtain significant coefficients for government debt (and/or for social security wealth) and government revenues, while the coefficient of the deficit variable is almost always significant and negative. In addition, there is some evidence of a negative effect of government consumption on private consumption.

Tables 1-3 also point to several weaknesses of these empirical investigations. First, the coefficient estimates of the fiscal variables are extremely sensitive to model specification. Results change dramatically with the choice of the dependent variable (aggregate consumption, non-durable consumption or the sum of the latter and the services from durables), with the specification of wealth and income (inclusion or exclusion of debt and deficits, decomposition of income into anticipated and unanticipated components) and with the choice of the additional regressors (interest rates, inflation, stock of durables, etc...). This suggests that rather than using ad hoc consumption functions it would be preferrable to estimate models having enough structure to allow for a check of the model specification.

Second, the estimations suffer from three econometric problems: collinearity, simultaneity and measurement errors. In many instances the multicollinearity between the explanatory variables results in the low significance and in the instability of coefficient estimates. This, of course, biases tests of zero restrictions (or equality tests between coefficients having low significancy) towards acceptance. Unfortunately, variables as debt and debt service or income and government revenues, which are essential to the analysis, are strongly correlated over time. It seems therefore that this problem can be eased only by resorting to pooled cross-section time-series estimation and/or by estimating model specifications that induce orthogonal transformations of the regressors.

As for simultaneity, it is clear that, given cyclical fluctuations, consumer spending, disposable (or national) income and the government deficit (or its components) are highly correlated so that, in general, it is difficult to obtain satisfactory estimates of the separate effects of these variables on consumption (15). In order to overcome this problem many authors suggested the use of instrumental variable estimators. For instance, some of them 
report significant changes in the estimates when higher order lags of the regressors are used as instruments.

Measurement errors affect especially three variables: public debt, the government surplus and government consumption. In principle, the fiscal variables that accurately represent the resources drained by the public sector are government current consumption and net savings. However, the debt stock generated by these flows, i.e. the "deadweight" debt, is generally not observable. In addition, current consumption and net savings often underestimate government consumption since many items that are accounted for as investment do not generate revenue flows equal to their initial cost. Another source of mismeasurement of debt is its valuation procedure. Ideally, debt should be adjusted for inflation and at market value. Both these adjustments, when possible, involve a considerable degree of approximation $(16,17)$.

\section{B. Limitations of the models}

The modelling approach surveyed in the previous paragraph suffers from two related flaws. First, save for a vague reference to the Life-Cycle or the Permanent Income hypotheses, there are no explicit microeconomic foundations to justify the particular consumption function specifications used. The relationships between the functional specification, the hypotheses tested and the underlying model of individual behaviour -- in terms of preferences, time. horizon, constraints faced by consumers and attitude towards uncertainty -are usually ignored. This source of specification errors could be eliminated by a more consistent derivation of the model, possibly leading to additional structural restrictions. As it stands, the models are affected by a set of specification errors basically consisting of omissions of important explanatory variables.

The first important omission concerns the question of inflation-adjustment. Generally, disposable income and the deficit are defined gross of the inflation premium component of interest payments, and expected inflation is not allowed to influence the agents' perception of their wealth (18). To maintain that agents suffer from this kind of "money illusion" is clearly at odds with the considerable degree of rationality and foresight required by the tax-discounting hypothesis. In addition, while tax discounting behaviour is far from having been validated empirically, there is a significant body of empirical evidence pointing out that, in many countries, partial or complete Hicksian correction of disposable income accurately describes the behaviour of private agents (19). Ignoring inflation-adjustment may therefore result in biased and inconsistent estimates. The simultaneous estimation of the "Hicksian correction factor" and of the "tax-discounting factor" presents the double advantage of avoiding this possible mis-specification and of allowing a cross-check of the consistency of the results.

In the second place, most of the models make no attempt to account for the intertemporal components of wealth (20). On theoretical grounds, this omission could be justified only if agents where completely myopic. However, the tax-discounting hypothesis requires that agents have some foresight. The difficulty to find closed-form solutions in forward-looking models of consumption is well known, but, by relating consumption only to current wealth 
and expressing their null hypothesis in terms of the Barro Model, most authors are either mis-specifying their models or misinterpreting their results (21).

The disregard for future expected components of wealth is particularly disturbing in view of the interpretation of the coefficient estimates of the (included) current fiscal variables. For instance, the significant negative coefficient which is almost always associated with the deficit could be explained by the strong correlation between this variable and the (omitted) future transfers and taxes. Similarly, wher current taxes are significant, this could be related to their signalling role vis-à-vis the (omitted) future government expenditures. In such cases the estimations cannot yield reliable information on the validity of the tax-discounting hypothesis.

The last mis-specification error concerns the models that use the current deficit as a proxy for tax-discounting behaviour (i.e. the models in Tables 1 and 2). In order to test the Barro Model, these models define current income as National Accounts disposable income less the deficit of the public sector. Thus the null hypothesis implies that the relevant definition of income for agents is net national product net of government consumption. However, the CA implies that agents' income is net national product net of government dissipation, defined as the difference between government consumption and the value to the consumers of the goods and services handed back by the government. It follows that the consumption specifications in Tables 1 and 2 are correct only if government consumption is equal,to government dissipation. In other words these models contain the implicit assumption that government consumption is of no value to the private sector. If government consumption were to yield valuable services to the private sector, this variable should be included separately among the regressors.

The omission of the government consumption variable has two potentially damaging repercussions on the estimates. On the one hand, since this variable may be positively correlated with the deficit, its omission implies an upward bias on the coefficient of the latter. Given that this coefficient is generally negative, this biases the coefficient toward zero and hence favors the Basic Model. On the other hand, while tests using F-statistics are still consistent, their interpretation is now difficult since the models are not properly nested (unless, of course, government consumption is pure waste). Note, finally, that, while government consumption can be important for assessing the extent of consolidation and of substitutability between private and public consumption, it has no direct bearing on the tax discounting issue. In particular, the presumption that tax discounting would imply a negative coefficient of government consumption has no compelling theoretical justifications.

The consumption model presented in the next section attempts to overcome some of the weaknesses and limitations discussed so far.

\section{A MODEL OF CONSUMPTION BEHAVIOUR}

This section presents a framework for nesting the Life Cycle Hypothesis and the CA. This framework will be used to assess the empirical content of the hypothesis of ultrarationality. 
The model is an extension of the work by Rossi (1986). Rossi derives a life-cycle consumption function using Theil's "differential approach" to modelling demand systems. This section extends Rossi's model by deriving a life-cycle demand system for durables and non durables and by nesting the CA into the life-cycle framework. The advantage of the differential approach is that it yields a flexible functional form that combines many alternative hypotheses of consumption behaviour (22). The model below encompasses, under certain conditions, both the "random walk" and "error-correction" models of consumption (23). This characteristic is particularly desirable when the aim of the analysis is to fit the same consumption model to different countries. The model also allows for a varying real interest rate and, consistently with the $\mathrm{CA}$, accounts for the direct substitutability between public and private consumption.

\section{A. The model}

Consider the following intertemporal optimization problem solved by a representative consumer (24):

$$
\begin{gathered}
\max _{c} U\left(f\left(c_{t}^{n}, c_{t}^{d}, g_{t}\right), h\left(c_{t+1}^{n}, \ldots, c_{t}^{n} ; c_{t+1}^{d}, \ldots, c_{t}^{d} ; g_{t+1}, \ldots, g_{t}\right)\right) \\
\text { s.t. } \\
M_{t}=\sum_{i=0}^{T-t}\left(p_{t+i}^{\wedge n} c_{t+i}^{n}+p_{t+i}^{\Lambda d} c_{t+i}^{d}\right)
\end{gathered}
$$

$$
\text { where } \begin{aligned}
c_{t}^{n} & =\text { demand for non-durable goods } \\
c_{t}^{d} & =\text { demand for services from durable goods } \\
g_{t} & =\text { real public consumption of goods and services } \\
p^{n} & =\text { price of non-durable goods } \\
p^{d} & =\text { user cost of durable goods } \\
R_{t+s} & =\text { nominal interest rate }
\end{aligned}
$$

$$
\begin{aligned}
\hat{p}_{t+i}^{j} & =p_{t+i}^{j} / \pi_{s=1}^{i}\left(1+R_{t+s}\right) \text { for } i \geq 1 j=n, d \\
& =p_{t+i}^{j} \quad \text { for } i=0 j=n, d \\
M_{t} & =\text { intertemporal nominal wealth }
\end{aligned}
$$

Note that preferences are assumed to be weakly separable between present and future consumption and non-separable between broad aggregates of goods (25). In this framework agents decisions are assumed to follow a process of continual replanning in the light of new information received in each period (26). It is well known that the assumption of strong separability (additivity) severely limits substitutability, both between goods and over time (27). While still excluding habits formation, the assumption of weak separability implies a higher degree of substitutability over time and is 
consistent with a variable interest rate in the context of the model of consumption derived below. In addition, the lack of separability between durables and non durables implies the presence of cross-substitution price effects.

Demand functions deriving from the above maximization problem will be of the following kind:

$$
\begin{aligned}
& c_{t}^{n}=c^{n}\left(p_{t}^{n}, \ldots, \hat{p}_{T}^{n} ; p_{t}^{d}, \ldots, \hat{p}_{T}^{\wedge d} ; g_{t}, \ldots, g_{T} ; M ; t\right. \\
& c_{t}^{d}=c^{d}\left(p_{t}^{n}, \ldots, p_{T}^{n} ; p_{t}^{d}, \ldots, p_{T}^{d} ; g_{t}, \ldots, g_{T} ; M_{t}\right)
\end{aligned}
$$

Defining, for any variable $x, \hat{x}=\Delta(\ln x)$, and applying Theil's "differential approach" (Theil, 1980), the following demand system can be derived (28):

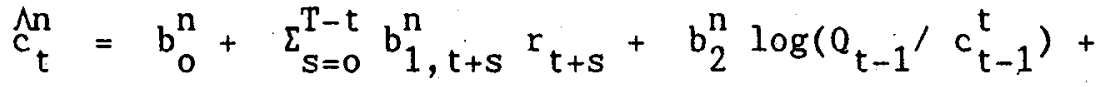

$$
\begin{aligned}
& +b_{3}^{n} \Delta_{t}+\Sigma_{s=0}^{T-t} b_{4, t+s}^{n} \hat{g}_{t+s}+ \\
& +b_{5}^{n}\left(p_{t}^{n} \lambda p_{t}^{t}\right)+e_{t}^{n} \\
& c_{t}^{\Lambda t}=b_{0}^{t}+\Sigma_{s=0}^{T-t} b_{1, t+s}^{t} r_{t+s}+b_{2}^{t} \log \left(Q_{t-1}^{\prime} c_{t-1}^{t}\right)+ \\
& +b_{3}^{t} \Delta_{t}+\Sigma_{s=0}^{T-t} b_{4, t+s}^{t} \hat{g}_{t+s}+e_{t}^{t}
\end{aligned}
$$

where $r_{t}=$ real rate of return on assets held from period $t-1$ to $t$;

$Q_{t}=$ real intertemporal wealth;

$c_{t}^{t}=c_{t}^{n}+c_{t}^{d}=$ total consumption;

$\Delta_{t}=$ innovations in net labor incomes;

$e_{t}^{j}=$ random component

Equations (1a)-(1b) relate the rates of growth of consumption to the beginning-of-period wealth-to-consumption ratio, to innovations in real human wealth, to a weighted average of current and future expected real interest 
rates, to changes in relative prices and to current and future rates of growth of government consumption (29).

These equations describe the equilibrium response of consumption to
changes in relative prices and intertemporal budget set. The presence of the lagged wealth-consumption ratio depends on the fact that, contrary to standard life-cycle models, homotheticity of preferences was not assumed. With no homotheticity, consumption shares in each period depend both on relative prices and on the stock of intertemporal wealth. If preferences where homothetic, the lagged wealth-to-consumption ratio would be a function of lagged real interest rates and relative prices. By adding to homotheticity the assumption of rational expectations, the income innovation $\Delta_{t}$ becomes a white noise disturbance and (1a)-(1b) can be interpreted as a generalization of Hall's random walk model (30). It is worth noting, however, that equations (1a)-(1b), as well as most of the analysis that follows, may be interpreted also in terms of the error-correction model proposed by Davidson et al . (1978), the lagged wealth-consumption ratio playing the role of an integral control mechanism.

The empirical analysis in the next section will be carried out using estimable versions of (1a), ( $1 b)$ and an equation identical to (1b) for aggregate consumption expenditure $c(31)$. In order to use (1a)-(1b) to assess the empirical scope of the hypothesis of ultrarationality, two more steps are needed. First; an expression for intertemporal wealth, $Q_{t}$, which nests the Basic Model and the Barro Model must be derived. Second, this wealth specification, as well as other variables in the model, must be expressed in terms of observables. This is done in the next two paragraphs.

B. Nesting the Basic Model and the Barro Model

In the $C A$ the private sector is fully aware of the consequences of government activities for its own attainable welfare levels. This has two main implications. On the one hand it requires that due account be taken of the imputed value to the private sector of services deriving from government consumption. This was accounted for in model (1a)-(1b) by introducing government consumption in individual preferences. On the other hand the private sector embeds the intertemporal constraint of the government into its own sectoral constraint. Consider the following standard expression for the private sector intertemporal budget constraint (32):

$$
Q_{t}=w_{t-1}\left(1+r_{t}\right)+b_{t-1}\left(1+r_{t}\right)+y_{t}^{T}-\tau_{t}^{T}
$$

where $w_{t-1}$ is real end-of-period non-human wealth net of the real end-of-period stock of government debt $b_{t-1}$; and $y_{t}$ and $\tau_{t}$ are the discounted values of real human wealth and of the real resources absorbed by the public sector during the economic lifetime of the decision unit, which is assumed to end at $\mathrm{T} \quad(0 \leq \mathrm{T} \leq \infty)(33,34)$.

Assuming that the planning horizon of the government is TG $(0 \leq \mathrm{TG} \leq \infty)$ and ignoring money financing, the public sector's intertemporal budget can be expressed in an analogous way (35):

$$
b_{t-1}\left(1+r_{t}\right)+g_{t}^{T G}=\tau_{t}^{T G},
$$


where $\mathrm{g}^{\text {TG }}$ is the discounted value of current and future government expenditures and $\tau^{T G}$ is the discounted value of current and future taxes net of transfers (excluding interest payments on government debt) (36). Note that, if the planning horizon of the government is infinite, equation (3) only states that the stream of current and future interest payments on government debt must be financed through a corresponding stream of primary surpluses. It puts no constraints on the repayment of the principal (37).

It should be clear from the discussion in Section II that the validity of the hypothesis of "ultrarationality" depends on two factors, agents' foresight and their perception of the constraints binding current and future government policies. In the sequel, agents will be assumed to perceive correctly the public sector constraint, so that deviations from ultrarationality will be only due to the lack of coincidence between the timing of taxation and the economic horizon of the private sector. A simple way to account for this is to pose that decision units have a fixed time horizon, known with certainty, and adopt the following measure of the tax burden borne by the agents during their lifetime:

$$
\delta=\left(\tau_{t}^{T}-\tau_{t}\right) /\left(\tau_{t}^{T G}-\tau_{t}\right)
$$

The parameter $\delta$ represents the share of government intertemporal revenues expected to be levied during the lifetime of a representative individual. It is defined as the ratio of the discounted net taxes expected by private agents and the discounted value of the net taxes implied by the government intertemporal budget constraint. The magnitude of $\delta$ may depend on both agents' time horizon and government policies. In particular, $\delta \rightarrow 1$ when either the economic horizons of the private and public sectors coincide or the distribution of taxes over time tends to concentrate within the economic lifetime of the decision units, while $\delta \rightarrow 0$ when either agents care only about current events or the distribution of taxes tends to concentrate after $T$. In general, if agents behave according to the life-cycle hypothesis and the government distributes taxes evenly over time, we will have $0<\delta<1$. Using $\delta$ we can define the net (intertemporal) resources perceived by the decision unit as (38):

$$
\tau_{t}^{T}=\delta \tau_{t+1}^{T G}+\tau_{t}
$$

Substituting (4) and (3) in (2) and using the definition of $\delta$, the following expression for intertemporal wealth can be obtained:

$$
\begin{aligned}
0_{t} & =w_{t-1}\left(1+r_{t}\right)+\left(1-a_{8}\right) b_{t-1}+ \\
& +Y_{t}^{d}-\pi_{t} b_{t-1}+a_{8}\left(s_{t}+\pi_{t} b_{t-1}\right)+ \\
& +y_{t+1}^{T}-\tau_{t+1}^{T}+a_{8} s_{t+1}^{n T G},
\end{aligned}
$$


where $Y_{t}^{d}=y_{t}+R_{t}\left(w_{t-1}+b_{t-1}\right)-\tau_{t}$, is National Accounts disposable income; $s$ and $s^{n}$ are respectively the government deficits gross and net of interest payments; and $a_{8}=\delta$.

Note that (5) contains the implicit assumption that the relevant measure of income for individuals is "inflation-adjusted" since only real interest payments are considered. Adjustment of disposable income for the holding losses due to inflation is consistent with Haig-Simons wealth accounting and with Hicks' "central concept of income" as "the maximum value (the agent) could have spent on consumption while maintaining the real amount of his capital stock intact". In view of the future discussion it is important to allow for deviations from such a Hicksian perspective (39). For this purpose, suppose that agents perceive only a fraction $a_{7}, 0 \leq a_{7} \leq 1$, of the holding losses on their nominally denominated assets. Since, if foreign assets are ignored, private sector's net financial assets consist only of government debt, interest payments on financial assets can be expressed as follows (40):

$$
r_{t} b_{t-1}=R_{t} b_{t-1}-a_{7} \Pi_{t} b_{t-1}
$$

where $\Pi_{t}$ is the expected rate of inflation from $t-1$ to $t$ and $R_{t}$ is the nominal rate of return on government bonds.

Substitution of (6) into (5), implies the following expression for inter temporal weal th:

$$
\begin{aligned}
Q_{t} & =w_{t-1}+\left(1-a_{8}\right) b_{t-1}+ \\
& +Y_{t}^{d}+a_{8} s_{t}-a_{7}\left(1-a_{8}\right) \Pi_{t} b_{t-1}+ \\
& +\left(y_{t+1}^{T}-\tau_{t+1}^{T}\right)+a_{8} s_{t+1}^{n T G},
\end{aligned}
$$

Expression (7) nests the Basic Model and the Barro Model. As $a_{8}$ varies from zero to unity, it describes the wealth implications of various degrees of coincidence between the private and public intertemporal constraints. When agents are myopic or when the bulk of taxation is concentrated beyond their lifetimes $\left(a_{8}=0\right)$, only current disposable income, possibly adjusted for inflation losses, enters the definition of human wealth; while non-human wealth includes the full amount of government debt. When agents behave as dynasties or when the bulk of taxation is distributed within their lifetimes $\left(a_{8}=1\right)$, human wealth includes current National Income and the future stream of labour incomes net of current and future government consumption, while non-human wealth excludes government debt. In the general case $\left(0 \leq a_{8} \leq 1\right)$, both government expenditures and their mode of financing affect perceived intertemporal wealth.

Equation (7) also incorporate an additional hypothesis about $a_{7}$. If $a_{7}=1$, inflation does not affect agents' perceived income. If $a_{7}=0$ agents 
suffer from a kind of money illusion and inflation increases their perceived incomes through nominal interest transfers. Finally, if $0<a_{7}<1$, inflation affects agents' perceived incomes only partially. It is important to notice that the effect of inflation (and hence the Hicksian correction of disposable income) is relevant only as long as $a_{8}$ is not unity, since in this case government debt ceases to be private wealth.

\section{The estimable model and its properties}

Substituting $Q_{t}$ by (7) in the demand system (1a)-(1b) and using a linear approximation in order to decompose the $\log$ of $Q_{t}$ into its three components -- beginning-of-period wealth, current income and future expected human wealth --, the following expression is obtained for $j=n, t(41,42)$ :

$$
\begin{aligned}
& \hat{c}_{t}^{j}=a_{0}^{j}+a_{1}^{j}, r_{t-1} r_{t}^{T}+a_{2}^{j} \log \left(w_{t-2}^{*} / c_{t-1}^{t}\right)+ \\
& +a_{3}^{j} \log \left(Y_{t-1}^{d^{*}} / w_{t-2}^{*}\right)+a_{4}^{j} \log \left({ }_{t-1} \bar{Y}_{t}^{T} / Y_{t-1}^{d *}\right)+ \\
& +a_{5}^{j} \Delta_{t}+a_{6}^{j}, t-1^{\hat{g}}{ }_{t}
\end{aligned}
$$

where $t-1 x_{t}$ denotes the expectation of any variable based on information available at time $t-1$, and the following variables are defined:

$$
\begin{aligned}
& w_{t-2}^{*}=w_{t-2}+\left(1-a_{8}^{j}\right) b_{t-2} \\
& Y_{t-1}^{\star d}=Y_{t-1}^{d}+a_{8}^{j} s_{t-1}-a_{7}^{j}\left(1-a_{8}^{j}\right)_{t-2} \prod_{t-1} b_{t-2} \\
& t-1 \bar{Y}_{t}^{T}={ }_{t-1} y_{t}^{T}-t-1 \tau_{t}^{T}+a_{8}^{j} t_{t-1} s_{t}^{n T G} \\
& t-1^{r^{T}}=\Sigma_{s=0}^{T-t}\left(a_{1, t+s^{j}} a_{1}^{j,}\right){ }_{t-1}{ }^{r} t+s
\end{aligned}
$$

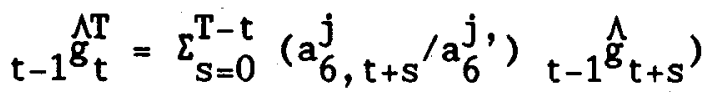

Except for $a_{8}^{j}$ and $a_{7}^{j}$, which represent respectively the degrees of "tax discounting" and of "hicksian correction", the other coefficients in (1c) are ratios between the structural parameters -- which depend on preferences and initial conditions -- and expenditure shares on the two kinds of goods. Barnett (1979) shows that, under mild conditions, (1c) can be interpreted as an aggregate demand system for durables and non durables, with coefficients constant over time. In particular, the constancy of the macro coefficients does not imply nor require the same constancy at the micro level. 
Clearly, for the system (1c) to be estimable, additional assumptions and approximations need to be made to express the variables appearing as expectations in terms of observable magnitudes. To this purpose, myopic expectations are assumed, i.e. for any $x$,

$$
t-1 x_{t+i}=t-1 x_{t} \quad \text { for any } i>0 \text {. }
$$

Under this assumption the following simplifications can be done:

$$
\begin{aligned}
& a_{1}^{j,}{ }_{t-1} r_{t}^{T}=a_{1 t-1}^{j}{ }_{t} ; \\
& a_{6}^{j,}{ }_{t-1}{ }^{\hat{g}}{ }_{t}^{T}=a_{6}^{j} t-1^{\hat{g}} t
\end{aligned}
$$

with $\quad a_{1}^{j}=\Sigma_{s=0}^{T-t}\left(a_{1, t+s^{j}}^{j} a_{1}^{j,}\right), \quad a_{6}^{j}=\Sigma_{s=0}^{T-t}\left(a_{6, t+s^{j}}^{\prime a_{6}^{j} \prime}\right)$

Unfortunately, given the maintained hypothesis of a variable interest rate and the "nested" definition of net incomes, future human wealth, $\left({ }_{t-1} \overline{\mathrm{Y}}_{\mathrm{t}}^{\mathrm{T}} / \mathrm{Y}_{\mathrm{t}-1}^{\mathrm{d}}\right)$, and the new information about human wealth arriving between $t-1$ and $t, \Delta_{t}$, cannot be rigorously reduced to simple expressions. Since these features of the model are central to the analysis, these variables are proxied in the following (admittedly rough) way:

$$
\begin{aligned}
& \log \left({ }_{t-1} \bar{Y}_{t}^{T} / Y_{t-1}^{d \star}\right)=t-\overline{\bar{Y}}_{t} \\
& \Delta_{t}={\frac{\Lambda}{Y_{t}}}_{t-1} \overline{\mathrm{Y}}_{t}
\end{aligned}
$$

The log of the discounted future "nested" incomes over the current "nested" disposable income is approximated by the one-period-ahead expected growth of "nested" income, and innovgtions in expected human wealth are approximated by the error in forecasting $\bar{Y}_{t}$.

These simplifications lead, for $j=n, t$ to the following model, which will be the basis of the subsequent analysis:

$$
\hat{c}_{t}^{j}=a_{0}^{j}+a_{1}^{j} t_{t-1}{ }^{r} t+a_{2}^{j} \log \left(w_{t-2}^{*} / c_{t-1}^{t}\right)+
$$

$$
+a_{3}^{j} \log \left(Y_{t-1}^{d *}{ }^{/ w_{t-2}^{*}}\right)+a_{4}^{j}{ }_{t-1} \overline{\mathrm{Y}}_{t^{+}}+
$$




$$
+a_{5}^{j}\left(\hat{\mathrm{Y}}_{t}-t_{t-1} \overline{\mathrm{Y}}_{t}\right)+a_{6}^{j} \cdot \hat{\mathrm{g}}_{\mathrm{t}}
$$

The model relates the rate of change of consumption to the expected real interest rate, to the previous period wealth-consumption and income-wealth ratios, to the anticipated and unanticipated growth in net labour incomes and to the rate of growth of government consumption.

In order to be cast in more manageable terms, the expected and unexpected income growth variables need some additional manipulation. To this purpose, the following "nested" tax-to-income and expenditure-to-income ratios are defined:

$$
\begin{aligned}
& r_{t}=\left(g_{t} / \bar{Y}_{t}\right) \\
& \theta_{t}=\left(\tau_{t} / \bar{Y}_{t}\right)
\end{aligned}
$$

Using these definitions, it is straightforward to show that ${ }_{t-1} \frac{\Lambda}{\mathrm{Y}} t$ and $\left(\overline{\mathrm{Y}}_{t}-{ }_{t-1} \overline{\mathrm{Y}}_{t}\right)$ can be expressed as follows:

$$
\begin{aligned}
& { }_{t-1}^{-\frac{\hat{y}}{y_{t}}}={ }_{t-1} \hat{y}_{t}+a_{8} \gamma_{t-1}\left(\hat{y}_{t}-t_{t-1} \hat{g}_{t}\right)+\left(1-a_{8}\right) \theta_{t-1}\left(\hat{\tau}_{t}-t_{t-1} \hat{\tau}_{t}\right) \\
& \left(\frac{\Lambda}{\bar{Y}_{t}}-{ }_{t-1} \bar{Y}_{t}\right)=\left(1+a_{8} \cdot r_{t-1}+\left(1-a_{8}\right) \theta_{t-1}\right)\left(\hat{y}_{t}-{ }_{t-1} \hat{y}_{t}\right)+ \\
& -a_{8} \gamma_{t-1}\left(\hat{g}_{t}-{ }_{t-1} \hat{g}_{t}\right)-\left(1-a_{8}\right) \theta_{t-1}\left(\hat{\tau}_{t}-{ }_{t-1} \hat{\tau}_{t}\right)
\end{aligned}
$$

The computation of (9) and (10) at different values of $a_{8}$ involves the choice of proxies for the anticipated rates of growth of income, net taxes and government consumption. The choice of appropriate proxies for these variables is discussed in the next section. A few observations about the characteristics of the model are in order at this point.

Note first that the derivation of (1d) relates consumption to the equilibrium behaviour of agents. Under this interpretation, coefficients $a_{2}-a_{5}$ are directly related to the slutzky income-effects and the dynamic structure of the model derives from the assumption that preferences are not homothetic. Second, note that the model is non-linear in the inflation-correction and tax-discounting parameters, $a_{7}$ and $a_{8}$. This is because wealth, disposable income and net labour income correspond to the "nested" definitions derived in the previous paragraph. The hypothesis of ultrarationality affects the model in three ways: through the definition of non-human wealth, $w^{*}$, through the definition of current disposable income, 
$\mathrm{Y}^{\mathrm{d}}$, and through the definition of "nested" future expected income. Note that the last effect is usually ignored in the literature.

The restrictions on the coefficients are of two kinds: within-equation and cross-equations. Within-equation restrictions require that:

$$
\begin{array}{ll}
\text { R1 } & a_{2}^{j}, a_{3}^{j}, a_{4}^{j}, a_{5}^{j}>0 ; \\
\text { R2 } & a_{2}^{j} \geq a_{3}^{j} ; \\
\text { R3 } & 0 \geq a_{7}^{j}, a_{8}^{j} \geq 1 .
\end{array}
$$

The first restriction depends straightforwardly from the assumption that income effects are positive. The second is implied by the fact that the short-run wealth elasticity is equal to $\left(a_{2}-a_{3}\right)$. The third is a requirement for rationality that was already discussed in the previous paragraph.

Note that no sign restrictions can be put on coefficients $a_{0}, a_{1}$ and $a_{6}$. The interest rate coefficient combines a (negative) intertemporal substitution effect and a (positive) income effect. Its sign is therefore ambiguous. Similarly, the effect of government consumption is a priori ambiguous, since there are no reasons to believe that this kind of government activity is a substitute (or a complement) for private consumption. Finally, note that, although in the context of the above derivation the constant has no specific role to play (while the other coefficients are related to preferences, $a_{0}$ is just a function of initial conditions), it is easy to think of extensions of the model in which this coefficient would capture changes in the structure of preferences over time (Theil, 1975).

Two obvious cross-equations restrictions concern the tax-discounting and the Hicksian-correction factors. The rationality of agents requires:

R4 $\quad a_{7}^{n}=a_{7}^{t}$ and $a_{8}^{n}=a_{8}^{t}$

A less obvious restriction involves the income and wealth coefficients. Symmetry in the derivation of the two equations implies that,

R5

$$
\left(a_{2}^{t} / a_{2}^{n}\right)=\left(a_{3}^{t} / a_{3}^{n}\right)=\left(a_{4}^{t} / a_{4}^{n}\right)=\left(a_{5}^{t} / a_{5}^{n}\right)
$$

These restrictions state that the ratios of the income effects on the two consumption aggregates must be equal, no matter the component of intertemporal wealth they refer to.

Note also that, in accordance with the life-cycle theory of consumption, (1d) restricts the steady state elasticity of consumption to income and wealth to be unity (43). Labelling the steady state rates of growth of income and government consumption respectively $n$ and $\lambda$, the long-run expression for (1d) is: 


$$
\begin{gathered}
c^{j}=\exp \left(\left(a_{0}^{j} / a_{2}^{j}\right)+\left(a_{1}^{j} / a_{2}^{j}\right) r+\left(\left(a_{4}^{j}-1\right) / a_{2}^{j}\right) n+\left(a_{6}^{j} / a_{2}^{j}\right) \lambda\right) * \\
\star_{w}^{\star}\left(a_{2}^{j}-a_{3}^{j}\right) / a_{2}^{j} \quad y^{d *} a_{3}^{j} / a_{2}^{j}
\end{gathered}
$$

Finally, it is important to emphasise again that, under suitable restrictions on the parameters $a_{2}$ and $a_{3}$, the model is undistinguishable from an error-correction model with an integral control mechanism (Hendry \& Von Ungern-Sternberg, 1981). However, in such a disequilibrium interpretation, the meaning of the coefficients $a_{2}-a_{5}$ changes. These must be related to the parameters of the underlying adjustment-cost function, $a_{2}$ representing the "proportional control", $\left(a_{2}-a_{3}\right)$ the "integral control" and $a_{4}, a_{5}$ the "derivative controls" (44). If the adjustment-cost function is quadratic, the higher are $a_{2}$ and/or $\left(a_{2}-a_{3}\right)$ the slower is the error-correction mechanism.

\section{EMPIRICAL ANALYSIS}

Model (1d) was estimated using three different measures of consumption in per capita terms: total consumption (CT) -- defined as the sum of non-durables and services and services from durable goods --, non-durable consumption (CND) and aggregate consumption expenditure (C). Estimations were carried out on annual data over the period 1961-85 for eight OECD countries and on the pooled data set. The countries are: United States, Japan, Germany, France, United Kingdom, Italy, Canada and Belgium. Although the choice of the panel was mainly dictated by data availability, these countries provide a large spectrum of historical experiences of debt and deficits. The next paragraphs briefly describe the data set and provide some stylized facts about the behaviour of public debt, deficits and private savings over time. Finally the results of the estimations are reported. In this context, "rationality tests" opposing the preferred estimated equations to the Basic Model, the Hicks Model and the Barro Model are implemented. In addition, further discrimination between the competing models is attempted by performing non-nested tests of the Mackinnon \& Davidson variety.

A. The data

The data set was gathered with two major concerns: ensuring a maximum degree of comparability among countries in order to make the pooling possible and obtaining time series long enough to make possible the estimation of the single-country equations. The sample period, 1961-85, is the same for all countries. In general, flow data (private and government consumption, income and net taxes), deflators, interest rates and population have been drawn from OECD sources (National Accounts, Analytical Data Base interest files, Labour Force Statistics) while stock data were collected, when possible, from sectoral balance-sheet accounts or other national sources. In a few cases stock series were partially generated from flows using perpetual inventory methods. The Annex provides a detailed description of the data and of their sources. In this paragraph some of the problems faced in collecting the data 
are briefly discussed. The main problems concerned consumption, wealth, government debt and expectations.

Consumption. For the purposes of this study total consumption was defined as the sum of the consumption of non-durables and services and the service flow of the stock of durables. The real service flow of durables was equated to the depreciation of their beginning-of-period stock, assuming, for simplicity, that their rate of return is on average close to zero (45). Since the expenditure on durables can be assimilated to investment, total consumption should reflect the consumption flow of the private sector more adequately than aggregate consumption expenditure. However, while long series for the latter are readily available for most countries, the series of the expenditure on durables, and even more so of their stocks, are more difficult to obtain. For this reason it was possible to obtain estimates of total consumption only for five countries: United States, France, United Kingdom, Italy and Canada. For United States, United Kingdom and Canada official series for net durable stocks are available. In the case of France and Italy it was possible to compute them using durable flows, base-year benchmarks and constant depreciation rates. Unfortunately no benchmarks were found for Belgium so estimations for this country were limited to CND and C. In the case of Germany and Japan not even the expenditure on durables was available over the sample period (46). For Germany it was possible to estimate this series in order to obtain a series for CND (see the Annex for details). For Japan, however, estimations could be carried out only for $C$.

Wealth. Wealth was defined as the sum of the private sector's capital stock, the private sector's housing stock, the stock of durables and the stock of net foreign assets. Land was excluded for lack of consistent and reliable data across countries. The capital stock at constant cost, net of scrapping but gross of depreciation, was available, from different sources, for all countries (47). Complete housing stock series were available for all countries except France and Japan. The French housing stock series was extended by the perpetual inventory method (assuming a constant depreciation rate) to cover the sample period. However, an attempt to do the same for Japan was unsuccessful (48). Finally, series on the stock of net foreign assets were partially estimated from current account flows in the case of France and, again, Japan. For the other countries official series were used.

Government net debt. To ensure homogeneity among countries, government debt, the government surplus, net revenues and government consumption are defined on a general government basis (49). Net government debt is defined as outstanding liabilities less financial assets. A net worth approach would have been more consistent with the spirit of the hypotheses being tested. However this approach raises formidable conceptual and measurement problems which are beyond the scope of this study (50). Government surpluses are the current net savings of the general government sector. This, as opposed to net lending (or the borrowing requirement), is the relevant variable in analyses of the tax discounting hypothesis, since it approximates the source of government "deadweight" debt. As it was noted in Section III.A, there is an inconsistency between net debt and net saving that is hard to avoid, since the "deadweight" debt is not observable. Generally, government data was drawn from sectoral balance sheet accounts or from OECD data files. However, due to changes in the classification of sectors, general government debt was partially estimated for the early sixties in the case of France and Japan. 
Expectations. Approximation of expected variables can be done either by assuming specific stochastic processes for these variables and computing the corresponding mathematical expectations, or by using survey data and/or proxies. The second approach was chosen for two reasons. First, the estimation of ARIMA processes for all the variables appearing as expectations in the original model and the simultaneous estimation of the demand system and the postulated autoregressive expectation functions is an endeavour which is beyond the possibilities of the data set used in this paper. Second, a large sample of OECD annual forecasts of inflation, income growth and public consumption growth is available for the major seven OECD countries. Given the way these forecasts are generated (i.e. through a complex interaction between the national governments, the opinions of OECD country desks and, only recently, the results of INTERLINK simulations) and the influence they exert on the public, they probably represent good proxies for the average opinion of the market. In view of these considerations and given that expectations play an important role in our analysis, it seemed preferrable to rely on this kind of "survey" data rather than on necessarily arbitrary econometric models of expectation formation.

One-period-ahead forecasts were approximated by the simple average of the OECD annual forecasts published in the Spring and Fall issues of the Economic Outlook. This procedure partially accounts for the learning process occurring between the two issues. These averages were substituted for the expectations about income, government consumption and inflation appearing in expressions (9) and (10) above (51). Two different proxies for the expected growth in net taxes were tried: income growth expectations and actual growth rates of government revenues. The second option, equivalent to the assumption of perfect foresight, seemed more consistent with the framework being used. In addition it performed better in the estimations. Hence it was retained throughout the paper. In the case of Belgium, the OECD forecasts series was too short (52). Rather than dropping the country altogether, the distinction between anticipated and unanticipated variables was abandoned and the model was estimated with actual rates of growth instead of expectations.

B. Debts, deficits and saving in eight OECD countries

Charts 1-4 provide some evidence on the behaviour of public debts, deficits, private saving and consumption in eight OECD countries during 1961-85. Chart 2 plots, for each country, the ratios to the NNP of the net saving (SAGG) and of the basic surplus (SAGGN) of the general government (53). Chart 1 shows the time profile of the net financial liabilities of the general government (NFLGG).

The inspection of these graphs highlights three major tendencies of debts and deficits in the period under consideration. First, in all countries, the level of government surpluses has been, during the last decade, persistently lower than in the earlier period. In most cases, this change in levels has been coupled, at least up to the early eighties, by a decreasing trend of the government budget balance. This suggests that these balances have deteriorated independently of the short-term fluctuations due to the oil shocks and to the economic cycles. 
Second, except for Japan and Germany, where an upward trend of the basic surplus started as early as 1975, the change in the levels of government net saving and its decreasing trends were due both to smaller basic surpluses and to the effect of debt accumulation on the debt service component of current transfers. The profile of the debt ratio shows that, except for Italy, where the debt ratio increased steadily since the early sixties, in the last decade all countries have experienced an inversion of the after-war downward (or flat) trends. This phenomenon, initially due to the combination of the lower basic surpluses and the weak overall performance of the OECD economies (resulting in insufficiently large cyclical surpluses to compensate for the deterioration of the basic balances), was compounded in the eighties by the high level of real interest rates and by the resolve of the monetary authorities to limit the monetary financing of the deficits. As a result, with the exception of Japan and Germany, which apparently succeeded in stabilizing their debt ratios, by the early eighties, the upward tendency of these ratios had become very pronounced and in some cases (Italy, Belgium, United States and Canada) even explosive (54). In these countries the repercussions of debt growth on the interest bill widened the gap between the basic and the gross-of-interest surpluses.

Third, except for Italy and Canada, one notes an improvement in the net-of-interest government balances in the most recent period. However, perhaps because real interest rates have stayed well above the economies' rates of growth, this recent improvement has been, in most cases, still insufficient to stabilize debt ratios.

These tendencies suggest that the history of recent years represents an ideal experiment for testing the implications of the CA and of the Barro Model. Government saving has decreased in a persistent way and, in most countries, if governments actually intend to be solvent in the long run, the apparently unsustainable paths of debt accumulation call for budgetary adjustments in the near future (55). In such an economic context, the CA predicts that public dissaving should, at least to some extent, have been offset by increased private saving. On the contrary, traditional life-cycle models predict that private saving should have declined together with government saving, causing the national saving rate to decline even more.

What is the evidence on the comparative behaviour of the saving rates of the government sector, of the private sector and of the nation? Chart 3 superimposes the time profile of the private and national saving rates to that of general government net saving. Private and national savings (labelled respectively SAPR1 and SANA) are measured net of the consumption of fixed capital. These measures are consistent with Net National Product, the appropriate concept of private sector disposable resources under the REP. For illustrative purposes, broken linear trends were fitted to the time series behaviour of sectoral savings (56).

The evidence provided by these graphs does not lend much support to the "ultrarational" view. Although, in the period 1961-73, the private saving rate generally behaved consistently with the tax-discounting hypothesis (in all countries, except Canada, its trend was inversely related to the trend of the government surplus), its behaviour in the more recent period is largely inconsistent with the Barro Model (57). Of course, in the light of the earlier discussion, the period $1974-85$ provides a more significant check of 
the validity of the model, since it is precisely over this period that the budget balance of many governments took on an unsustainable stance. This notwithstanding, except in the United Kingdom and Canada, the private saving rate seconded the downward trend of the government saving with a, generally mild, trend decline which, prima facie, contradicts the predictions of the Barro Model. In no country the private saving rate was sufficiently sustained to offset the decrease in government saving. As a result, in all countries the national saving rate was lower in 1985 than in 1970.

of course this casual evidence on the contemporaneous behaviour of private and public savings need not falsify the CA or the REP. It is logically possible that increased deficits actually raised private savings but that other factors caused private savings to decline, offsetting the Ricardian effect (58). Only an econometric analysis which controls for the contemporaneous effect on saving of other variables (as income, wealth, real rates, etc...) can yield additional information on this point.

\section{Estimation and tests}

The next paragraphs discuss the results of estimations and tests of hypotheses performed on the single countries and on the pooled data set. The basis for this analysis is model (1d) without the government consumption variable. This variable turned out to be insignificant in most regressions. Moreover, contrary to earlier presumptions, its presence did not affect the results of the regressions in any essential way. Therefore estimates including government consumption are presented in a separate section. Relative prices were dropped from the non-durable consumption equation for similar reasons.

Equations were estimated by ordinary least squares and values for the parameters $a_{7}$ and $a_{8}$ were found by scanning procedures. At this stage of the analysis, the demand system for CT and CND was not estimated simultaneously. Hence, the cross-equations restrictions shown in Section IV.C could not be formally tested. Likewise, non-linear estimation of $a_{7}$ and $a_{8}$ was not at tempted. Future work will be dedicated to fill this gap.

In the tests of hypotheses the "preferred" equations (resulting from the scanning procedures) are contrasted to three alternative model specifications: the Basic Model (with $a_{7}=a_{8}=0$ ), the Hicks Model (with $a_{7}=1$ and $a b_{8}=0$ ) and the Barro Model (with $a_{8}=1$ ). In addition, further discrimination among these limiting cases is attempted by applying non-nested testing procedures.

\section{Single equation estimates}

\section{The performance of the model}

Tables 4-12 report the results of the regressions on a country-by-country basis. For each consumption equation, the first column contains the estimates of the preferred equation. These were obtained by a "grid search" over five values of the parameters $a_{7}$ and $a_{8}$ over the square $((0,1),(0,1))$. The next three columns contain the results obtained by imposing particular restrictions on $a_{7}$ and $a_{8}$ (except, of course, when the 
preferred equation coincides with one of the limiting cases). These restrictions can be interpreted as expressing different degrees of rationality of agents. In the first, the Basic Model, agents suffer from "money" and "fiscal" illusion. In the second, the Barro Model, agents have'no "fiscal" illusion. As explained earlier, this implies that inflation adjustment is irrelevant. In the third, agents have no "money" illusion but suffer from complete "fiscal" illusion, this case is called the Hicks Model.

Before discussing in detail the results of the tests of hypotheses, some general features of the model performance must be stressed, referring to some of the single country results. The following discussion concentrates on the estimates of the preferred equations.

Note first that, given the available degrees of freedom (19), the fit of the model appears quite good. Except in the equation for Japan, which probably suffers from the data problems discussed in Section V.A, the model explains a large part of the time-series behaviour of consumption in the different countries. The standard errors of the estimates (SEE) range from .5 per cent (for the United States and France) to 1.2 per cent (for Italy) and the adjusted $R^{2}\left(R^{2}\right)$ range from 63 per cent (for Belgium) to 86 per cent (for France). These are better than average for a model of consumption expressed in log-changes (59). The model performs well in all consumption equations (CT, CND and C) however, as expected, in three out of the five countries for which data on durable services were available (United States, United Kingdom and France) the CT equation dominates the other two (in terms of SEE and $R^{2}$ ). This partially confirms the presumption that total consumption is to be preferred to aggregate consumption in empirical analysis. The opposite ranking obtained for Italy and, especially, Canada probably point out that our proxy for the service flow from durables is inadequate for these countries.

Another encouraging aspect of the regression results is that coefficients are generally correctly signed, of acceptable magnitudes and sufficiently stable across equations, suggesting that, in most cases, the specification of the model is correct.

As far as signs are concerned, the interest rate effect $\left(a_{1}^{j}\right)$ deserves some discussion. The coefficient estimates show a strong and negative effect of the real interest rate in Germany and France (with long-run elasticities of consumption respectively of -0.03 and -0.01 ), an insignificant effect in Italy, Belgium and Japan, and a significant and positive effect in the United States, the United Kingdom and Canada. It was argued earlier that the equilibrium framework in which the model was derived does not suggest a priori reasons to find a definite sign on this variable, since $a_{1}$ combines an income and a substitution effect of uncertain magnitudes. Similarly, no definite sign would be expected in an error-correction interpretation of the model. However, Hall's Euler-equation approach, on which much of recent research is based, predicts a positive relationship between the growth of consumption and the real rate of interest (60). This could be of some interest for the results since Muellbauer (1986) recently showed that models as (1d) can be derived from Euler-equations under the hypothesis of non separable preferences (habits formation). In any case, independently of the interpretation of model (1d), one would expect to find a coefficient on aggregate consumption and total consumption lower than that on the consumption of non durables, 
since there are strong empirical and theoretical reasons to believe that the expenditure on durables and the consumption of durable services are negatively affected by the real interest rate (61). In fact this is the case for the United Kingdom and Canada. Using the relation between the estimated CT and CND coefficients and the coefficients of CSD given in Section IV.A (see Footnote 31), one can actually derive negative real interest rate effects on the consumption of services from durables for these countries. (62). The same, however, cannot be obtained for the United States. Moreover the estimates of $a_{1}$ for this country appeared to be insensitive to a) changes in the definition of wealth (substitution of the wealth series with the households net worth series of the U.S. Flow of Funds); b) changes in the definition of the real interest rate (substitution of the original interest rate variable with a measure of the real after-tax rate, with the nominal rate and with the lagged nominal or real rate); and c) changes in the specification of the model (re-estimation of the equations omitting the wealth variable). The somewhat puzzling result obtained for the United States could perhaps be related to the collinearity between the income variables and the real interest rate (63). As will be seen, this guess is partially confirmed by the results of the pooled regressions.

The examination of the coefficients' magnitudes points out that for most countries restriction $R 2$ is satisfied. Using sample means of consumption, wealth and income, the estimates of $a_{2}$ and $a_{3}$ imply long-run propensities to consume out of wealth and income ranging respectively from .0 to .08 and from .61 to .81 . On average, these estimates are respectively lower and higher than, but broadly consistent with, the propensities predicted by Modigliani \& Ando (1963) in the case of a stationary economy with a zero real interest rate. A casual inspection of the ratios between the wealth and income coefficients of the CT equations and the corresponding coefficients of the CND equations shows also that restriction R5 is likely to be satisfied in most instances. Of course this conjecture needs to be confirmed by likelihood ratio tests on the demand system as a whole. One should also note that, in a few cases (the $\mathrm{C}$ equation for the United.Kingdom and Canada, the CND and the CT equations for Italy and Canada) restriction R2 is not satisfied, implying negative long-run wealth elasticities. While for the United Kingdom and Italy these results are statistically insignificant (it is impossible to reject on the basis of a simple t-test the equality between $a_{2}$ and $a_{3}$ ), in the case of Canada the violation of the restriction is particularly disturbing because it is statistically significant and persistent across equations. This suggest that further checks of the model specification are needed.

Note finally that the "nested". definitions of anticipated and unanticipated income growth are always very significant, explaining alone a large part of the time series behaviour of the dependent variable.

On the whole, the estimates in Tables 4-12 are encouraging. The specification of the model seems in most cases to be supported by the data and, in light of the differing behaviour vis-à-vis the real interest rate and the income and wealth variables, the adoption of a flexible functional form seems justified. With the exception of Japan, the results do not favour the rational expectations-permanent income approach. Lagged and anticipated variables always play an important role in predicting consumption. This suggests that models containing error-correction mechanisms (both in the adjustment of stocks and in the formation of expectations) are more appropriate depictions of reality for the countries examined in this study. 
Evidence on inflation correction and tax discounting

Turning now to the evidence concerning the inflation-correction and tax-discounting hypotheses, a priori reasoning suggests that these effects should be higher in countries that have experienced a long history of inflation and in which the sustainability of public debt and deficits has raised serious concerns. In such situations one would expect agents to anticipate quite correctly the inflation tax levied on the value of their government bond holdings and, possibly, to foresee the chance of a more restrictive fiscal stance in the future. Both these expectations should affect negatively consumption by reducing perceived disposable income and, perhaps, by inducing precautionary saving. Moreover, one would expect that agents who can recognize the consequences of future budget adjustments on their lifetime resources have an even clearer recognition of the short-run losses due to the inflation tax, implying that the degree of inflation-correction cannot be smaller than the degree of tax-discounting. As will be seen, the estimation results provide some support to this kind of argumentation.

Before discussing the results in detail, a general remark about the methodology followed is necessary. Note that, given that the estimates of the parameters $a_{7}$ and $a_{8}$ are obtained by scanning procedures, their quantitative magnitudes have a limited meaning per se. The likelihood surface associated with the regressions is at times too flat for the results of the scanning to have any statistical reliability and, of course, without non-linear estimation the individual statistical significance of $a_{7}$ and $a_{8}$ cannot be assessed. It is possible, nonetheless, to extract useful information from the data in two ways. First, the joint location of $a_{7}$ and $a_{8}$ over the grid chosen for the scanning can be tested for. To this purpose F-tests of various restrictions on $a_{7}$ and $a_{8}$ are performed under the maintained hypothesis that their "true" values are those resulting from the scanning. These tests are interpreted as checks of the robustness of the scanning results. The resulting F-statistics are shown, for each country, at the bottom of Tables 4-11.

Second, further discrimination between the model specifications resulting from the restrictions can be attempted under the assumption that these specifications are non-nested, i.e. that neither one can be obtained from the other by imposing suitable restrictions on the parameters: A very simple procedure for comparing non-nested models has been developed by Davidson \& Mackinnon (1981). The test designates one specification as the null hypothesis and regresses the dependent variable on this model augmented by the prediction of the alternative model(s) (64). For linear models (such as the present one, when $a_{7}$ and $a_{8}$ are restricted to preassigned values), the appropriate test-statistic is Davidson and Mackinnon's J. This is simply the regression t-value associated with the coefficient of the prediction of the alternative model. If this value is larger than the corresponding critical threshold, the null hypothesis is rejected (65). The intuition behind the test is obvious: a model specification is rejected if the information brought in by the competing specification improves its fit in a significant way. The test can be reversed (reversing the roles of the null and alternative hypotheses) allowing, in principle, to choose a model specification that is 
never rejected by the data. of course, it is possible that both hypotheses are rejected in turn or that neither one is rejected. In these cases nothing substantial can be inferred from the test about the "correct" model specification. J-tests are performed on the three limiting cases discussed earlier on, the Basic Model, the Hicks Model and the Barro Model. The results of the J-tests are shown, for each country, in Tables 12-19.

In the remainder of this paragraph, the results of the scanning procedures and of the tests of hypotheses are analysed on a country-by-country basis.

For the United States the scanning results suggest for CT and CND a value of $a_{7}$ close to unity and a value of $a_{8}$ between 0 and 0.25 . These values are broadly consistent with earlier estimates of the inflation-correction and the tax-discounting factors in the United States (66). Moreover the equation resulting from the scanning remarkably improves the fit of the model relative to the basic specification (in terms of SEE, $R^{2}$ and t-statistics) (67). As a result the Basic Model is rejected at conventional significance levels both by the F-tests and by the J-tests. These tests reject even more clearly the Barro Model. Results relating to the $C$ equation are more difficult to interpret. The scanning suggests a lower value for the inflation-correction factor. In addition the $F$ and $J$-tests are inconclusive in this case. The former only narrowly reject the Barro model, the latter are unable to reject the Basic Model when opposed to the Hicks Model and reject both models in the other cases. These results suggest that in testing the $\mathrm{C}$ equation multiple alternatives tests would be more appropriate. In sum, relying on the CT and CND equations, which are superior from an econometric point of view, one can conclude that there is evidence that agents' behaviour in the United States is characterized by the absence of money illusion and by $a$ small, but significant, degree of tax-discounting.

As mentioned earlier, for Japan the performance of the model is not completely satisfactory. The fit of the model is worse than in the other countries and only the anticipated and unanticipated components of the "nested" measure of future income growth are significant. This may be an indication that the error-correction model is not appropriate for this country. But the regressions probably suffer also from the problems met in finding data for the wealth series. Moreover, it is difficult to assess the model performance on the basis of the $\mathrm{C}$ equation alone. The estimated equations for CT and CND, even over a shorter period, might clarify this issue. As it stands, the scanning results yield values of 0.5 and 0.25 for $a_{7}$ and $a_{8}$. But the regression results are quite insensitive to changes in these parameters. In fact the preferred equation cannot be distinguished from either the Hicks or the Barro models. The J-tests too are uninformative, no specification can be rejected at conventional significance levels.

The estimates for Germany are also difficult to interpret. The scanning results yield zero values for $a_{7}$ and $a_{8}$. The regression results are not very sensitive to changes in these parameters. When F-tests are performed, the Barro Model is clearly rejected in the $\mathrm{C}$ equation but barely passes the test in the CND equation. In addition, the data cannot discriminate between the preferred equation and the Hicks Model. The J-tests reject the Barro Model when it is confronted to the Hicks and the Basic 
models. However, when the last two models are opposed, both are rejected. From the point of view of inflation-correction the results of the $F$ and $\mathrm{J}$-tests seem contradictory. In addition they are inconsistent with earlier findings that detected, on the basis of households data, significant inflation-correction effects (68). A possible explanation could be that the grid is too coarse to yield a preferred equation that improves sufficiently upon the Basic and the Hicks models to allow discrimination among them. It is possible also that inflation losses on public debt showed too little variation over time for aggregate data to be able to yield any meaningful information (69).

The estimates for Prance show a strong sensitivity of the regression coefficients to changes in $a_{7}$ and $a_{8}$. The scanning results suggest values of these parameters close to 0.5. However, while the fit of the model does not change in an appreciable way when we increase $a_{7}$ and $a_{8}$ from 0 to 0.5 , from an economic point of view the regressions get worse. In particular, the coefficients on the lagged wealth and income variables become statistically insignificant. One cannot interpret this result as evidence in favour of the "random-walk" model since, at the same time, the anticipated income growth variable becomes more significant. In fact the $F$ and $J$-tests show that the data are unable to reject any of the model specifications hypothesized. Multiple alternatives tests might resolve this inconclusiveness. As for Germany, however, it is legitimate to think that inflation losses and government deficits displayed insufficient variability over time to allow the statistical identification of $a_{7}$ and $a_{8}$ and the discrimination among the different specifications (70). Overall, these considerations suggest that the basic specification could be the most appropriate for France.

The equations for the United Kingdom were modified in the estimation stage introducing a dummy to account for the demand effects of the 1975-76 income policies and tax changes (71). The dummy greatly improved the $f i t$ of the model and the significance of the lagged wealth and income variables, especially in the non-durables equation (72). Tables 5 and 14 report the estimates and test results obtained with the dummy-augmented equations. The scanning results suggest values close to zero for both $a_{7}$ and $a_{8}$. This contradicts earlier results showing a significant degree of inflation-correction in this country (73). With no dummy, the scanning yielded values of unity for the inflation-correction parameter. The results of the tests, however, point out that $a_{7}$ cannot be estimated precisely, since neither the $\mathrm{F}$ nor the J-statistics are able to discriminate between the Basic and the Hicks models (74). Given that earlier estimates of inflation-correction were based on household data, this apparent inconclusiveness could be interpreted as an indication that aggregate data are inappropriate to detect this effect in the United Kingdom. Note finally that the Barro Model is strongly rejected by both tests.

The estimates for Italy send a suprisingly clear message. The scanning procedure provides values for $a_{8}$ close to one in all consumption equations. The improvement in the fit of the regressions when $a_{8}$ varies from zero to unity is impressive. Unsurprisingly, the F-tests clearly reject both the Basic and the Hicks models. The J-tests reject these two models at 5 per cent levels of significance while they cannot reject the Barro Model. In contrast with earlier estimates, these results suggest that a strong degree of tax discounting characterizes the private sector consumption behaviour in Italy. 
of course the preferred equations cannot deliver quantitative estimates for $a_{7}$. However the regression results point out that the Hicks Model is a significant improvement over the Basic Model in this country. Moreover when the Basic and the Hicks models are opposed, the J-tests favour the latter. This evidence supports inflation-correction and is consistent with the findings of earlier studies based both on aggregate and households data (75). However nothing more precise can be said about inflation-correction until joint non linear estimates of $a_{7}$ and $a_{8}$ are obtained.

Except for the CT equation, whose overall performance is not completely satisfactory, the estimates for Canada yield values of $a_{7}$ close to unity and values of $a_{8}$ close to 0.25 . Earlier results on inflation-correction in Canada have been mixed but, in general, estimates of the inflation-correction factor were deemed to be too low. The present results provide evidence against the "money" illusion of agents. Apparently, no other study on tax-discounting in this country has been made, however comparing the present estimate with that for the United States, the value appears credible. The results of the scanning are supported by the $F$ and J-tests. The first are not able to reject either the Basic or the Hicks models but, save for the CT equation, they reject strongly the Barro Model. The second confirm these results and, in addition, reject the Barro Model in the CT equation as well. Overall, although not as clearly, the regressions and the tests deliver a picture similar to that found for the United States: a sizeable degree of inflation-correction coupled with a weak tax-discounting effect.

Results for Belgium resemble in many ways those obtained for Italy. The preferred equations yield a value of 0.5 for $a_{8}$ and of unity for $a_{7}$. These equations considerably improve upon the performance of the Basic Model: the wealth and income variables become significant, the SEE is reduced and the $\mathrm{R}^{2}$ increases substantially. In fact the $\mathrm{F}$-tests strongly reject the Basic specification but are unable to discriminate between the preferred equations and the Hicks and the Barro models. This is reflected in the J-tests. These reject the Basic model against both the Hicks and the Barro models. In addition they provide some evidence that, at somewhat high significance levels, the Hicks specification too can be rejected when directly opposed to the Barro one. Multiple alternatives tests would probably allow to discriminate more clearly between the Hicks and the Barro specifications in this case. In sum the results indicate that both inflation-correction and tax-discounting take sizeable proportions in Belgium.

overall the hypothesis tests and the scanning results confirm the intuition referred to in the introductory remarks. The estimates of $a_{7}$ and $a_{8}$ are higher and statistically more reliable in countries with a persistent inflationary environment and with an explosive behaviour of debt and deficits. Moreover the estimates of $a_{7}$ and $a_{8}$ always respect the intuitive ranking according to which the degree of tax-discounting should not exceed the degree of inflation-correction.

Two elements seem to be important for $a_{7}$ to be significantly positive, the level of the debt ratio and the level of inflation. The Table below shows the sample means of (expected) inflation and net debt ratios for the eight countries in our cross-section: 


$\begin{array}{lcccccccc} & \text { USA } & \text { Japan } & \text { Germany } & \text { France } & \text { UK } & \text { Italy } & \text { Canada } & \text { Belgium } \\ \text { Inflation \% } & 5.0 & 5.3 & 3.9 & 6.9 & 7.5 & 9.6 & 5.2 & 5.4 \\ \text { Debt-ratio } & .37 & .08 & .01 & .15 & .43 & .6 & .2 & .8\end{array}$

With the remarkable exception of the United Kingdom, in countries where expected inflation and the debt ratio were relatively high over the sample period -- Belgium, Italy, the United States and, to a lesser extent, Canada -inflation correction is supported by the data. This confirms the presumption, consistent with basic economic reasoning, that agents perceive correctly the inflation tax levied by the government. On the contrary, in Germany and Japan, where inflation and/or the debt ratio have been relatively low, the data are unable to support any significant inflation correction. This of course does not mean that in these countries money illusion prevails but simply that aggregate data is uninformative in this respect. In fact, at least for Germany, evidence from the personal sector behaviour suggests that inflation losses on this sector's liquid asset holdings are perceived quite correctly by agents (76).

Unfortunately, this taxonomy of inflation-correction does not seem to apply well to France and the United Kingdom. France experienced average inflation levels higher than Canada and comparable debt ratios over most of the sample period (the Canadian debt ratio started growing rapidly only from 1980). In the United Kingdom, inflation levels, debt ratios and money financing were relatively high during the sample period. However, definite inflation-correction effects could not be detected in these countries. Earlier studies found evidence of full inflation-correction of liquid asset stocks by the personal sector in the United Kingdom. The estimates in this paper contradict both these findings and the tentative taxonomy suggested above. It seems therefore that more work is needed on the equations for France and the United Kingdom before assessing the scope for inflation-correction of disposable income in these countries.

With regard to the tax-discounting issue, the indications delivered by the data are more clearcut. Estimates of $a_{8}$ tend to be sizeable and statistically sound only for Italy and Belgium. In the case of Italy it is even impossible to reject the "pure" Barro Model on the basis of the tests. In these countries the recent history of debt and deficits is characterized by unprecedented peace-time levels of the debt ratios, steep downward trends of the government balances and widening gaps between the net and gross-of-interest budget deficits. To a lesser extent, some of these features are present for the United States and Canada as well. However, estimates of $a_{8}$ for these countries are much less precise and of a smaller magnitude. One is tempted to relate the difference in the estimates to the relatively lower debt and deficit ratios in the last two countries. If this were true the tax-discounting effect would depend both on the dynamics and on the levels of debt and deficits. Unsurprisingly, in countries as France and the United Kingdom where debt problems are perceived by many observers as being less 
urgent, and Japan and Germany, where the debt outlook is relatively less dramatic, no tax-discounting effects could be detected.

Before attempting a more thorough. interpretation of these results, additional evidence delivered by the pooled data set is provided in the next section.

\section{Estimates from pooling}

Equations for CT, CND and $C$ were also estimated on the pooled data set following the dummy-variable approach. As with the single-country regressions, scanning procedures were used to find estimates of $a_{7}$ and $a_{8}$. The pooling of the data increases the degrees of freedom and, by reducing the multicollinearity between the explanatory variables, improves the efficiency of the estimates. In general pooling methods present two dangers: selectivity and heterogeneity bias. The first type of bias is unlikely to be important in this case, since the international cross-section provides a wide spectrum of national debt and deficits experiences. On the contrary, heterogeneity is certainly a problem given the different estimates obtained for some crucial parameters (in particular $a_{1}, a_{7}$ and $a_{8}$ ) across countries.

The scope for heterogeneity bias was explored by performing a set of standard analysis-of-covariance tests. First, using the results of the preferred equations, the pooled model (i.e. the null hypothesis of homogeneous intercept and slope coefficients) was tested against the single-country equations (i.e. the alternative hypothesis of heterogeneous intercept and slope coefficients). Then the model with country-specific intercepts was estimated and tested against the single-country equations. Finally, a test of the joint significance of the country-specific intercepts was performed conditional on the homogeneity of the slope coefficients (i.e. the model with the country intercepts was opposed to the pooled model). The first test rejected the hypothesis of complete homogeneity at very high levels of significance in all consumption equations. The second test strongly rejected the hypothesis that heterogeneity is due to the intercepts alone, suggesting that the intercept dummies are not able to catch in a satisfactory way the differences between countries. Finally, the conditional test was barely able to reject the hypothesis that the country intercepts are jointly equal to zero (77). Unsurprisingly, these results point out that the source of the heterogeneity is mainly among the slope coefficients of the different countries. Individual estimates of the country-specific intercepts in the dummy-variable model were insignificant in all countries except the United States and Canada. And the coefficients associated with the constant term in the pooled equations were also found to be insignificant. The results of the last two tests and the insignificance of the constant terms were interpreted as an indication that intercept heterogeneity does not add any essential information to the regressions. It was decided therefore to rely at this stage of the analysis on the evidence provided by the estimates of the pooled model (78). Of course the introduction of slope dummies would be an interesting area for future research.

Tables 20 and 21 show the estimates and tests obtained from the pooled regressions, for CT, CND and C. The Tables are organized as for the single-country estimates. Regressions were run using the first order autocorrelation correction proposed by Kmenta (1971) (79). A discussion of the results follows. 
As with the single-country estimates the fit of the model appears satisfactory. The standard errors are 0.9 per cent for CT and CND and 1 per cent for $\mathrm{C}$ confirming the earlier ranking of the consumption equations. A negative and significant real interest rate coefficient is found for CND and C. In the CT equation this coefficient is negative but not significant. These results partially support the guess that the insignificant, and in some cases significantly positive, interest rate coefficients found in many single equation estimates are to be related to the multicollinearity between income and the real rate over the sample period. In the future this will have to be further analysed by introducing country-specific slope dummies for the real rates. The lagged wealth and income variables are both very significant and suggest long-run marginal propensities close to zero for wealth and close to the corresponding average propensities for income. Restriction $R 2$ is satisfied and restriction $\mathrm{R} 5$ does not seem rejected by the data.

The "grid search" yielded estimates of unity for $a_{7}$ and estimates ranging from 0.5 to 0.75 for $a_{8}$. These estimates bring additional support to the conclusion that what matters for consumption are real interest payments on public debt. However the impact of these real transfers is considerably lowered by the apparently strong degree of tax-discounting. This is somewhat surprising given the low values generally found for $a_{8}$, in the single-country estimates. Nonetheless the result appears quite robust. Except for the preferred CT equation which cannot be distinguished from the Barro Model, the F-tests reject at high levels of significance the three limiting model specifications. Similarly, the J-tests reject in turn the Basic Model, the Barro Model and the Hicks Model. These results together suggest that the "correct" model specification may be at an intermediate level of tax-discounting such as that resulting from the scanning.

This conclusion, however, must be qualified in several respects. There are at least two possible improvements in the estimation procedures which could modify the outcome of the estimations. The first concerns the econometric methodology. A Breusch-Pagan test performed on the residuals of the single-country regressions strongly rejected the hypothesis of a diagonal covariance matrix, implying that the most efficient method for estimating the pooled equations is Zellner's SUR estimator ( 80$)$. Moreover, al though, given the log-change specification of the consumption variables, there are no a priori reasons to expect the residuals to be heteroskedastic, it would be desirable to perform homoskedasticity tests in the future. Finally, the results of the $F$ and $J$-tests point out that there is considerable scope for estimating $a_{7}$ and $a_{8}$ by non-linear methods in the case of pooling, since the sum of square residuals of the regressions changes dramatically when the values of these parameters are modified.

The second possible improvement concerns the use of country-specific slope dummies. As suggested by the analysis of covariance, presently the results could suffer from a sizeable heterogeneity bias. This problem could be allievated by the use of dummies for the real interest rate coefficient and the inflation-correction and tax-discounting parameters. These dummies woul. make it possible to use the information of the pooled data set to verify and possibly improve the soundness of the results of the single country regressions. 
iii) Effects of government consumption

Tables 22-29 contain the estimates of the single-country equations when the rate of growth of government consumption is added to the explanatory variables. As noted earlier, in general this variable is insignificant and its introduction does not affect in any appreciable way either the results of the scanning or the other coefficient estimates. In only two cases is $a_{6}$ significant: in the $\mathrm{C}$ equation for the United States, with a negative sign, and in the CND equation for Germany, with a positive sign. The positive coefficient for Germany implies a long-run elasticity of consumption of 0.75 , which is too high to be ascribed to the complementarity between public and private consumption. This estimate probably reflects also spurious elements linked to the distributional effects of government transfers.

For the United States the government consumption coefficient is consistently negative across the three consumption equations. The estimates of the short-run semielasticity of the various consumption measures to government consumption are -0.16 for CND, -0.24 for $\mathrm{CT}$ and -0.5 for $\mathrm{C}$. These coefficient magnitudes are coherent with earlier findings yielding estimates of the direct substitution effect ranging between -0.2 and -0.4 ( 81 ). In addition the results suggest that, in the United States, this direct crowding-out effect mainly operates through the consumption of durables.

The government consumption coefficients are negative, although insignificantly so, in a number of other cases but, apart from the United States, there is very little evidence of a crowding-out effect operating through this channel. As for the interaction between $a_{6}$ and $a_{8}$, there is some evidence that, as suggested earlier, the omission of the government consumption variable can affect the estimates of the tax-discounting parameter. This is probably true in the United States where the estimate of $a_{8}$ drops from 0.25 to zero when this variable is added to the regressions. In general, however, the bias due to the omission of government consumption seems to be negligible.

The inability to detect a sizeable crowding-out (or crowding-in) effect of government consumption suggests that further investigations of this issue should replace this variable by narrower aggregates reflecting a closer relationship with particular components of private consumption.

\section{SUMMARY AND CONCLUSIONS}

The "ultrarationality" hypothesis states that, because economic agents correctly perceive the current and future constraints faced by the public sector, increases in government deficit financing reduce the stimulus to private consumption implied by tax cuts. In its most extreme formulation, which we called the Barro Model, this hypothesis implies that government debt has no impact at all on private consumption and that government deficits are exactly offset by increased private savings. While there are strong theoretical and empirical reasons for rejecting this extreme view of agents'. rationality, it would be inconsistent with basic economic thinking to assume that the private sector is completely unaware of the constraints that bind government actions, especially in periods of rising concern about the sustainability of public debt and deficits. 
This paper examined the empirical basis for the "ultrarational" view using a life-cycle consumption specification that nests the Barro Model and two other models embodying different degrees of foresight and rationality on behalf of agents. The first, which we called the Basic Model, expresses the traditional view, assigning to government debt and deficits a positive impact on private consumption through wealth and income effects. The second model, which we called the Hicks Model, imposes the rationality requirement, logically prior to full tax-discounting, that agents recognize the inflation tax levied by the government on the outstanding value of the stock of monetary and non-monetary debt.

The "nested" consumption specification allowed the simultaneous estimation of the degree of inflation correction of disposable income and of the degree of tax discounting. Moreover, in order to avoid biases due to the omission of important variables, intertemporal wealth was decomposed into current and future (expected and unexpected) components and the effect of changes in the real interest rate was estimated as well as the direct crowding-out effect of government consumption.

The analysis was carried out for three different consumption aggregates on an international cross-section comprising eight major OECD countries in the period 1961-85. Estimations involved both the single countries and the pooled data set. The fit of the model was generally satisfactory and supported the chosen consumption specification. Significant negative real rate effects were found for the pooled data set but were absent in the single-country estimates with the exception of Germany and France. Evidence of direct crowding-out effects was found only for the United States.

The empirical investigation of the inflation correction and tax-discounting issues unfolded in two stages. The parameters of interest were first estimated by. scanning. Then, as a check of the soundness of the results obtained, two sets of tests were performed: a) one trying to reject the model specification(s) not supported by the data by pairwise testing the Barro Model, the Hicks Model and the Basic Model against each other; and b) the other trying to assess the joint statistical significance of the estimates of the inflation-correction and tax-discounting parameters by testing the equations resulting from the scanning procedures against each of the three limiting specifications.

The results from these tests and their interpretation should not be overstated. The limitations of such an analysis include a) the possible mis-specification of the model due to the lack of an explicit consideration of liquidity constraints, non-neutral taxation and other market distortions; b) the failure to use non-linear methods to estimate the inflation-correction and tax-discounting parameters; c) the partial nature of the work done on the pooled data set, i.e. the fact that it did not allow for slope dummies expressing country-specific degrees of inflation correction and tax discounting.

Subject to these limitations, a joint assessment of the quantitative estimates obtained through the "grid search" and of the results of the tests suggests several interesting considerations: 
a) The hypothesis that agents correctly perceive the inflation tax levied by the government cannot be rejected either at the single-country level or in the pooling. Indeed, in at least half of the countries considered in this study, as well as in the pooling, the hypothesis is supported by the data. Countries with relatively high average levels of the inflation rate and of the debt ratio -- as Belgium, Italy, the United States and Canada -- yield estimates of the inflation-correction parameter close to unity and reject the Basic Model at conventional significance levels when it is opposed to the Hicks Model. In the remaining countries, it is impossible to distinguish between the two model specifications on the basis of our tests. For Japan and Germany this can be attributed to the relatively low and stable levels of the inflation tax over the sample period. For France and especially for the United Kingdom this result is puzzling and remains to be explained. on the whole, there is evidence that disposable income as commonly defined in most econometric models of consumption (i.e. gross of the inflation-premium component of the interest transfers) performs at best as well as and often worse than our measure of inflation-adjusted income. The absence of this kind of money-illusion of agents is consistent with the basic rationality hypotheses concerning consumer behaviour in an inflationary environment.

b) With the remarkable exceptions of Italy and Belgium, the full tax-discounting hypothesis does not receive much support from the data. In the majority of the countries, as well as in the pooling, the Barro Model is strongly rejected when it is opposed to the Basic and Hicks models and to the equations resulting from the scanning. Moreover, most single-country estimates of the tax-discounting parameter are close to zero. This overwhelming rejection of the pure Barro Model should not obscure the fact that for half of the countries -- the United States, Canada, Italy and Belgium -- the estimates of the tax-discounting parameter are non-zero, taking sizeable and statistically significant magnitudes in the case of Italy, Belgium and in the pooling. These countries display striking common features. Canada and the United States, which provided estimates close to 0.25 , and Belgium and Italy, which provided estimates of respectively 0.5 and 1 , all share fiscal stances that are deemed to be unsustainable by most analysts. Moreover, the last two countries, for which it was impossible to reject the Barro Model, have reached unprecedented peace-time debt ratios and display explosive debt dynamics.

The results on tax discounting pose two related problems, one of interpretation and the other of policy. As to the first, the data clearly show a relationship between the perceived urgency of the budget adjustments and the saving behaviour of agents. Should one conclude that this is evidence in favour of the Barro Model and of the tax-discounting hypothesis? As already mentioned, this hypothesis establishes a mechanical relationship between the intertemporal budget constraint of the government and the lifetime resources of dynastic agents by stating that sooner or later taxes will have to be levied in order to satisfy the government budget constraint. By 
ignoring the timing of taxation, the implications of this hypothesis are valid only in extremely unrealistic situations. In particular it relies heavily on the absence of non-neutral taxation and of liquidity constraints and on the existence of important private intergenerational transfers. In addition it implies that offsetting private savings should be observed whenever persistent deficit financing is employed, irrespectively of the levels of debt and deficits and of their implied dynamics. The results presented in this paper contradict both these features of the tax-discounting hypothesis.

On the one hand the countries yielding sizeable estimates of the tax-discounting parameter can hardly be characterized as having perfect capital markets. There is substantial evidence, for instance, that in Italy, but also in the United States, liquidity constraints affect large sectors of the population (82). Similarly, taxation has important distortionary effects in all. countries and, in some cases, as in Italy, distortionary taxes are directly designed to slow down the explosive dynamics of the debt (82). On the other hand, instead of supporting the tax-discounting hypothesis in all cases of prolonged deficit financing, the results establish a pattern in which only the countries where budget restrictions appear likely in the near future display a negative effect of deficits on consumption.

Rather than supporting the tax-discounting hypothesis per se this evidence suggests that agents may interiorize a policy reaction function of the fiscal authorities in periods in which the sustainability of the fiscal stance is questioned both by the government and in the press. This behaviour, which can lead to increased precautionary savings, is independent of the restrictive assumptions of the Barro Model but is broadly consistent with the rational expectations approach to the analysis of the effects of economic policy. Indeed it is surprising that, while a lot of attention has been paid to the implications of this approach for the effects of monetary policy, virtually no studies exist that assume the knowledge by agents of the policy rule of the fiscal authorities. The results of the present study, despite their limitations, provide some evidence that such an analysis could be motivated on empirical grounds.

If the interpretation of the evidence attempted above is correct, its policy implications differ substantially from those of the Barro Model. Far from being neutral, debt accumulation induces precautionary savings precisely when it surpasses the threshold beyond wich its consequences on the economy (in terms of high real interest rates, unwanted redistribution of income, current account deficits etc...) are felt to be unsustainable. These additional private savings are unable to compensate fully for the dissavings of the government since in "normal" times debt and deficits have the traditional wealth and income effects on consumption and, even if at the margin new debt were fully offset, the problems created by the earlier accumulation of government liabilities will remain. 
ANNEX

Definitions, sources and methods

This annex provides definitions, sources and computation methods for the series used to estimate equations (1d). The upper-case variables below are the nominal analogues of the variables used in the text. When necessary, real variables were obtained using the GDP implicit deflator. The conversion of real capital, housing and durable goods stocks into values was made using the deflators of, respectively, gross private non residential capital formation, gross private residential capital formation and expenditure on durable goods. Deflators were drawn from OECD National Accounts (various issues). Consumption variables were expressed in per capita terms using the total population series of OECD Labour Force Statistics.

A. Flow variables issues);

The following series were drawn from OECD National Accounts (various

$\mathrm{C}=$ private final consumption expenditure;

$\mathrm{C}^{\mathrm{n}}=$ private final consumption expenditure of semi-durables, non-durables and services;

$Y=$ national income;

$G=$ general government final consumption expenditure;

$\mathrm{S}=$ general government net saving;

$\mathrm{RB}=$ general government net interest payments on public debt;

$T=S+G+R B$

$S^{n}=S+R B$

$Y^{d}=Y-S-G$.

Sources and definitions differ from the above in the following cases:

Japan: $\quad C$ was extended from 1969 to 1960 using data from Economic Statistics Annual, Bank of Japan (various issues);

$\mathrm{RB}$ refers to general government gross interest payments.

Germany: $\quad \mathrm{C}^{\mathrm{n}}$ was estimated from data on the expenditure on "Furniture, furnishing and household equipment and operation" and "Personal transport equipment" (OECD National Accounts) using the ratio of these $i$ tems to the expenditure on durables from French National Accounts; 
Italy:

$S, S^{n}, G, \cdot R B$ and $T$ refer to the public sector (i.e. the general government plus the public railways, the mail service and the tobacco monopoly); the sources are Rapporto alla V commissione della camera dei deputati su "L'indebitamento pubblico in Italia: evoluzione, prospettive e problemi", L. Spaventa, G. Morcaldo \& P. Zanchi, 1984, and Relazione annuale, Appendice statistica (various issues);

Belgium: $\quad \mathrm{C}$ and $\mathrm{C}^{\mathrm{n}}$ provided by Bureau du Plan, Bruxelles;

RB refers to general government net property income.

\section{B. Stock variables}

The following variables were drawn from national balance sheet accounts and other national sources:

$$
\begin{aligned}
& B=\text { net financial liabilities of general government; } \\
& B^{f}=\text { net financial claims on the rest of the world; } \\
& K^{b}=\text { business sector capital stock; } \\
& K^{h}=\text { private sector housing stock; } \\
& K^{d}=\text { stock of consumer durables; } \\
& W=B+B^{f}+K^{b}+K^{h}+K^{d}
\end{aligned}
$$

Definitions and sources for individual countries are the following:

United States: $B$ and $B^{f}$ from U.S. Flow of Funds, various issues;

$\mathrm{K}^{\mathrm{b}}, \mathrm{K}^{\mathrm{h}}$ and $\mathrm{K}^{\mathrm{d}}$ from Fixed Reproducible Tangible Wealth in the U.S. 1925-79, U.S. Department of Commerce, 1982, and Survey of Current Business, U.S. Department of Commerce, various issues;

Japan:

B refers to the stock of long-term and short-term government bonds minus the stock of Social Security assets; the source for the stock of government bonds is Economic Statistics Annual, Bank of Japan, various issues; the sources for the stock of Social Security assets are Annual Report, Economic Planning Agency, various issues, and Monetary and Fiscal Policy Division, OECD;

$\mathrm{K}^{\mathrm{b}}$ from OECD Capital Stock File;

Germany: $\quad B$ and $B^{f}$ from Zahlenubersichten und methodische Erlauterungen zur gesenwirtschaftlichen Finanzierungzechung der Bundesbank, Sonderdrucke der Deutschen Bundesbank, various issues; 
$\mathrm{K}^{\mathrm{b}}$ and $\mathrm{K}^{\mathrm{h}}$ from Volkwirtschaftliche Gesamtrechnungen,

France:

Fachserie 1B;

B (1970-85) from Comptes du patrimoine, INSEE C116, and Estimation provisoire des comptes du patrimoine des secteurs institutionnels, INSEE, 1985; B (1959-69) estimated using data from the financial accounts of the general government in Les comptes de la nation, INSEE, various issues;

$B^{f}$ (1970-85) same sources as for B; $B^{f}$ (1959-69) estimated using data from the financial account of the rest of the world in Les comptes de la nation, INSEE various issues;

$K^{b}$ from OECD Capital Stock File;

$\mathrm{K}^{\mathrm{h}}$ (1970-78) from Comptes du patrimoine, INSEE C89-90; $\mathrm{K}^{\mathrm{h}}$ (1959-69, 1979-83) estimated by the perpetual inventory method using INSEE's depreciation rate ( 1.16 per cent);

$\mathrm{K}^{\mathrm{d}}$ estimated by the perpetual inventory method using quarterly data on the consumption of durables from OECD National Accounts and the benchmark stock and constant depreciation rate adopted by INSEE in estimating the durable goods demand equation of METRIC;

United Kingdom: $B, B^{f}, K^{h}$ and $K^{d}$ from (a) The Financial Interdependency of the Economy 1957-66, A. Roe, Chapman \& Hall, 1971, (b) National and Sector Balance Sheets for the U.K., C.W. Pettigrew, Economic Trends N.325, 1980, and (c) Financial Statistics, CSO, various issues;

$\mathrm{K}^{\mathrm{b}}$ from OECD Capital Stock File;

Italy: B refers to the public sector net financial liabilities; from Rapporto alla $V$ commissione della camera dei deputati su "L'indebitamento pubblico in Italia: evoluzione, prospettive e problemi", 1984, and Relazione annuale, Appendice statistica, various issues.

Bf (1959-75) from Il sistema degli stati patrimoniali per l'economia italiana (1948-81), G. Della Torre, Studi e Informazioni, Banca Toscana, 1984; $B^{f}$ (1976-85) from Relazione Annuale, Appendice statistica, Banca d'Italia, 1986;

$\mathrm{K}^{\mathrm{b}}$ and $\mathrm{K}^{\mathrm{h}}$ from Ricostruzione di serie storiche settoriali dell'economia italiana, A. Heimler \& C. Milana, CNR, Proget to finalizzato economia, Working. Paper, 1986.

$\mathrm{K}^{d}$ estimated using the stock benchmark and the implicit depreciation rate in Flussi e consistenze di beni durevoli di consumo in Italia nel periodo 1951-73, A. Manfroni, Rivista italiana di economia, demografia e statistica, 1976. 
Canada:

$B, B^{f}, K^{b}, K^{h}$ and $K^{d}$ from The National Balance Sheet Accounts, System of National Accounts, Canada, various issues; data for $1959-60$ was estimated using general government's borrowing requirement, the current account balance, gross private non-residential capital formation, gross private residential capital formation and expenditure on durable goods; implicit depreciation rates were used;

Belgium:

B from Monetary and Fiscal Policy Division, OECD;

$B^{f}$ from De Financielle Rekeningen en Stroomtabellen van Belgie 60-84, Planning Papers, Bureau du Plan, Bruxelles;

$\mathrm{K}^{\mathrm{b}}$ and $\mathrm{K}^{\mathrm{h}}$ from Bureau du Plan, Bruxelles.

C. Expectations and interest rates

$t-1 \Pi_{t}=$ expectations at the end of period $t-1$ of the rate of change of the GDP/GNP deflator from $t-1$ to $t$;

$t-1 y_{t}=$ expectations at the end of period $t-1$ of the rate of change of real GDP/GNP from $t-1$ to $t$;

$t-1 g_{t}=$ expectations at the end of period $t-1$ of the rate of change of real final government consumption from $t-1$ to $t$;

Expectations are simple averages of the annual forecasts contained in the December and June issues of OECD Economic Outlook $(1967-85)$ and in OECD Internal Documents (1964-67). Missing values were replaced by actual rates of change.

Nominal interest rates are the long-term rates used in the Analytical Data Base of INTERLINK.

D. Estimation fo the services from durables

Services from durables were assumed to be proportional to the current period stock with proportionality factor equal to the current period
depreciation rate $\delta$ :

$$
c_{t}^{d}=\delta_{t} k_{t}^{d}
$$

For the United States, the United Kingdom and Canada where official data on the stock of durable goods are available, the rate of depreciation is a moving average of the implicit rate derived from expenditure flows and durable stocks. In general this rate oscillates between 10 per cent and 20 per cent. For Italy and France, the depreciation rate is the constant rate used to derive the stocks by the perpetual inventory method (respectively 8 per cent and 15 per cent).

The value of services was obtained by multiplying real services by the user-cost of services. The user-cost was computed as the product of the implicit deflator of durable consumption, $\mathrm{p}^{d}$, and the sum of the real expected interest rate and the depreciation rate: 


$$
c_{t}^{d}=p_{t}^{d}\left(\left(R_{t}-t-1 \Pi_{t}\right)+\delta_{t}\right) c_{t}^{d} \text {. }
$$

Total nominal consumption, $\mathrm{C}^{\mathrm{t}}$, is the sum of $\mathrm{C}^{\mathrm{n}}$ and $\mathrm{C}^{\mathrm{d}}$. 
NOTES

1. Apparently, the only cross-country analyses of the tax-discounting hypothesis are in Koskela \& Virèn (1983), Kessler et al. (1986) and Bernheim (1987).

2. See Modigliani $(1961,1986)$.

3. Miller \& Upton (1974), Buiter (1977) and Barro (1984) have developed this approach. An early investigation of its empirical implications is in David \& Scadding (1974).

4. Provided, of course, that the utility function is not additively separable in private and public consumption.

5. Ricardo was the first to remark that in a world in which the private and public sector are consolidated and agents have perfect foresight no "fiscal illusion" can exist. However he rejected this depiction of the economy as of no empirical relevance (see 0'Driscoll, 1977).

6. Individual preferences are said to be altruistic when the welfare levels of each generation's offspring, rather than the level of bequests, appear in the utility function of agents. This kind of preferences has been proposed by Becker (1974). Barro's results have been proven only for preferences additively separable over generations.

7. Blanchard (1985) shows that Barro's results break down when agents have uncertain lifetimes.

8. Of course the absence of liquidity constraints is a standard assumption of the Life Cycle Hypothesis too. A large literature is rapidly developing exploring the consequences of the violation of this hypothesis for the life-cycle theory of consumption. See, for instance, Flavin (1981, 1985), Hayashi (1985) and the references therein. To what extent capital market imperfections affect Barro's neutrality results is not yet clear. Hayashi (1985) and Yotsuzuka (1986) show that the neutrality result can still be valid when liquidity constraints are endogenous. Bernheim (1987) questions the relevance of such examples.

9. This assumption rules out the possibility that the government can borrow in real terms at a rate which is permanently higher than the real rate of return on government bonds.

10. This case is known in the literature as the "Polar Ricardian Regime" as opposed to a financing regime which mixes taxation with monetisation. In the latter, the Ricardian Equivalence Proposition fails to hold due to the distorting nature of the inflation tax. Of course, the REP can still hold in the presence of a positive rate of monetisation as long as the latter remains unchanged over time. 
11. In particular, many authors have stressed capital market imperfections as the main source for violations of the REP.

12. For space reasons, the literature using the "Euler equation" approach is not mentioned here. For a more thorough survey see Nicoletti (1987).

13. Many authors include estimates of Social Security Wealth (SSW) in the definition of non-human wealth. Conceptually, this variable is to be treated as government debt. If social security is fully-funded, agents will view social security benefits as neutral transfers. If it is unfunded, they will discount the future liabilities associated with the social security benefits. In both cases the coefficient of SSW must be zero in the consolidated-dynastic model.

14. The consumption function approach to testing the debt neutrality proposition is criticized by Carmichael (1987). This author distinguishes three channels of government debt non-neutrality: the "net wealth effect" (through the definition of private wealth), the "windfall effect" (through the definition of disposable income) and the "asset substitution effect" (i.e. the substitution of public debt for private capital in agents' portfolios). Carmichael argues that, while the first two effects are correctly accounted for by the consumption function approach, the asset substitution effect can only be captured by the estimation of a stock demand function for private assets. He suggests that, since the net wealth and windfall effects are of a second order of magnitude with respect to the asset substitution effect, tests based on consumption function estimations might be biased towards the acceptance of the debt neutrality proposition.

15. Time aggregation can aggravate this problem. For instance, if the dependent and independent variables are annual averages, low order lags of the regressors may be correlated with the error term. On this point see Hall (1985).

16. Seater (1985) shows that, for the United States, the measurement errors implied by this kind of adjustments can be very large.

17. of course, another likely candidate for mismeasurement is social security wealth, a variable whose lack of significance is used by many authors as evidence in favour of the Barro Model.

18. Exceptions are the studies by Koskela \& Virèn (1983) and Modigliani et al . (1985, 1986). The former includes expected inflation as a separate explanatory variable in order to capture an effect "à la Deaton" (1977) and uses inflation-adjusted deficit figures. While the "Hicksian correction factor" is not estimated, the coefficient estimate of expected inflation is found to be significant and close to minus one. Modigliani et al. restrict the "Hicksian correction factor" to be unity in the estimates of Table 3 and estimate this parameter in the consumption specification of Table 1. They relate the volatility of the estimates to the presence of multicollinearity between $w, R b$ and $b$. When the coefficient of $\mathrm{w}$ is restricted to be 0.03 , the estimate of the "Hicksian correction factor" is close to unity. 
19. Recent consumption studies show that, in Italy, the "Hicksian correction factor" is non-zero and ranges between 0.4 and unity (Rossi \& Schiantarelli, 1982; Marotta, 1983, 1984; Lecaldano et al. 1984; Rossi, 1986). Estimates close to unity were also obtained -- using personal sector data from Germany and the United Kingdom -- by von Ungern-Sternberg $(1981,1987)$, Hendry \& von Ungern-Sternberg (1981) and Pesaran \& Evans (1984).

20. Seater \& Mariano (1985), Seater (1982) and Tanner (1978, 1979) approximate future human wealth by the product of the current unemployment rate and income. They point out that even such a simple proxy considerably improved their results.

21. The omission of intertemporal components of wealth is sometimes justified (for example in the models of Table 2) by reference to a permanent income model with a Koyck transformation. However, even if the well-known theoretical and econometric problems associated with this approach are ignored, the specifications in Table 2 would generally require a) that income, taxes and deficits follow the same time-series process and $b$ ) that the parameters of these variables be linked by within-equations restrictions. Both these implications are usually ignored.

22. The Rotterdam model differs from other flexible functional forms in that it is a first order approximation in the parameter space instead of the space of variables.

23. The random walk model (Hall, 1978), combined with the rational expectations hypothesis, asserts that only past consumption levels, current relative prices and unexpected changes of wealth are useful to predict current consumption. The error-correction model (Davidson, Hendry et al . 1978) assumes that agents adjust slowly toward a desired consumption-to-wealth ratio and attributes an important role to lagged and anticipated wealth and income in the determination of consumption. Flexible functional forms have been very rarely used in time-series analysis of consumption. Diewert (1974) estimated an intertemporal translog consumption function; while, only recently, Rossi (1986) and Attfield \& Browning (1985) used the differential approach to study consumption behaviour over time.

24. In the subsequent analysis the discounted value of wealth at $T$ is assumed to be zero. The dynastic model is obtained by letting $T \rightarrow \infty$.

25. Theil (1980) calls this configuration of preferences "blockwise dependent".

26. In this intertemporal setting weak separability implies "strong recursivity" (Blackorby et al . 1978), which is a necessary and sufficient condition for the intertemporal consistency of agents' choices.

27. Recently, many authors suggested that relaxing this hypothesis could improve the empirical performance of the life-cycle model. See, for instance, Muellbauer (1986), Deaton (1986) and the references therein. 
28. A detailed derivation of equations (1a)-(1b) is available from the author on request.

29. Variables indexed $t, t+1$, etc..., must be understood as point expectations formulated at the beginning of period $t$ on the basis of information available at the end of period $t-1$.

30. In a simplified setting, Rossi and Schiantarelli (1985) show that the joint assumptions of homotheticity, rational expectations and a constant real interest rate reduce equation (1) to the consumption function estimated by Hall (1978).

31. Of course (1b) could be substituted by an equation in terms of durables, ${ }^{\wedge} \mathrm{d}$, the coefficients of the latter being related to those of (1b) in the following way:

$a_{i}^{d}=a_{i}^{t}+\left(a_{i}^{t}-a_{i}^{n}\right)\left(c^{n} / c^{d}\right)$

Estimations were carried out in terms of $c^{t}$ rather than $c^{d}$ in order to facilitate comparisons with earlier studies.

32. In deriving (2), it is assumed, as in most of the life-cycle literature, that the rate at which agents can borrow and lend is the same.

33. Defining the discount factor,

$$
\begin{aligned}
\rho_{t+i} & =1 / \pi_{s=1}^{i}\left(1+r_{t+s}\right) \quad \text { for } i \geq 1 \\
& =1 \text { for } i=0
\end{aligned}
$$

and imposing the boundary condition,

$\lim _{t \rightarrow T} \quad w_{t} \rho_{t}=0$,

$\mathrm{y}^{\mathrm{T}}$ and $\tau^{\mathrm{T}}$ can be defined as follows for $\mathrm{T} \leq \infty$ :

$y_{t}^{T}=\Sigma_{i=0}^{T-t} \quad y_{t+i} \quad \rho_{t+i}$

$\tau_{t}^{T}=\varepsilon_{i=0}^{T-t} \tau_{t+i} \quad \rho_{t+i}$

34. Present value terms and the real rate must be understood as point expectations based on information available at period $t-1$.

35. In deriving (3) the following intertemporal solvency constraint is imposed:

$\lim _{t \rightarrow T G} \quad b_{t+i} p_{t+i}=0$ 
36. Formally:

$$
\begin{aligned}
& g_{t}^{T G}=\Sigma_{i=0}^{T G} g_{t+i} \rho_{t+i} \\
& \tau_{t}^{T G}=\Sigma_{i=0}^{T G} \tau_{t+i} \rho_{t+i}
\end{aligned}
$$

37. In this case the solvency constraint does not imply that the growth of debt is bounded or that there exists a finite stationary value for $b$. As shown by McCallum (1984) in the context of a general equilibrium model, the constraint can be satisfied even if b grows indefinitely, provided that its growth rate is less than the real interest rate.

38. In the sequel, for any variable $x, x_{t+1}^{\infty}$ denotes the infinite $\operatorname{sum} x_{t}^{\infty}-x_{t}$.

39. For a theoretical discussion of Hicks' concept of income see Jump (1980).

40. Capital gains other than those implied by changes of the general level of prices are ignored. of course a correct Hicksian definition of income would include all sources of capital gains.

41. The following approximation formula is used to decompose $Q_{t-1}$ (Gandolfo, 1981, pp.98-99):

$$
\begin{aligned}
\log (x+y) & \equiv \log \left(e^{\log x}+e^{\log y}\right)= \\
& =\log \left(x^{\circ}+y^{0}\right)+\left(1 /\left(x^{\circ}+y^{\circ}\right)\right)\left(x^{\circ}\left(\log x / x^{\circ}\right)+y^{\circ}\left(\log y / y^{\circ}\right)\right)
\end{aligned}
$$

where $x^{\circ}$ and $y^{\circ}$ are initial conditions.

42. In order to simplify the notation, from now on the relative price variable is dropped from the non-durables equation.

43. See Modigliani \& Ando (1963).

44. Under this interpretation, (1d) is similar to the model estimated by Blinder \& Deaton (1986). A similar model also enters the consumption block of the new quarterly macro-econometric model of the Bank of Italy.

45. This assumption implies that National Accounts disposable income need not be modified.

46. Germany's National Accounts do not provide a breakdown of consumption expenditure between durables and non-durables. Due to the change in the Japanese SNA occurred in 1966, a consistent series for the expenditure on durables covering the period 1961-85 is not available. 
47. Stock market valuation would have been preferable. However valuation ratios (Tobin's q) are available over the sample period only for the United States. See Chan-Lee (1986).

48. It was impossible to derive meaningful scrapping rates for the Japanese housing stock using data published by the EPA since 1970 and earlier benchmarks. Any reasonable scrapping rate profile would yield negative stocks in the 1950 s.

49. Italy is an exception. Since the more reliable series for government debt relates to the public sector, the data refers to this government aggregate.

50. For a discussion of these problems and some estimates of government net worth, see Chouraqui et al. (1986).

51. The publication of inflation forecasts by OECD started only in 1966 for the GDP deflator and in 1973 for the CPI. The first series was used and inflation expectations were equated to actual values from 1961 to 1965.

52. OECD forecasts for the smaller countries started being published only in 1974 .

53. The basic surplus is defined as government current saving plus the interest bill.

54. For a more detailed analysis of actual and projected debt dynamics in OECD countries see Chouraqui et al. (1986).

55. Chouraqui et al . (1986) stress the need for such adjustments particularly for Italy, Belgium, the United States, Canada and, to a lesser extent, for the United Kingdom and France. Adjustments for Japan and Germany are also deemed necessary when the consequences of population ageing on pension disbursements are taken into account.

56. The break-point has been arbitrarily set in 1973 for all countries, except for the United Kingdom where the break was set in 1970 because it appeared more consistent with the data.

57. Save for a larger variability, the personal saving rate displays the same characteristics as the private saving rate over the sample period. The discussion in the text can therefore be applied to this rate as well. In any case the private saving rate seems a more appropriate reference series in descriptive analyses of the tax-discounting hypothesis. It would be strange that agents who are supposed to "pierce the government veil" could not pierce the corporate one.

58. Poterba \& Summers (1987) discuss the plausibility of this argumentation.

59. For the United States; the model performs better than most of the models used in earlier studies of the tax-discounting hypothesis. See, for instance, among the studies using the log-changes specification, Blinder \& Deaton (1986), Kormendi (1983) and Modigliani \& Sterling (1986). 
60. The empirical evidence based on this kind of models is mixed. Hansen \& Singleton (1983), Summers (1984), Mankiw (1981) and Wickens \& Molana (1983) all find positive and significant estimates of the interest rate effect. In criticizing these studies, Hall (1985) attributes these results to simultaneity bias. He presents instrumental variable estimates showing an insignificant or negative real rate effect. Deaton (1986) questions, on the basis of aggregation problems, the existence of a stable relationship between consumption and the real rate in Euler-equation models. Finally, Attfield \& Browning (1985) find a positive relationship between consumption growth and the real rate of interest in a differential demand system.

61. See, for instance, Mankiw (1985).

62. The average CND/CSD ratios for United Kingdom and Canada over the sample period are respectively 14 and 8 . Applying the formula of Footnote 31 one derives for the United Kingdom, $a_{1}^{d}=-0.05$, and for Canada, $\mathrm{a}_{1}^{\mathrm{d}}=-0.4$.

63. Hall (1985) gives an alternative explanation for excessively positive estimates of interest rate effects in the United States, based on the simultaneity between consumption growth and some of the regressors.

64. The method can also be used to test a model against multiple alternatives.

65. In the case of multiple alternatives one would perform an F-test of the restriction that the coefficients of the predictions of the competing specifications sum to zero.

66. Apparently, the only author who explicitly estimated the inflation-correction factor in the United States is Poole (1972). He reports estimates close to unity. As to the tax-discounting factor, see, for instance, the results reported in Tables 1-3.

67. Note that, with annual data, the preferred equation for non-durable goods performs as well as the equation estimated on quarterly data over the same sample period by the U.S. desk. The two equations yield almost identical estimates of the long-run propensities to consume out of wealth and income.

68. See von Ungern-Sternberg $(1981,1987)$.

69. In Germany inflation losses on public debt ranged between -0.1 per cent and 1 per cent over the sample period.

70. Inflation losses ranged from 1 per cent to 2 per cent of National Income and the government surplus from -1 per cent to 5 per cent, but basically followed a steady downward trend over the sample period (see Chart 1). 
71. In August 1975 a voluntary restraint on pay increases (the "6 pounds per week" policy) was introduced in the context of previous year's "Social Contract". The policy was carried on to 1976. Indirect taxes were sharply increased in 1975 along with a moderate increase of income taxes.

72. The coefficients and the t-statistics associated with the dumm in the $\mathrm{CT}, \mathrm{CND}$ and $\mathrm{C}$ equations were respectively,
CT
CND
$\mathrm{C}$
0.02
0.02
0.02
$(3.0)$
$(2.8)$
$(2.7)$

73. See von Ungern-Sternberg (1981) and Pesaran \& Evans (1984). These authors estimated functional forms similar to (1d) above. In fact, save for the inflation-correction parameter, their estimates are close to those in Table 8 .

74. The $F$ and J-statistics showed a similar inconclusiveness vis-à-vis the Hicks Model in the equations without the dumy.

75. See Footnote 18.

76. See von Ungern-Sternberg (1981, 1987). Note however that in studies based on personal sector data usually only the inflation losses are taken into account while capltal gains are ignored. This asymmetry could affect the estimates of the inflation-correction factor through an omitted variables bias. Aggregate data are exempt from this problem.

77. The F-statistics for the first test were 105 for CT, 127 for CND and 101 for C; for the second test they were 69 for CT, 83 for CND and 66 for $C$; the corresponding statistics for the third test were $2.6,3.0$ and 2.7 .

78. This approach was also corroborated by the insensitivity of the scanning results to the introduction of country-specific intercepts.

79. The degrees of freedom of the regressions were 114 for CT, 162 for CND and 186 for $\mathrm{C}$.

80. Unfortunately this statistical routine is unavailable on RAL.

81. See, for instance, Kormendi (1983) for estimates based on CT, Aschauer (1985) for estimates based on CND and Seater \& Mariano (1985) for estimates based on $\mathrm{C}$.

82. See, for the United States, the recent study by Hubbard \& Judd (1986) and, for Italy, a similar study by Jappelli \& Pagano (1987).

83. The recent introduction of taxes on the interest from the Italian Treasury Bills was partly seen as a means of reducing the basic government deficit. 


\section{TABLES AND CHARTS}

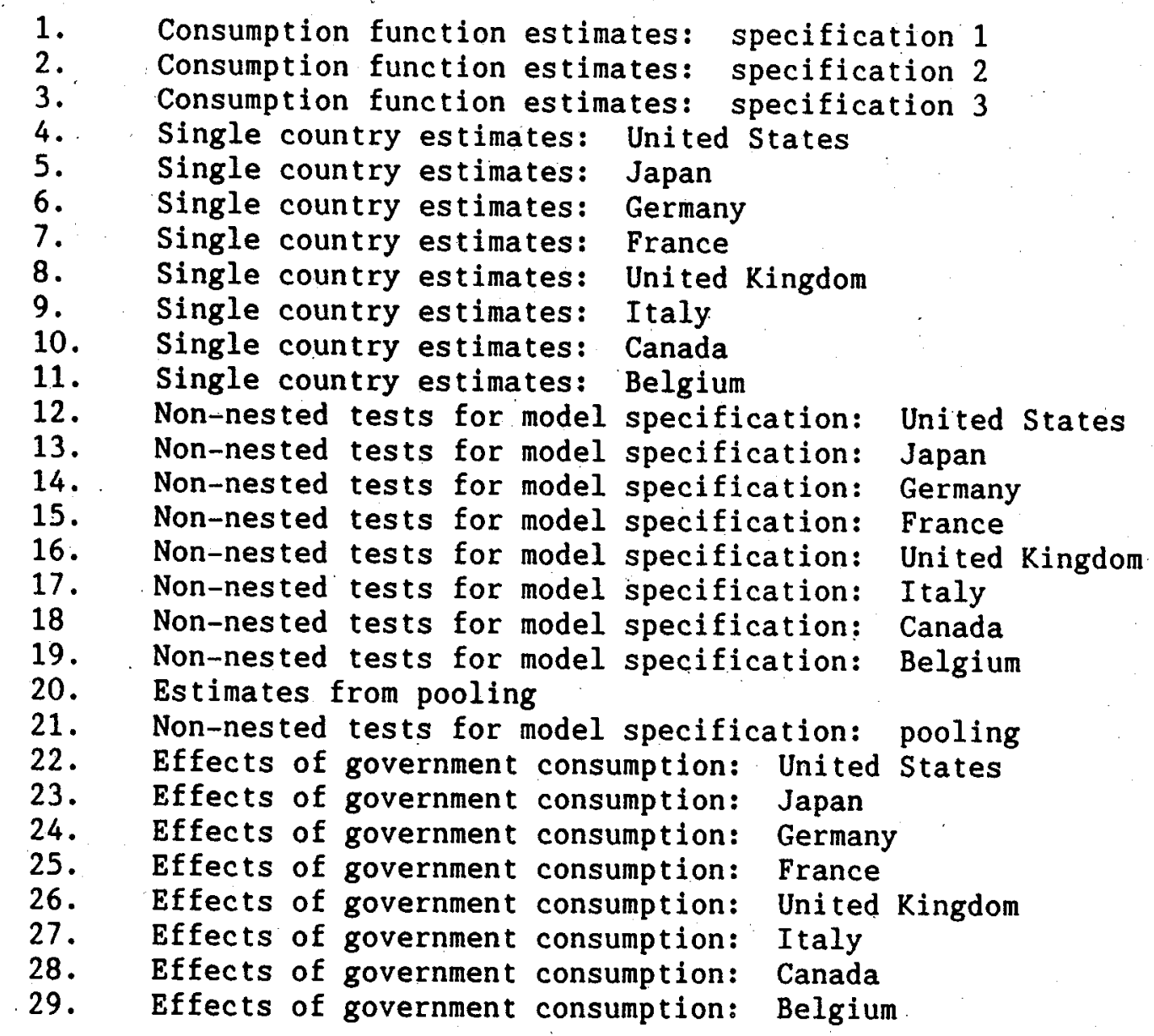

\section{CHARTS}

1. General government net debt ratios

2. Government net saving rates

3. Sectoral and national saving rates 


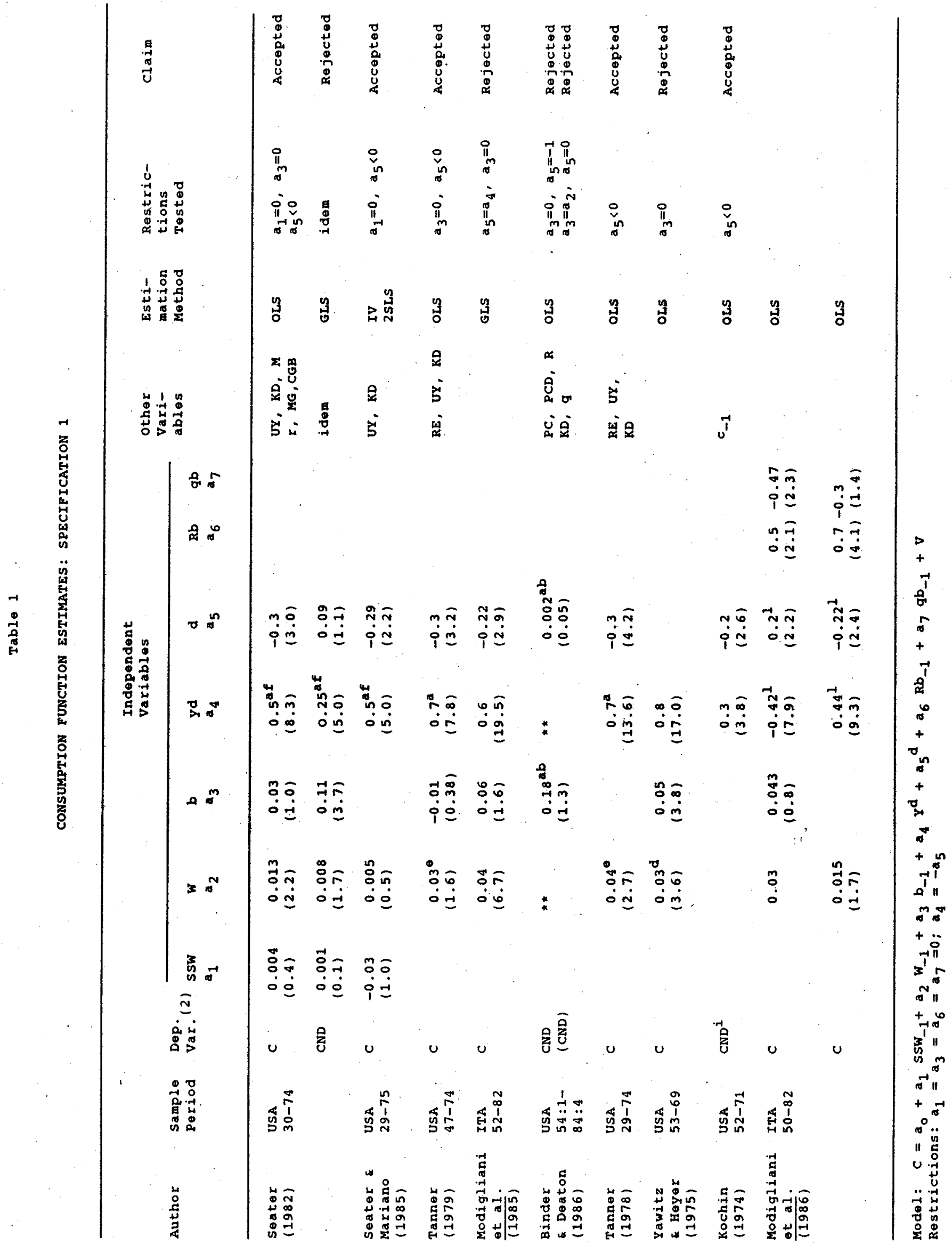


56

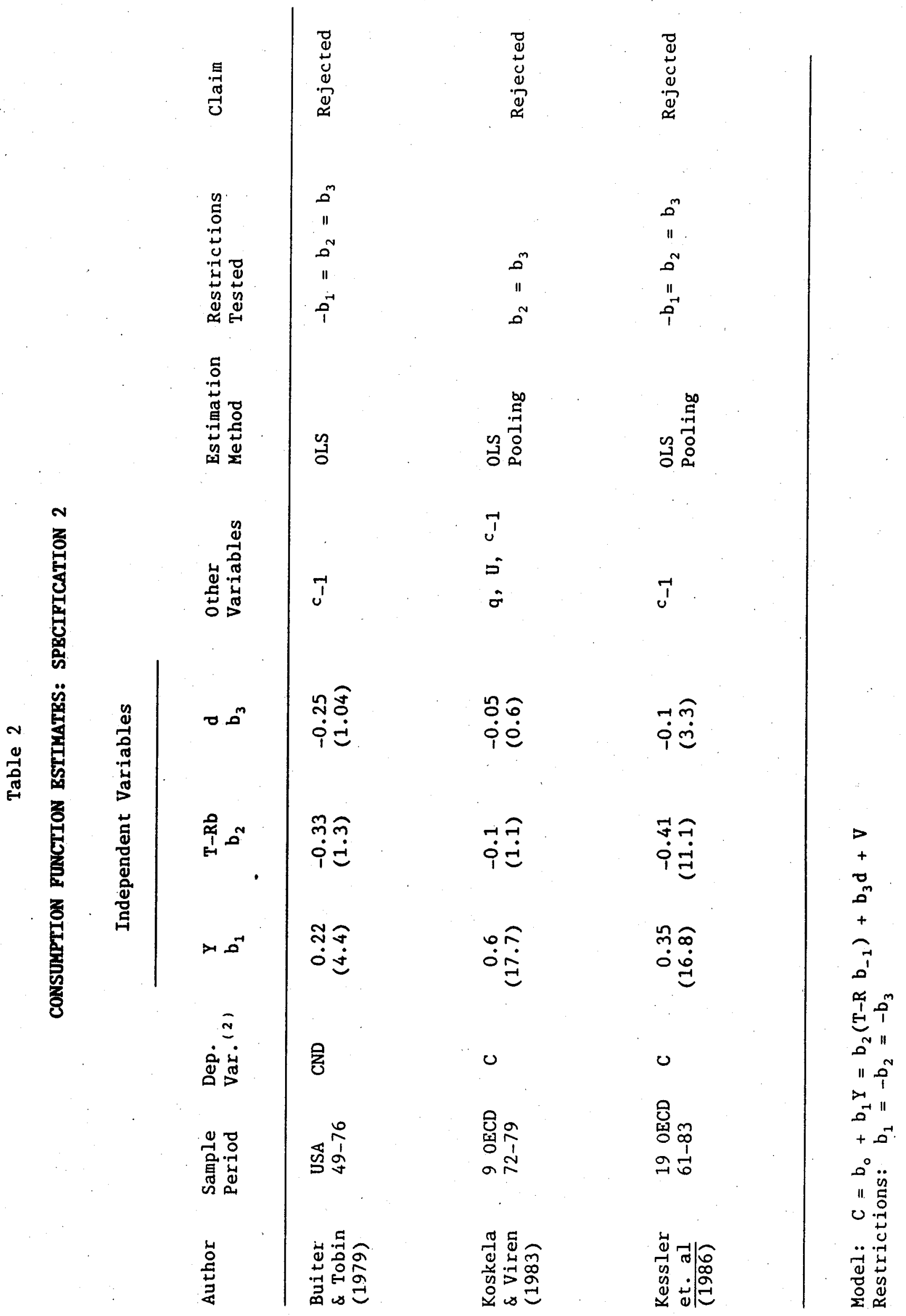




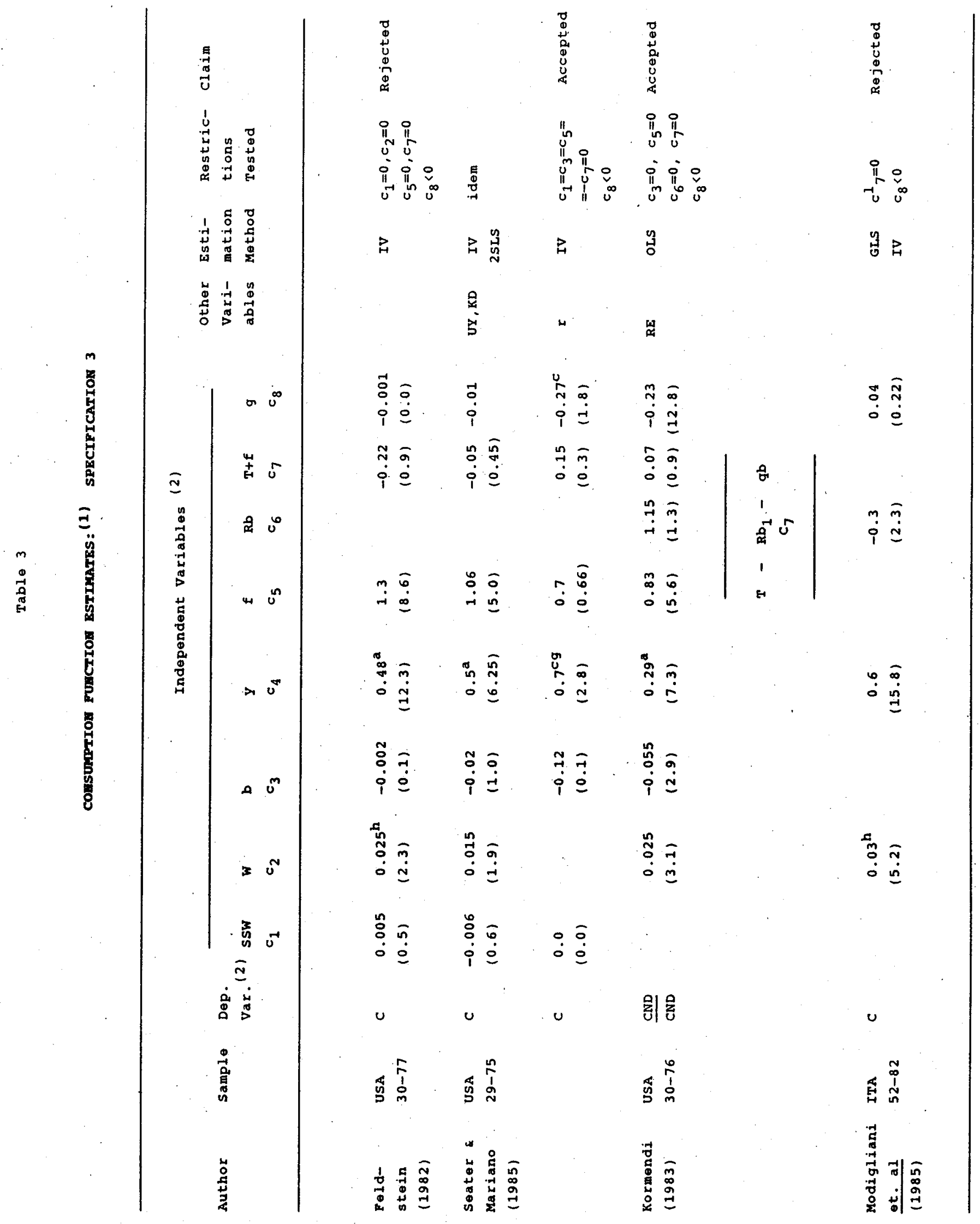


Notes to Tables $1-3$

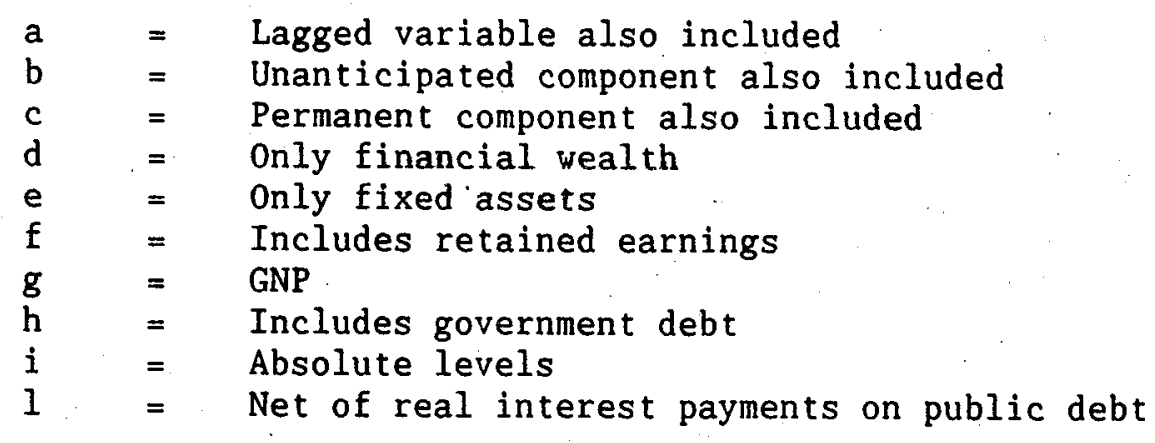

Key:

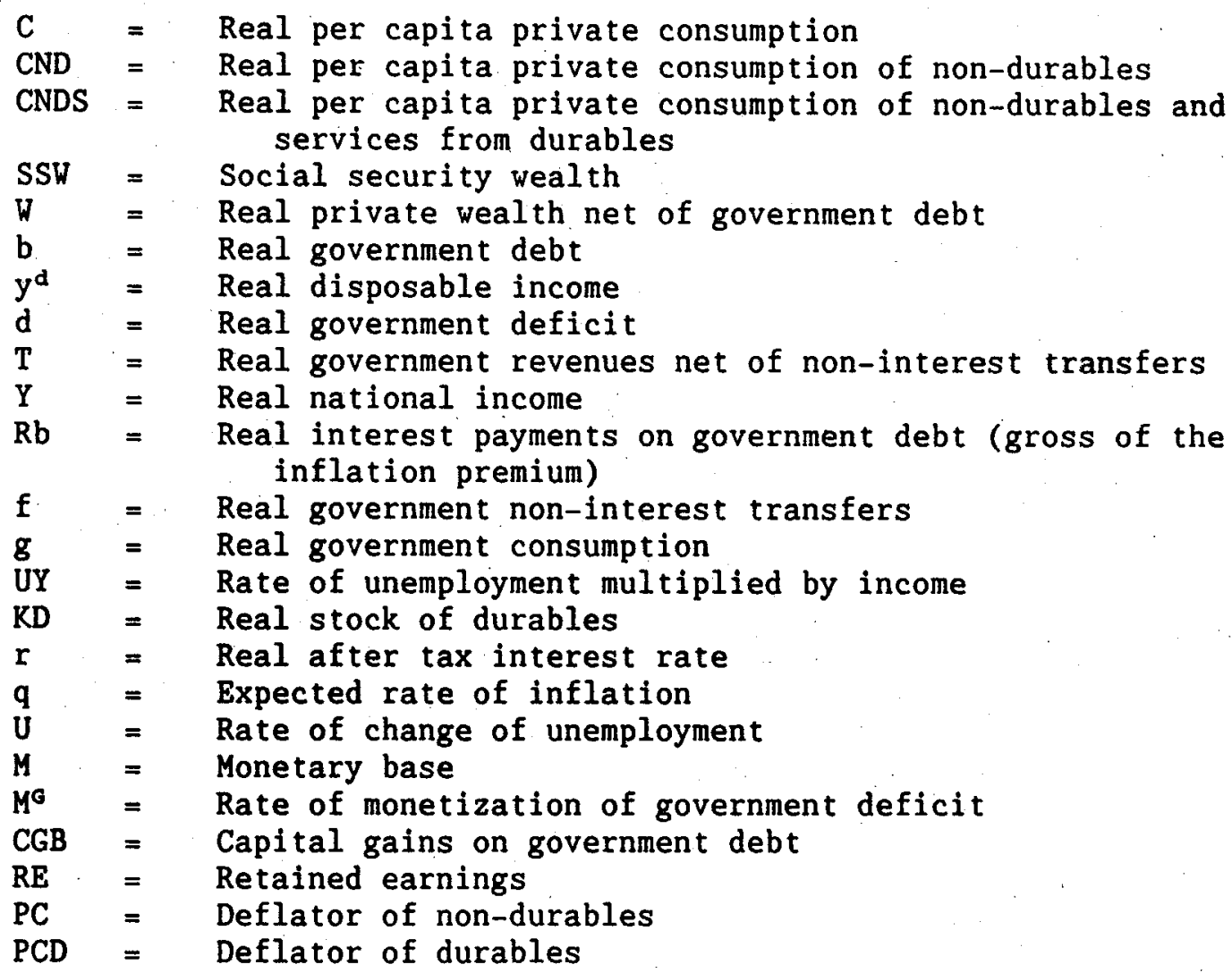



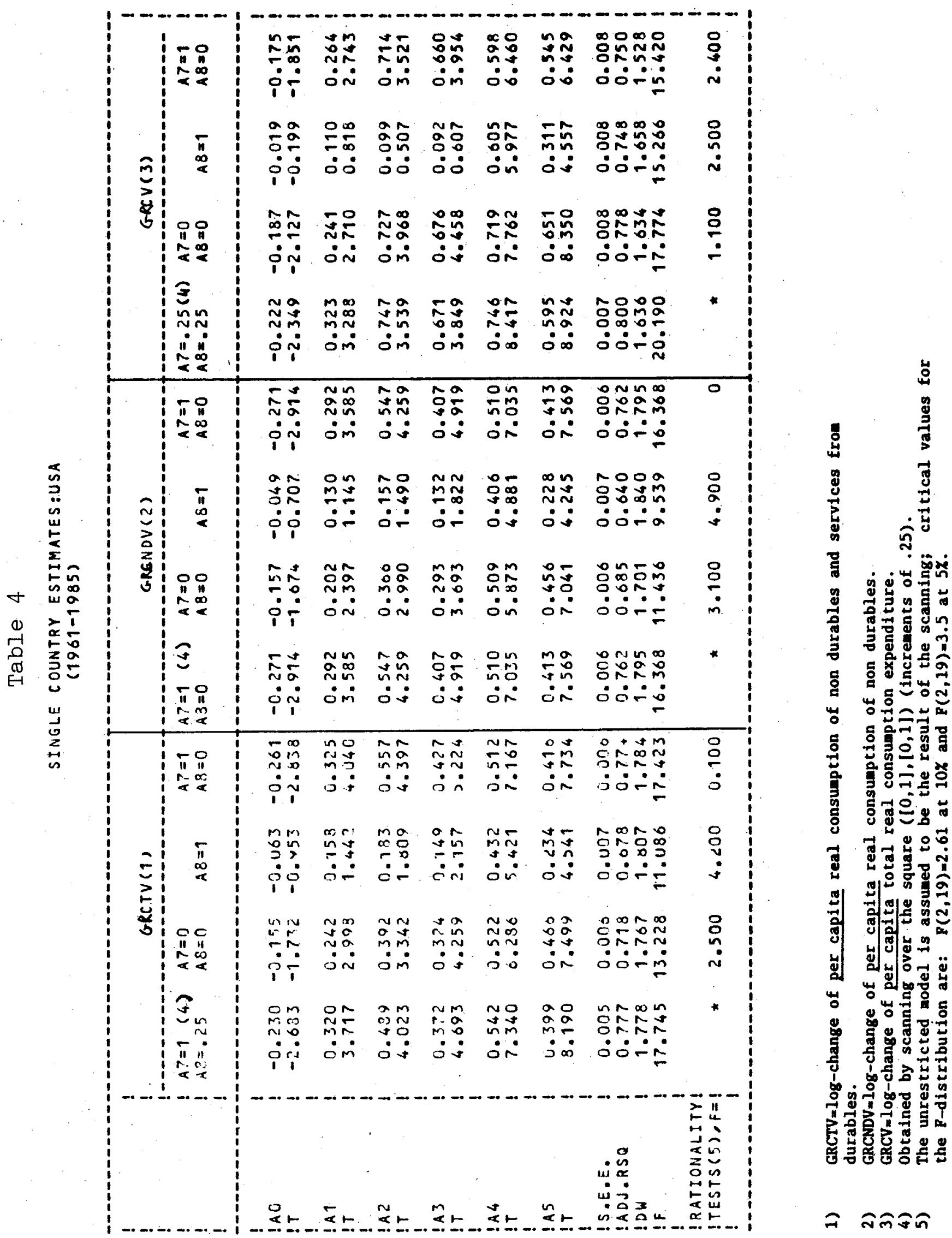
Table 5

SINGLE COUNTRY ESTIMATES:JPN $(1961-19 \varepsilon \subseteq)$

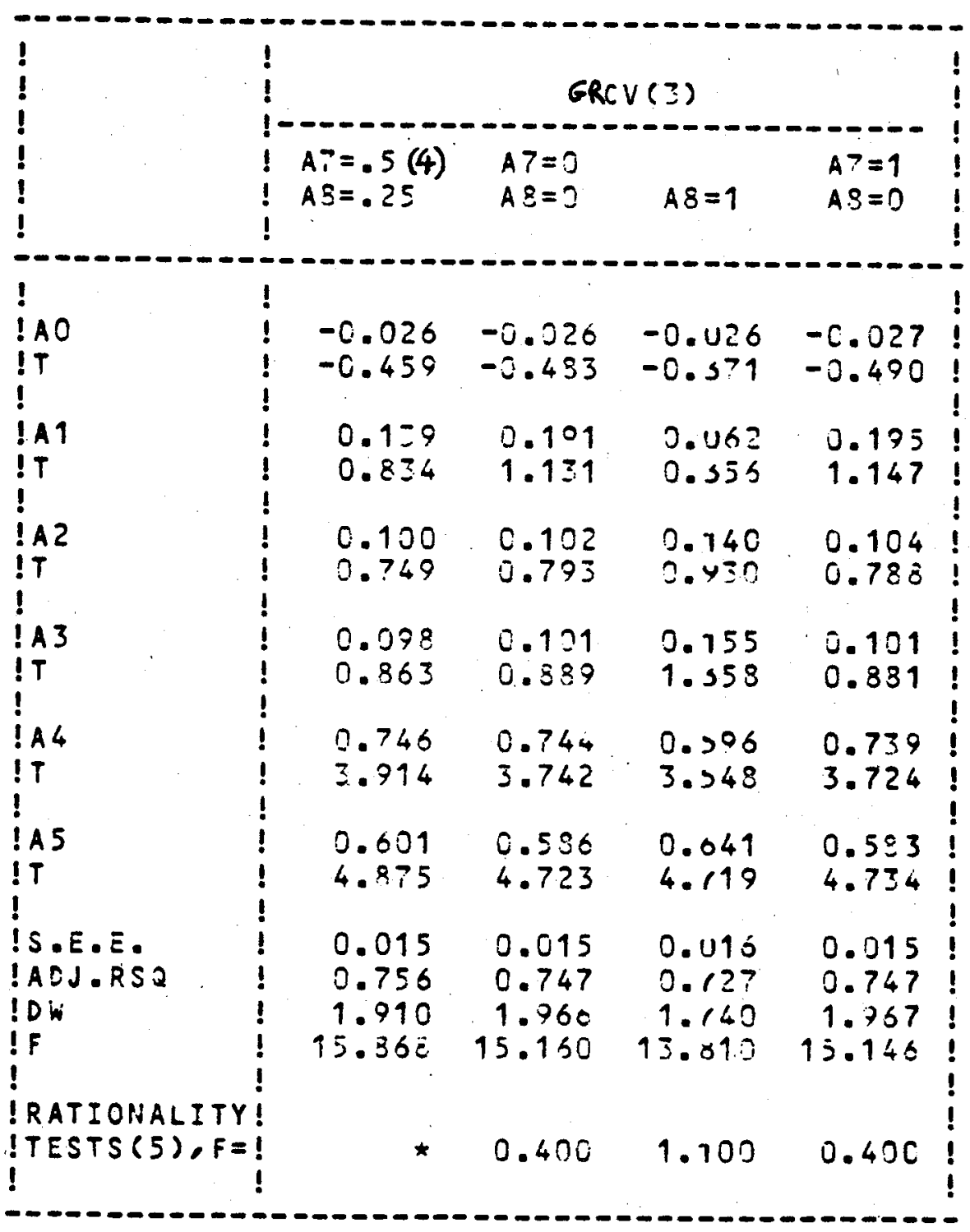

For notes see Table 4 
Table 6

SINGLE CDUNTRY ESTIMATES:GER $(1061-10 \times 5)$

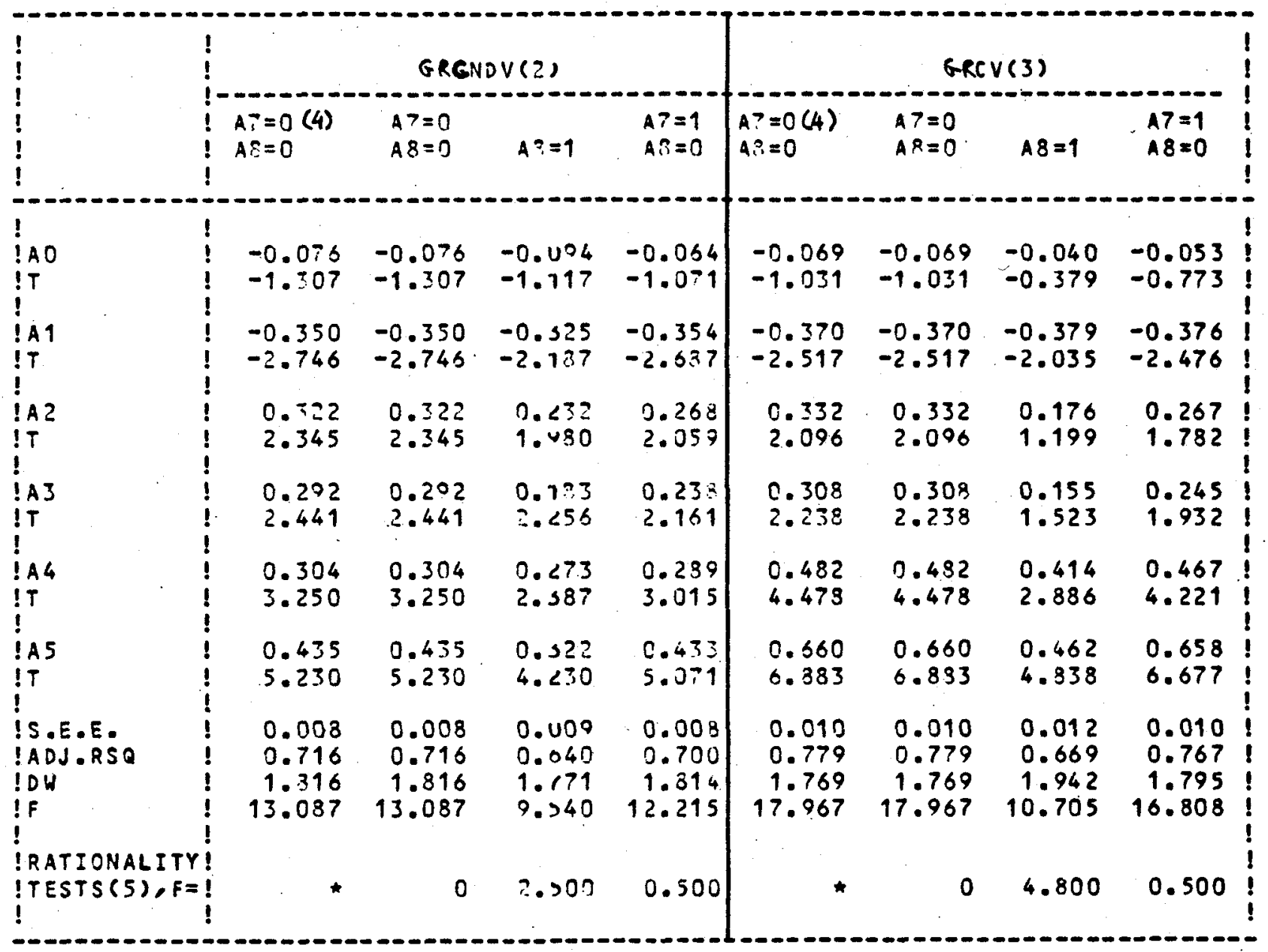

For notes see Table 4 


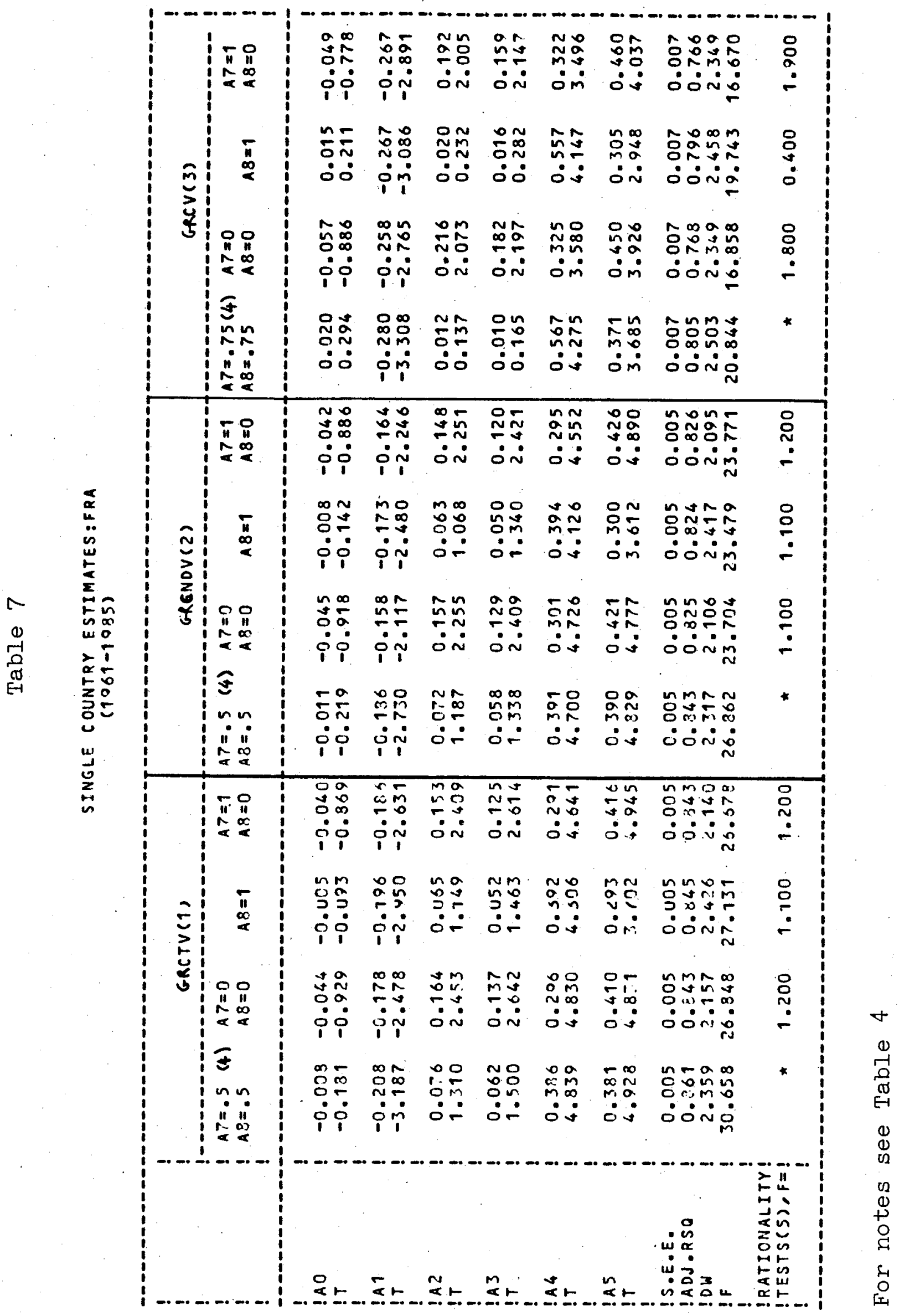




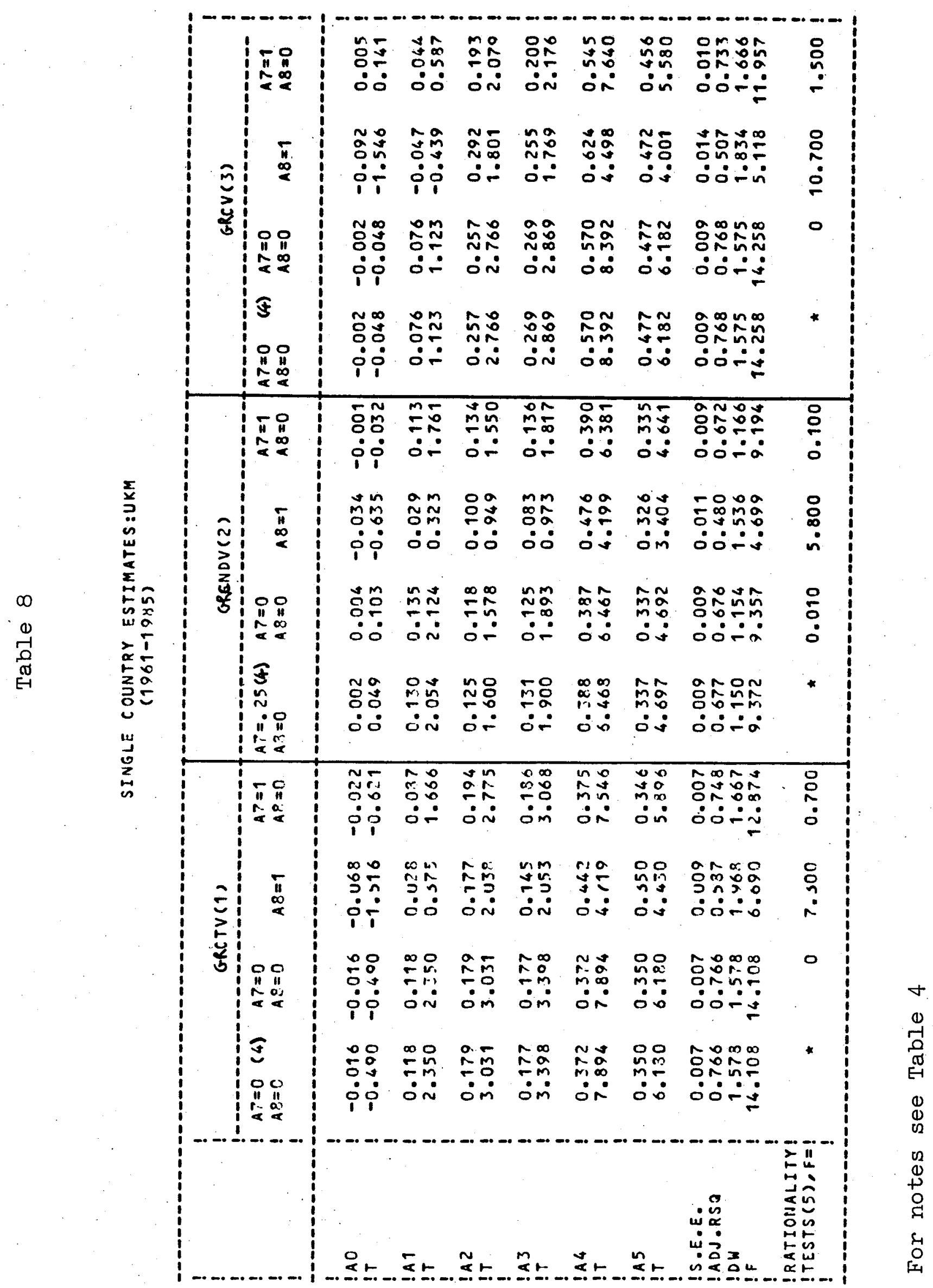




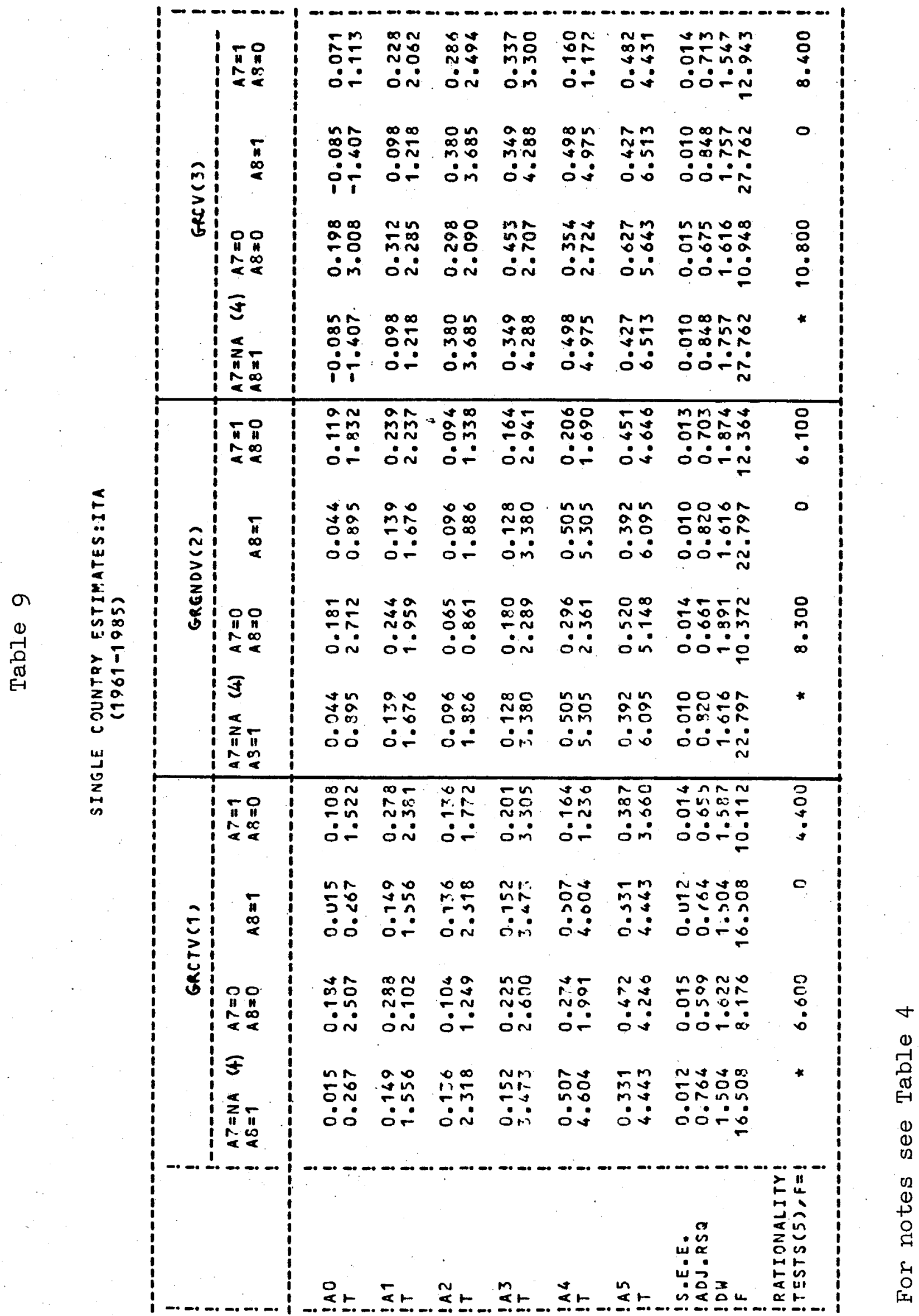




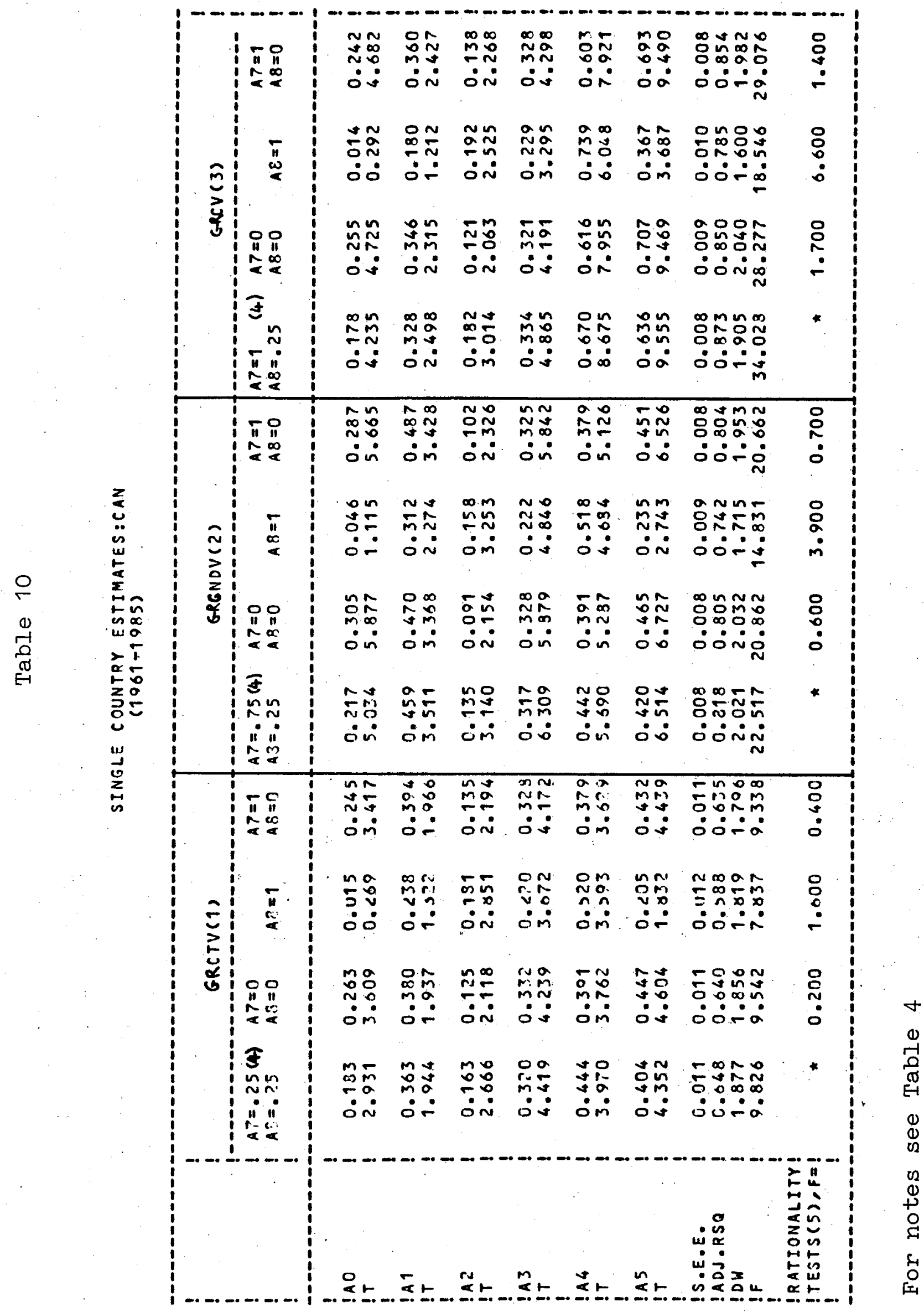


Table 11

SINGLE CUUNTPY ESTIMATES:BEL

(1061-1055)

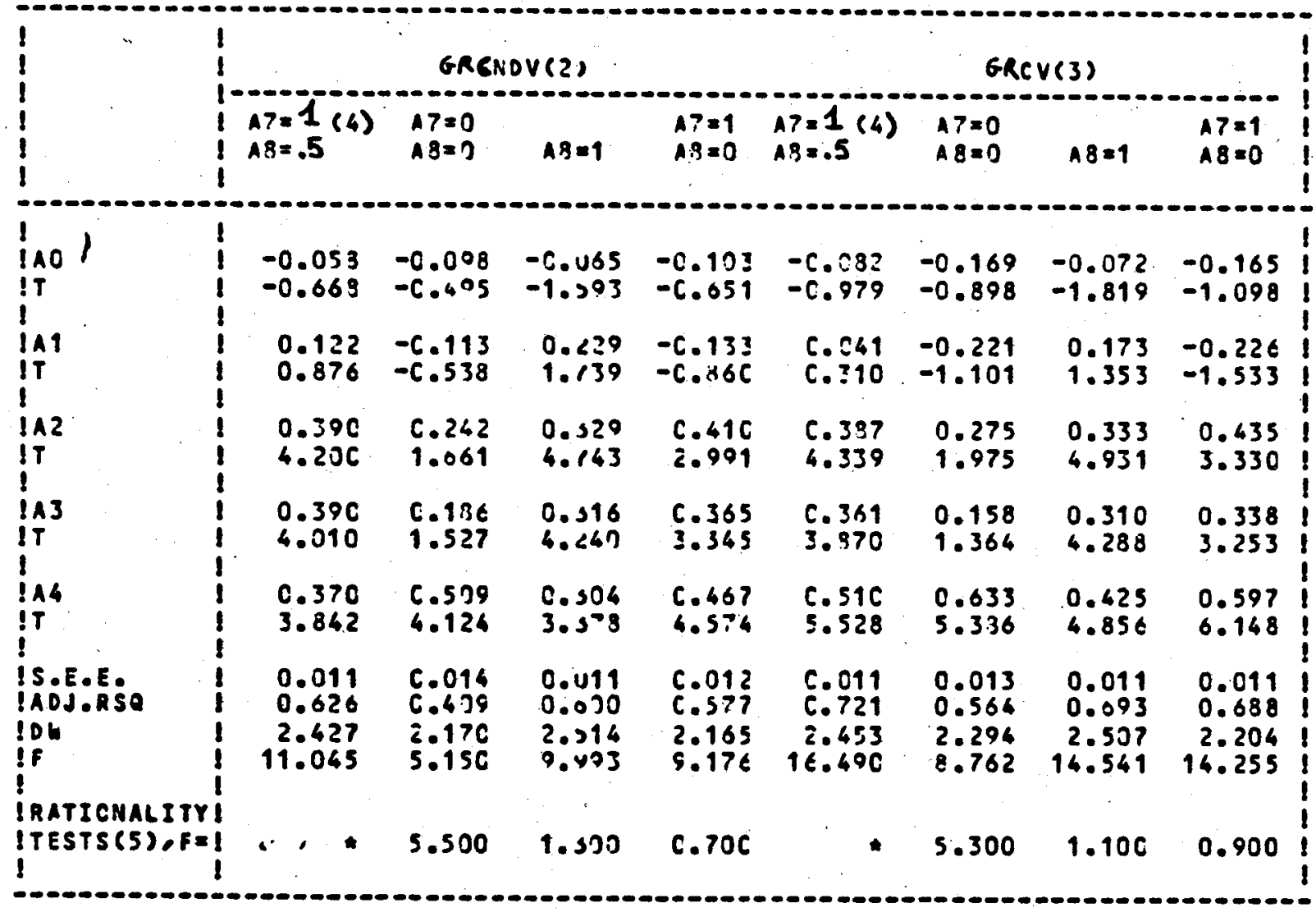

For notes see Table 4 
Table 12

NON NESTED TESTS FOR MODEL SPECIFICATION: USA $J-T E S T(1)$

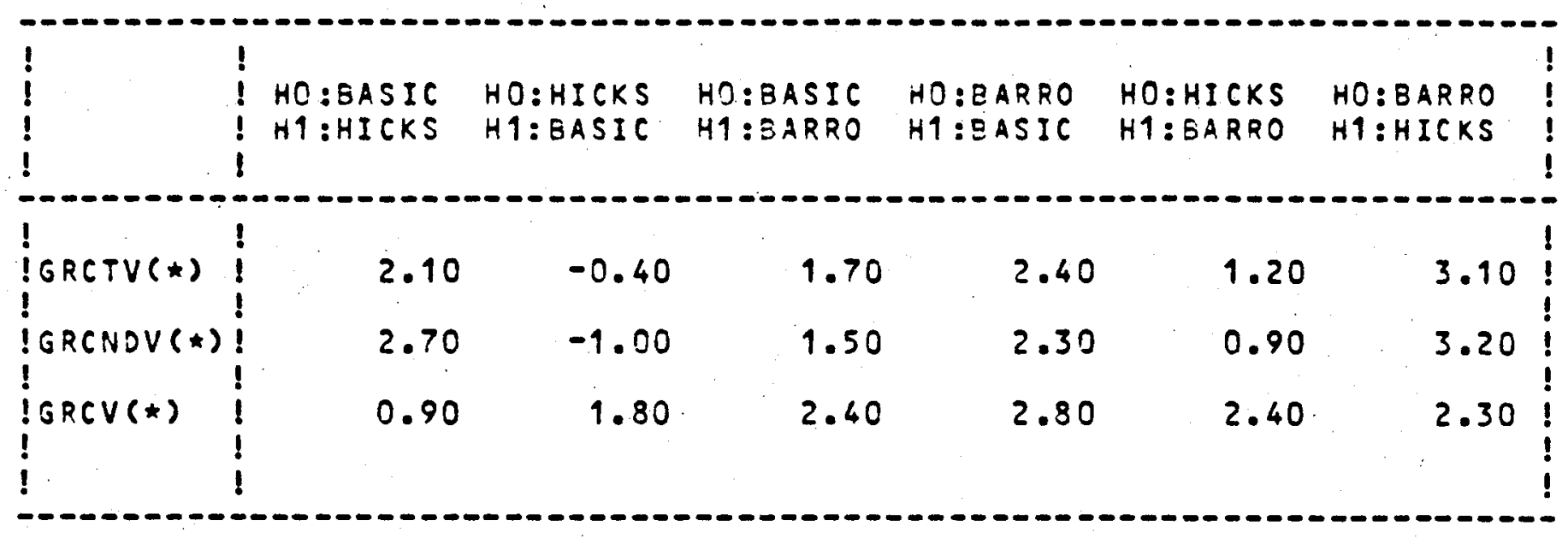

(*) SEE NOTES TO TABLE 1.

(1) THE J STATISTIC IS ASYMPTOTICALLY T-DISTRIBUTED. (MC KINNON AND DAVIDSON (1Yミ1)). 
68

Table 13

NON NESTED TESTS FOR MODEL SPECIFICATION: JPN
J-TEST(1)

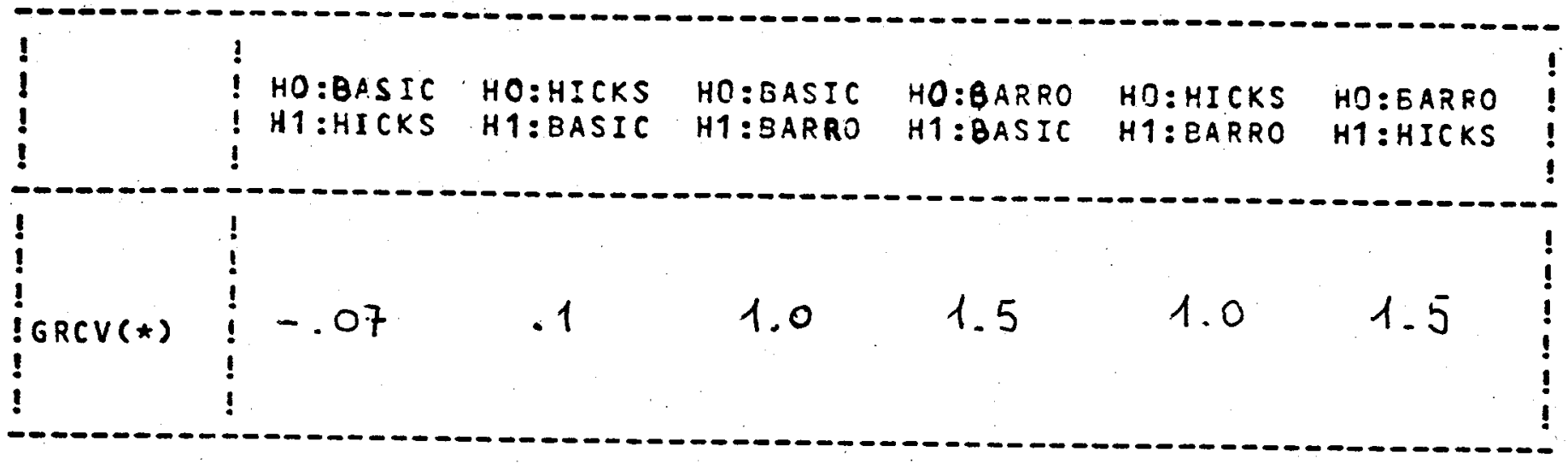

(*) SEE NOTES TO TABLE 1 .

(1) THE J STATISTIC IS ASYMPTOTICALLY T-DTSTẼIBUTED.

(IC KINMON AND DAVIOSON (1981)). 
Table 14 NON NESTED TESTS FOR MODEL SPECIFICATION: GER
J-TEST(1)

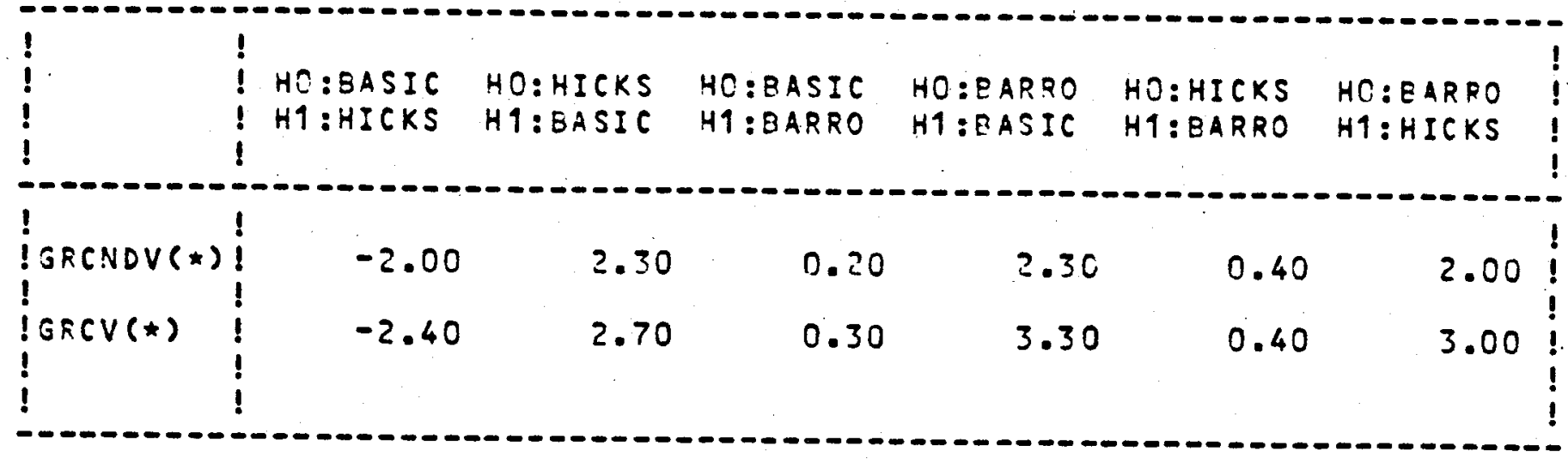

(*) SEE NOTES TO TABLE 1.

(1) THE J STATISTIC IS ASYYPTOTICALLY T-DISTRIBUTED. (MC KINNON AND DAVIDSON $(1 Y 81))$. 
NON NESTED TESTS FOR MODEL SPECIFICATION: FRA $J-$ TEST(1)

\begin{tabular}{|c|c|c|c|c|c|c|}
\hline $\begin{array}{l}! \\
\vdots \\
\vdots\end{array}$ & $\begin{array}{l}! \\
! \\
! \\
!\end{array}$ & $\begin{array}{l}\text { HO: HICKS } \\
\text { H1: BASIC }\end{array}$ & $\begin{array}{l}\text { HO:SASIC } \\
\text { HI:SARRO }\end{array}$ & $\begin{array}{l}\text { HO:BARRO } \\
\text { H1: :ASIC }\end{array}$ & $\begin{array}{l}\text { HO: HICKS } \\
\text { HI:BARRO }\end{array}$ & $\begin{array}{l}\text { HO: EARRO } \\
\text { H1: HICKS }\end{array}$ \\
\hline & $!$ & & & & & \\
\hline$!$ GRCTV( $!^{-1}$ & -0.05 & 0.30 & 1.60 & 1.60 & 1.60 & 1.50 \\
\hline$!$ GRCNDV $(*)$ & 0.20 & 0.04 & 1.50 & 1.60 & 1.50 & 1.60 \\
\hline $\begin{array}{l}! \text { SRCV }(*) \\
!\end{array}$ & -0.30 & 0.50 & 1.90 & 1.10 & 1.90 & 1.00 \\
\hline
\end{tabular}

(*) SEE NCTES TO TABLE 1 .

(1) THE J STATISTIC IS ASYMPTOTICALLY T-DISTRIEUTED. (MC KINIVON AND DAVIDSON $(1 Y S 1)$ ). 
Table 16

NON NESTED TESTS FOR MODEL SPECIFICATICN: UKM
J-IEST(1)

\begin{tabular}{|c|c|c|c|c|c|c|}
\hline$!$ & $\begin{array}{l}\text { ! HO: ZASIC } \\
\text { ! H1:HICKS } \\
\text { ! }\end{array}$ & $\begin{array}{l}\text { HO:HICKS } \\
\text { HI:SASIC }\end{array}$ & $\begin{array}{l}\text { HO: } 3 \text { ASIC } \\
\text { H1:BARRO }\end{array}$ & $\begin{array}{l}\text { HO: BAR RO } \\
\text { H1: BASIC }\end{array}$ & $\begin{array}{l}\text { HO: HICKS } \\
\text { H1: EARRO }\end{array}$ & $\begin{array}{l}\text { HO: BARRO } \\
\text { H1: HICKS }\end{array}$ \\
\hline ! & $!$ & & & & & \\
\hline ! GRCTV $(*)$ & 0.01 & 1.10 & 0.05 & 3.70 & 0.20 & 3.50 \\
\hline $\begin{array}{l}\text { ! G PC.NDV }(\star) \\
!\end{array}$ & 0.20 & 0.50 & -0.60 & $\therefore \geq 0$ & -0.60 & 3.30 \\
\hline $\begin{array}{l}\text { ! GRCV }(*) \\
!\end{array}$ & -0.50 & 1.70 & -0.20 & 5.80 & -0.10 & 5.00 \\
\hline
\end{tabular}

(*) SEE NOTES TO TABLE 1.

(1) THE J STATISTIC IS ASYMPTOTICALLY T-DISTRIBUTED.:

(MC KINNON AND DAVIDSON $(1 Y 81)$ ). 
Table 17

NON NESTED TESTS FOP MCDEL SPECIFICATION: ITA

J-TEST ( 9 )

\begin{tabular}{|c|c|c|c|c|c|c|}
\hline $\begin{array}{l}! \\
! \\
!\end{array}$ & $\begin{array}{l}\text { HO:BASIC } \\
\text { HI:HICKS }\end{array}$ & $\begin{array}{l}\text { HO:HICKS } \\
\text { HI:SASIC }\end{array}$ & $\begin{array}{l}H O: B A S I C \\
H 1: B A R R O\end{array}$ & $\begin{array}{l}H O: \text { : ARFO } \\
\text { H1:BASIC }\end{array}$ & $\begin{array}{l}\text { HO: HICKS } \\
\text { H1: SARRO }\end{array}$ & $\begin{array}{l}H O: B A R R O \\
H 1: H I C K S\end{array}$ \\
\hline ! & & & & & & \\
\hline ! GRCTV $(*) !$ & 2.70 & -1.90 & 4.10 & -0.90 & 3.30 & -0.10 \\
\hline ! GRCNDV $(*) !$ & 2.60 & -2.00 & 4.40 & -1.00 & 3.70 & -0.50 \\
\hline $\begin{array}{l}! \operatorname{GRCV}(\star) \\
!\end{array}$ & 1.60 & -0.50 & 4.90 & -1.10 & 4.20 & -0.70 \\
\hline
\end{tabular}

(*) SEE NOTES TO TAELE 1 .

(1) THE J STATISTIC IS ASYMPTOTICALLY T-DISTRIBUTED.

(MC KINNON AND DAVIDSON $(1 \cup 31)$ ). 
Table 18 NON NESTED TESTS FOR MODEL SPECIFICATION: CAN
J-TEST(1)

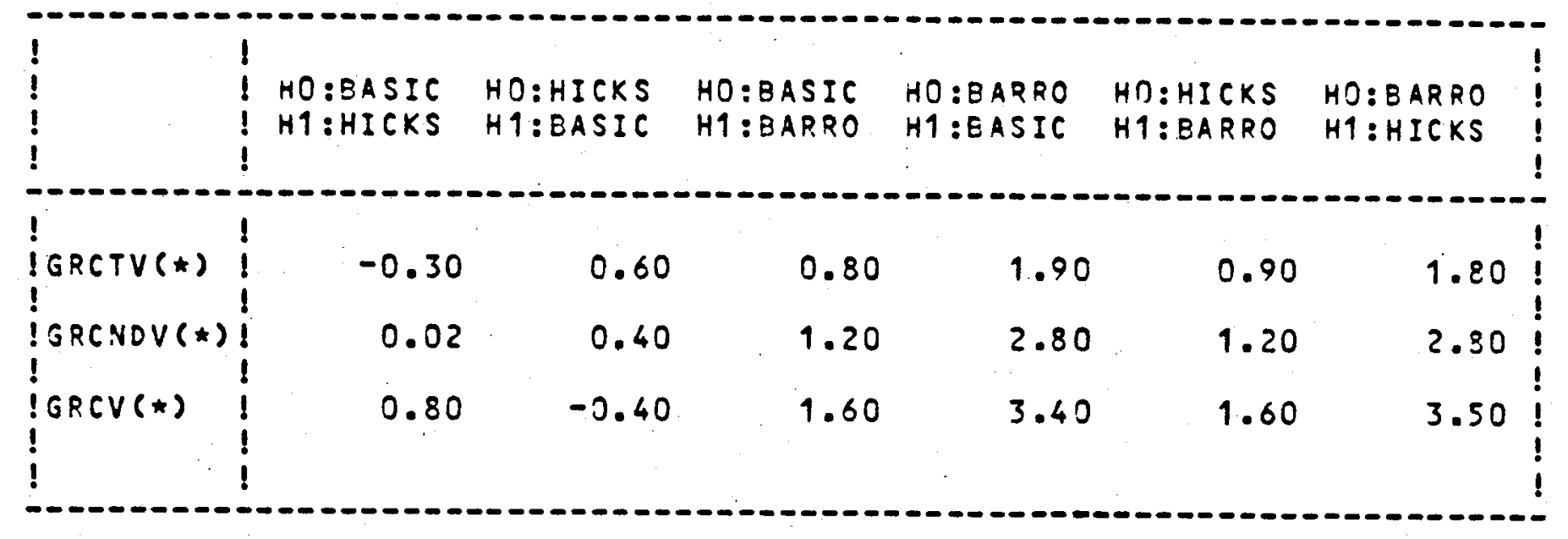

(*) SEE NOTES TO TABLE 1.

(1) THE J STATISTIC IS ASYMPTOTICALLY T-DISTRIBUTED. (MC KINNON AND DAVIDSON $(1 Y 81)$ ). 
NON NESTED TESTS FOR MODEL SPECIFICATION: BEL $J-I E S T(1)$

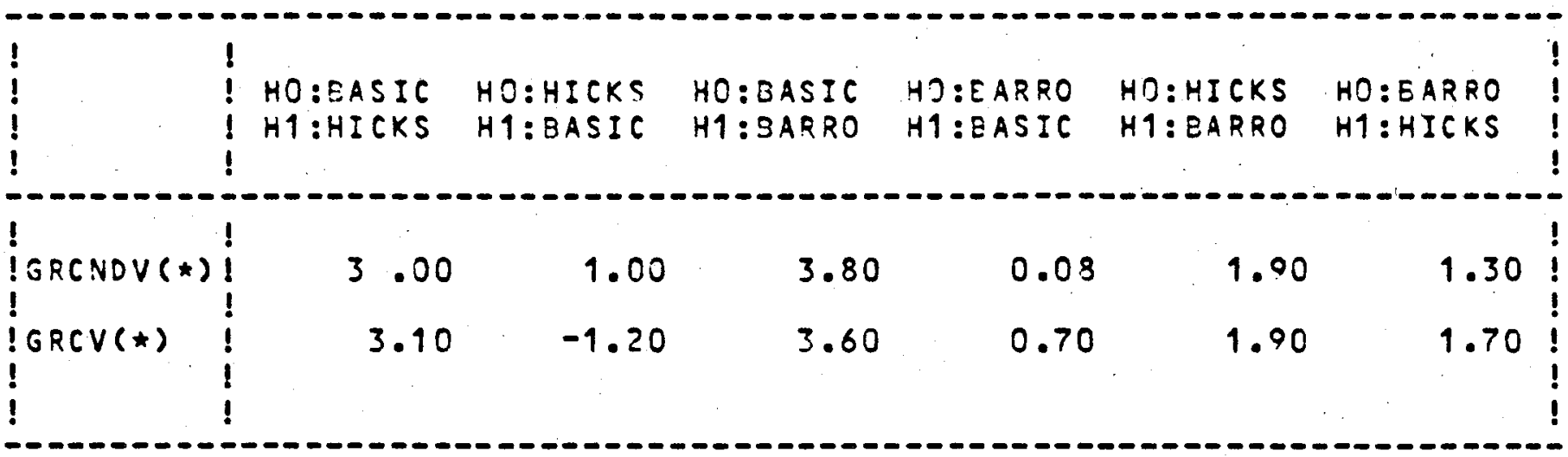

(*) SEE NOTES TO TABLE 1.

(1) THE J STATISTIC IS ASYMPTOTICALLY T-DISTEIBUTED. (MC KININON AND DAVIDSON $(1 Y 31))$. 


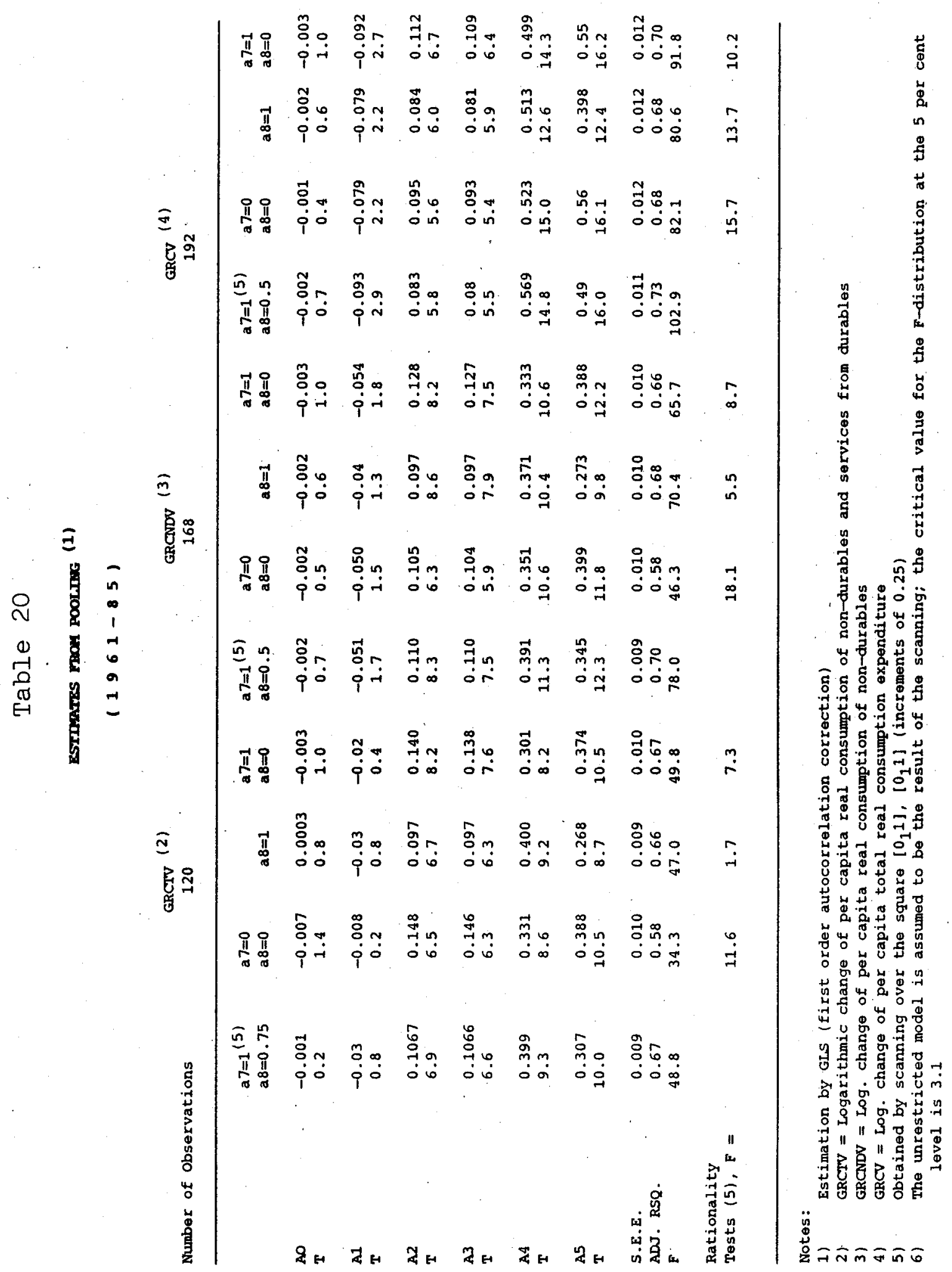


Table 21

NON NESTED TESTS FOR MUDEL SPECIFICATION: POOLING $J-T E S T(1)$

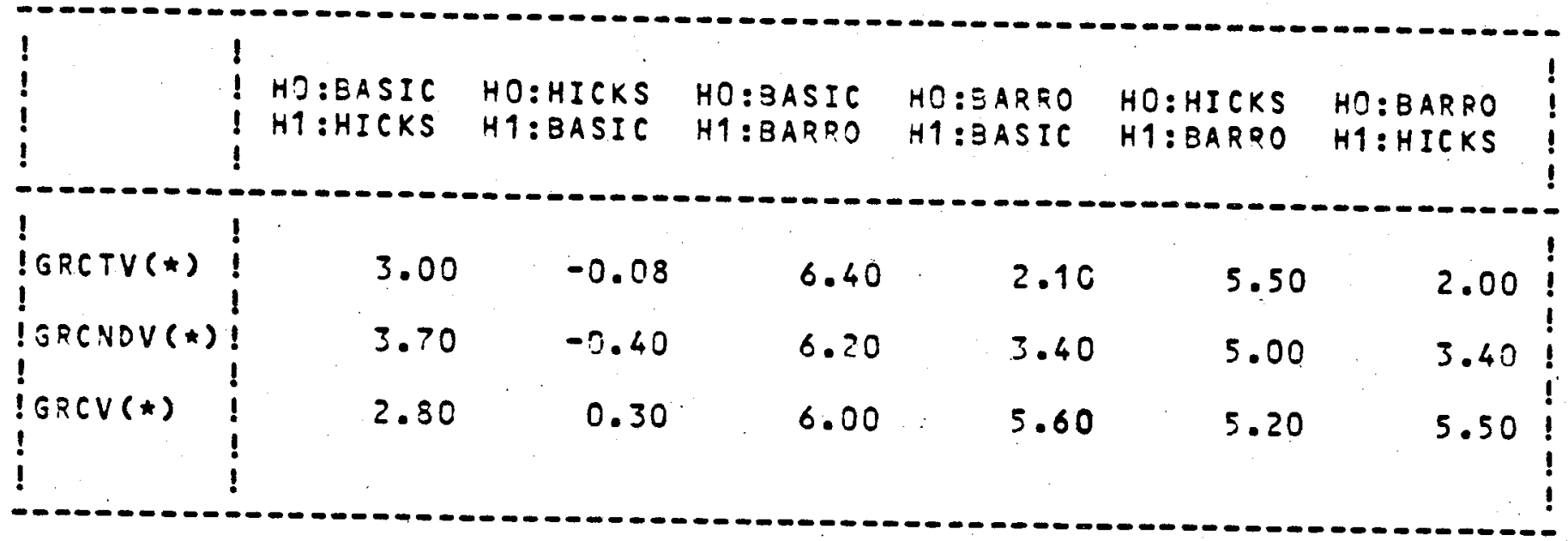

(*) SEE NCTES TO TABLE 1 .

(1) THE J STATISTIC IS ASYMPTCTICALLY T-DISTRIBUTED. (MC KINNON AND DAVIDSON (1Y31)). 
Table 22
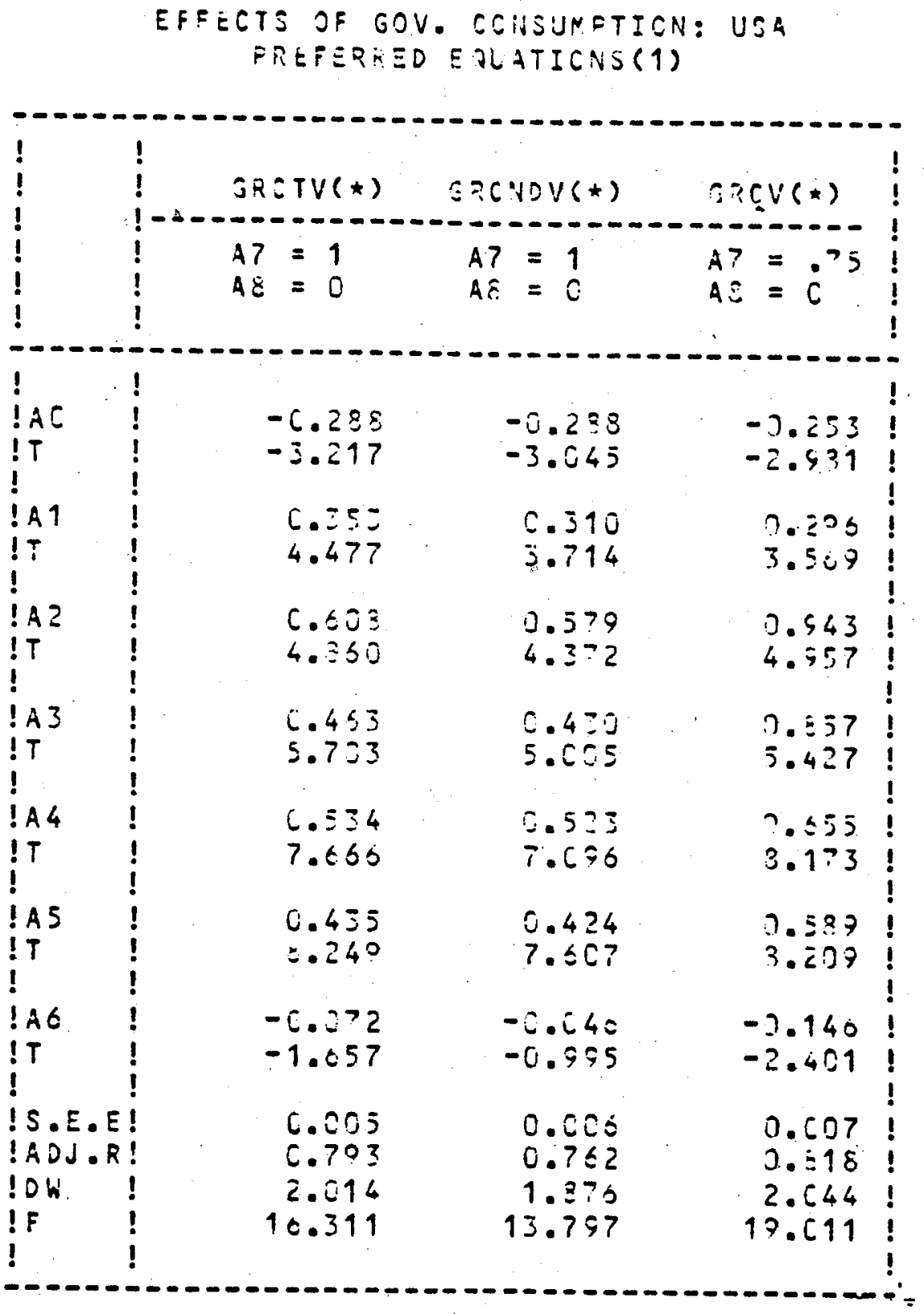

(*) SEE $A O T E S$ TO TABLE 4.

(1) CETAINED EY SGAUAING OVER THE SQUARE $[(0,1),(0,1)]$. 


\section{Table 23}

EFFECTS OF GOV. CONSUMPTIOH: JPN PREFERRED EQUATIONS(1)

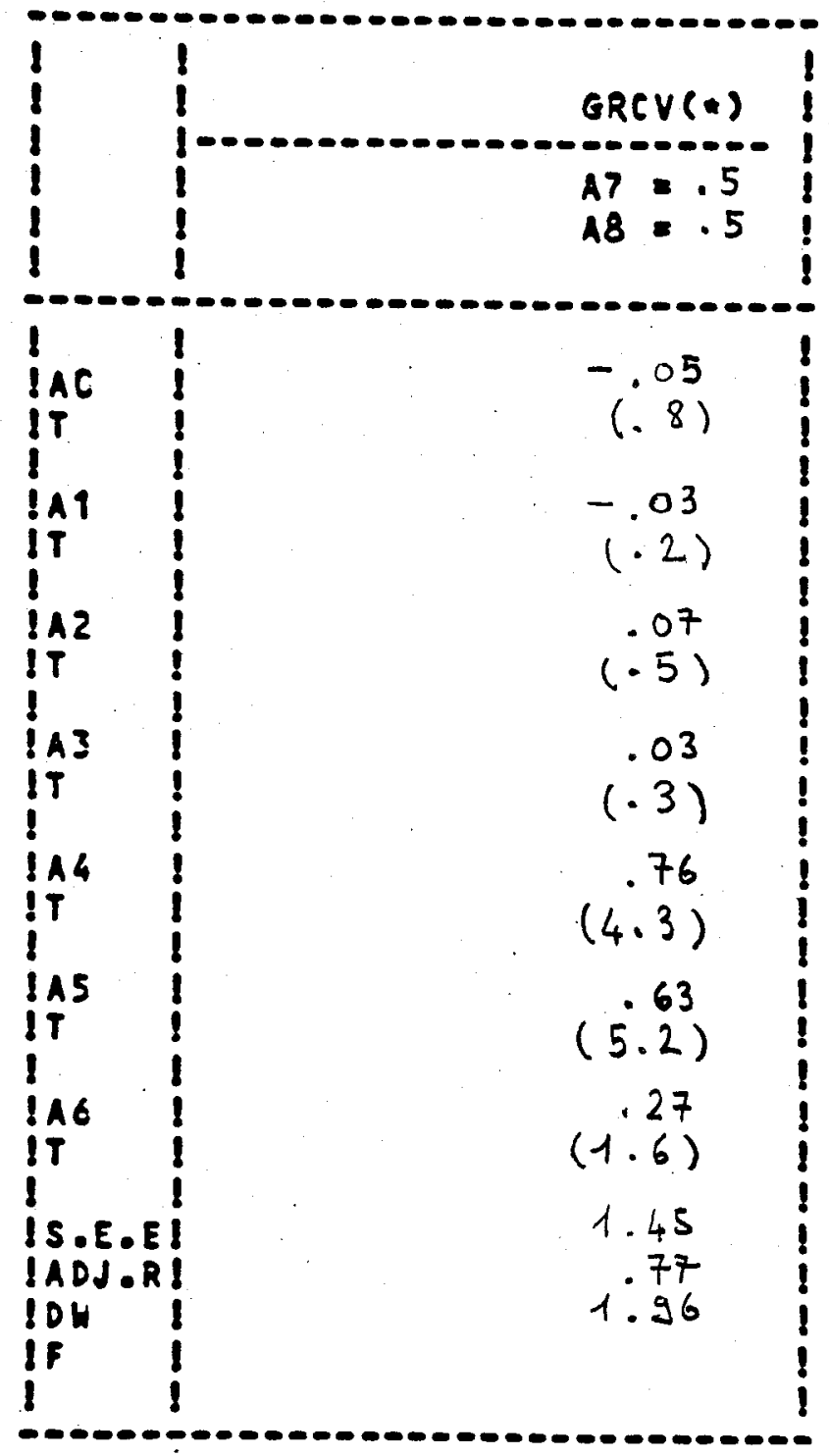

(\#) SEE nOTES TO TABLE 4 .

(1) OETAIHED BY SCAHAIHG CVER THE S2JARE $[(0,1),(2,1)]$. 
Table 24
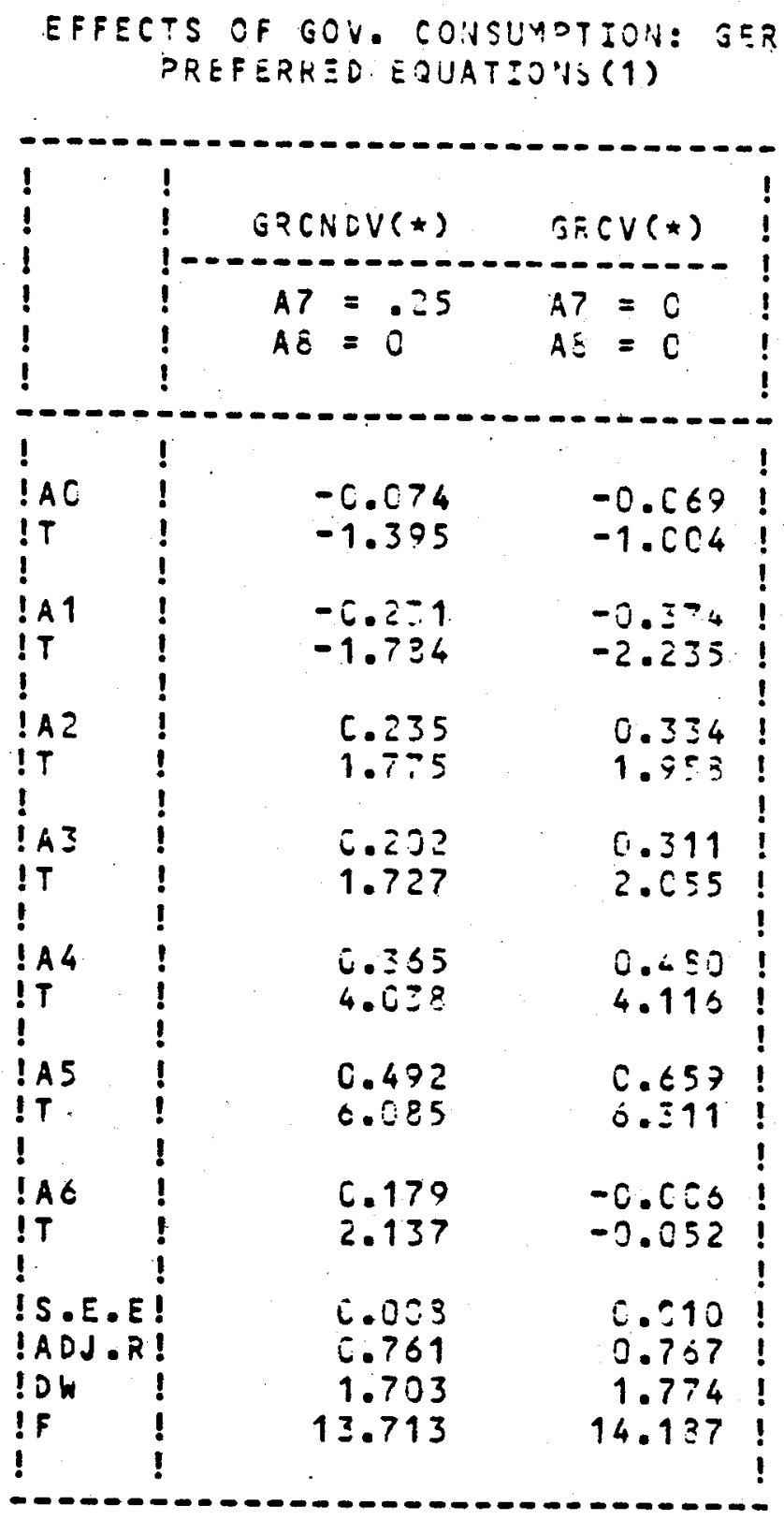

(*) SEE NOTES TO TABLE 4.

(1) DETAINED BY SCANNIHS CVER THE SUUARE $[(0,1),(2,1)]$. 
Table 25
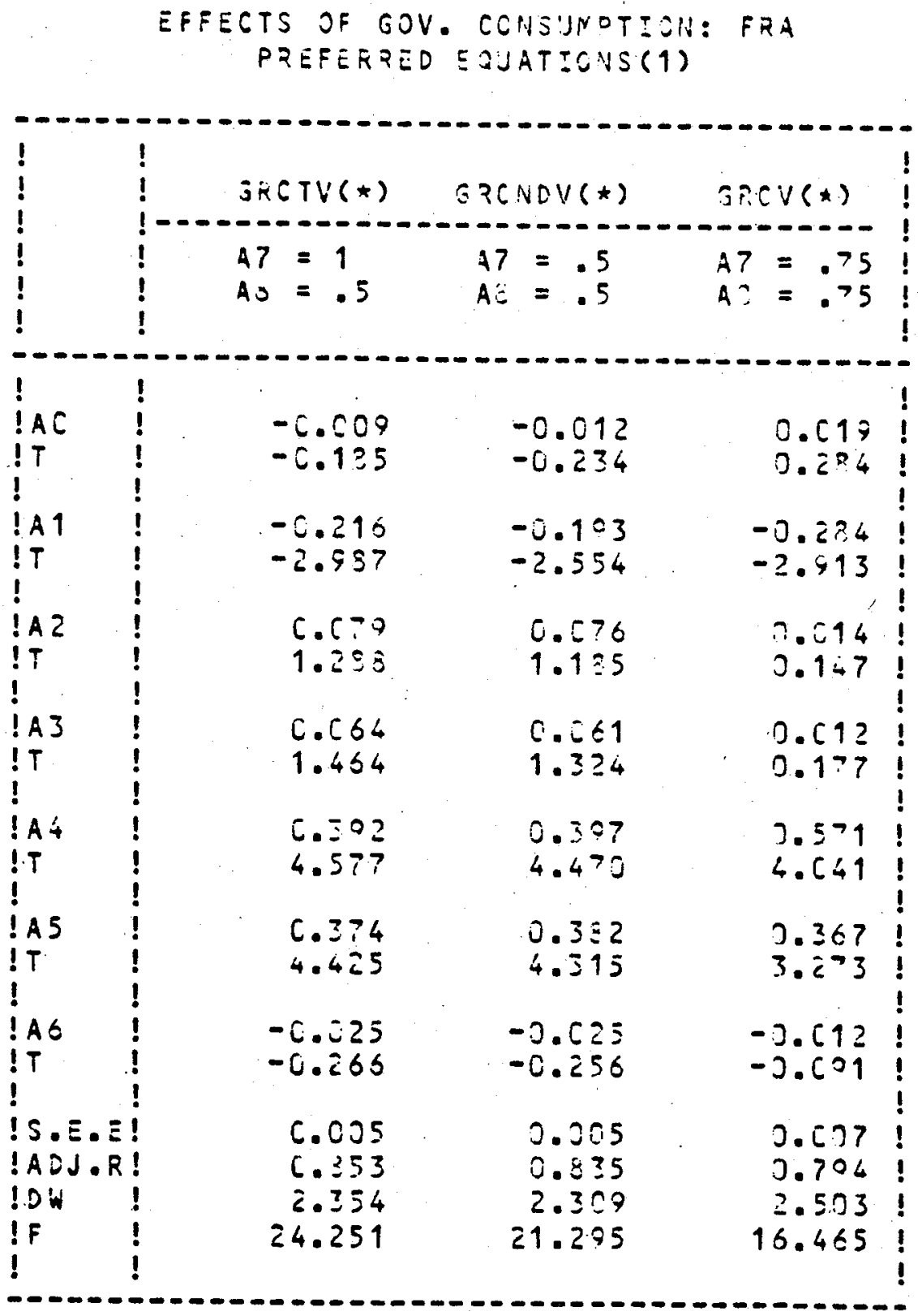

(*) SEE NOTES TO TABLE 4 .

(1) OETAINED SY SCAVNINS CVER THE SZUARE $[(?, 1),(0,1)]$. 
Table 26

\section{EFFECTS OF SOV. CENSUNOTION: UKH \\ PREFERPED ERUATICNS(1)}

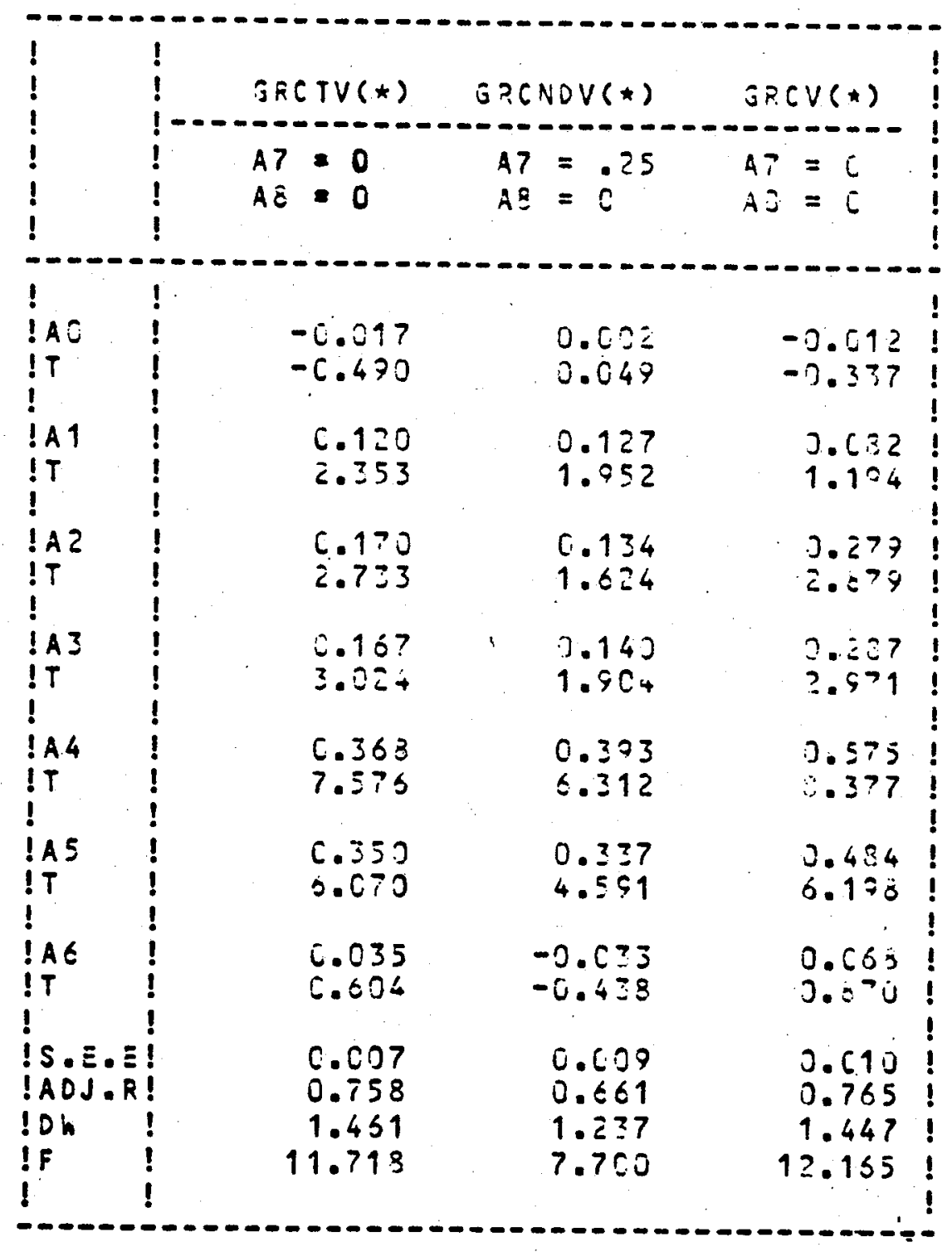

(*) SEE NOTES TO TABLE 4 .

(1) OETAINED EY SCAIVINZ CVEK THE SIUA?E $:(0,1),(0,1)$. 
Table 27
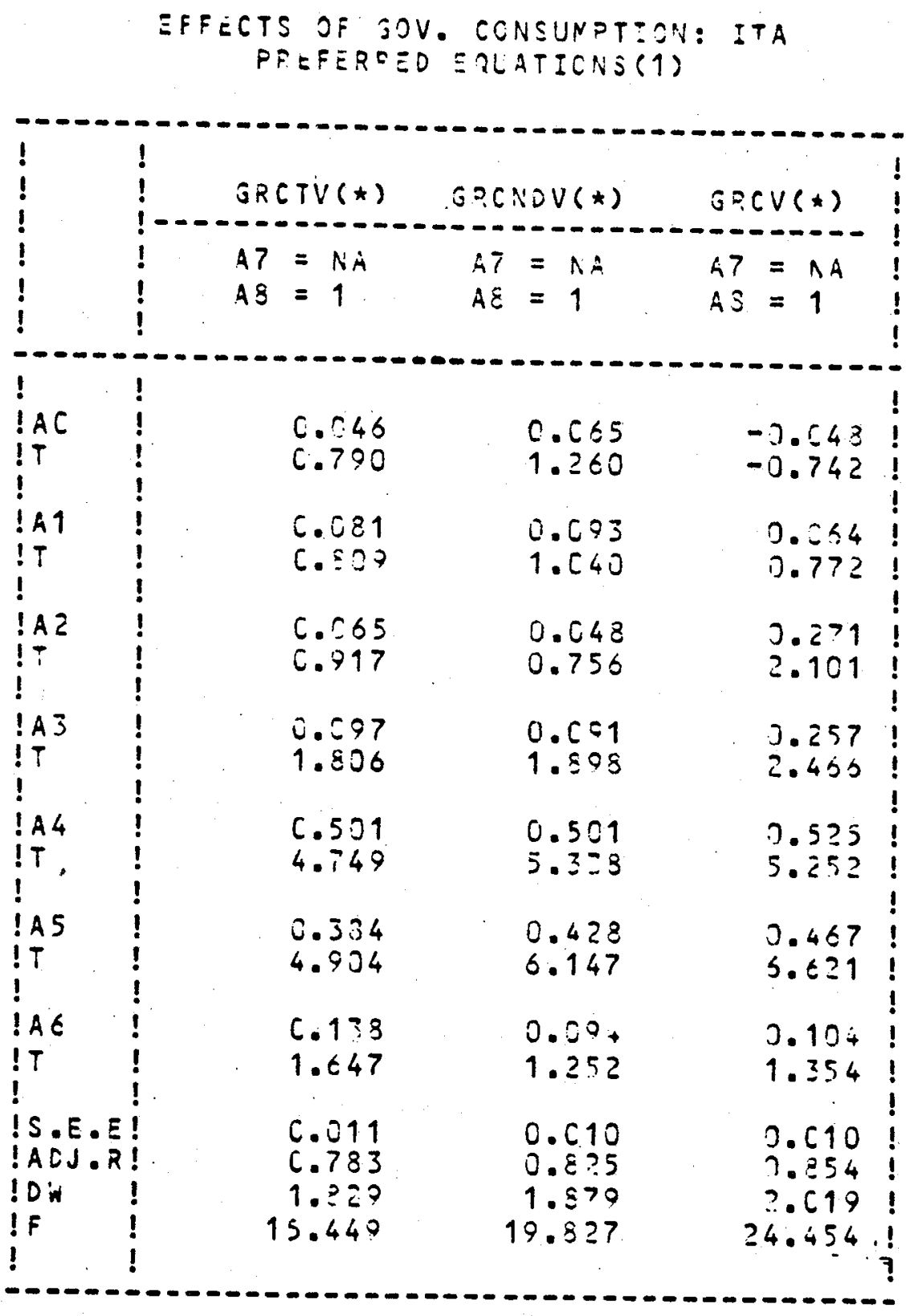

(*) SEE NOTES TO TABLE 4.

(1) OETAINED EY SCAUNINS OVER THE SQUARE $[(0,1),(0,1)]$. 
Tabìe 28

EFEECTS OF GOV. CONSUMETION: CAN

PREFERRED EQLATECNS(1)

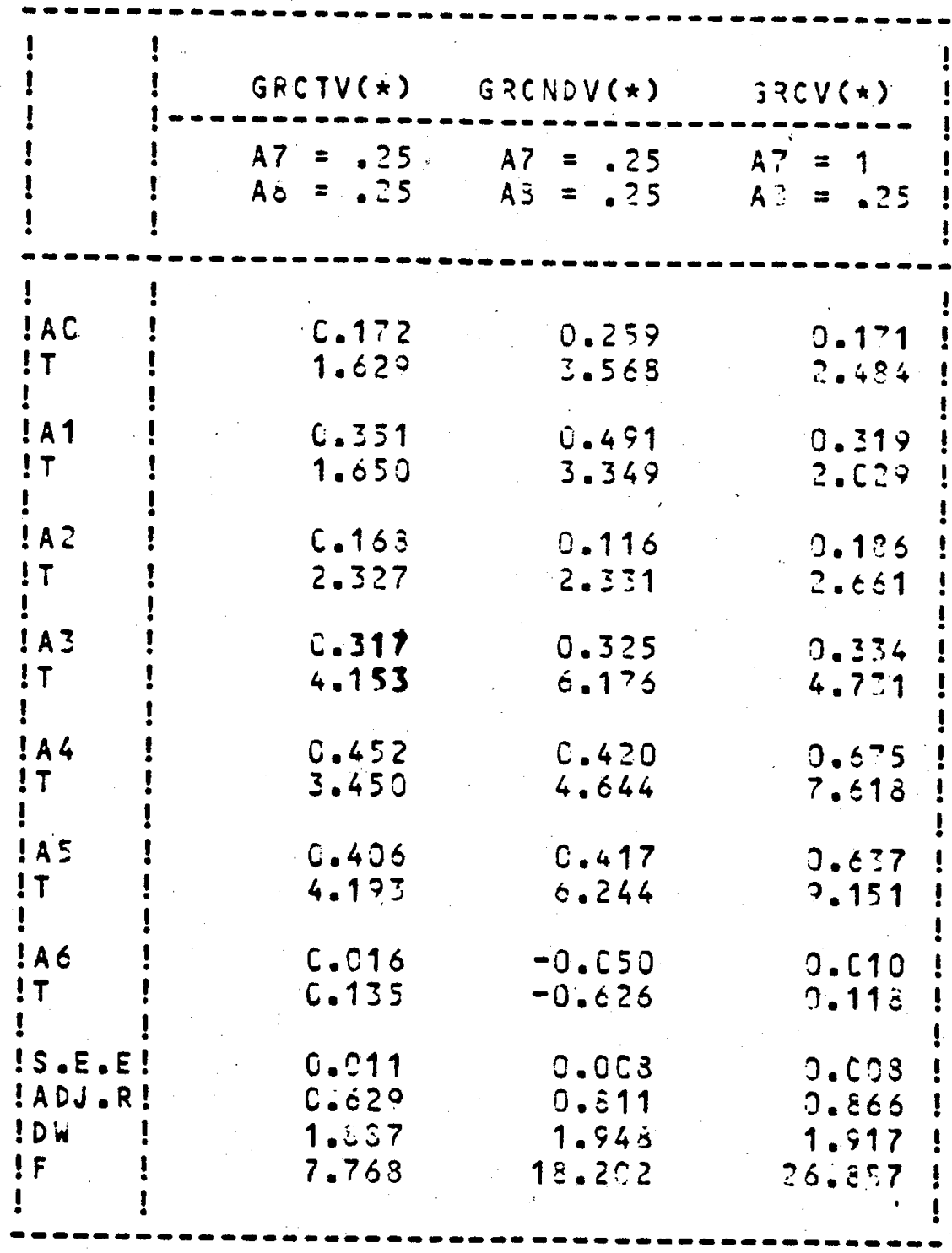

(*) SEE ACTES TO TABLE 4 .

(1) OBTALIIED BY SCAUNINS OVER THE SOUARE $[(0,1),(2,1)]$. 
Table 29
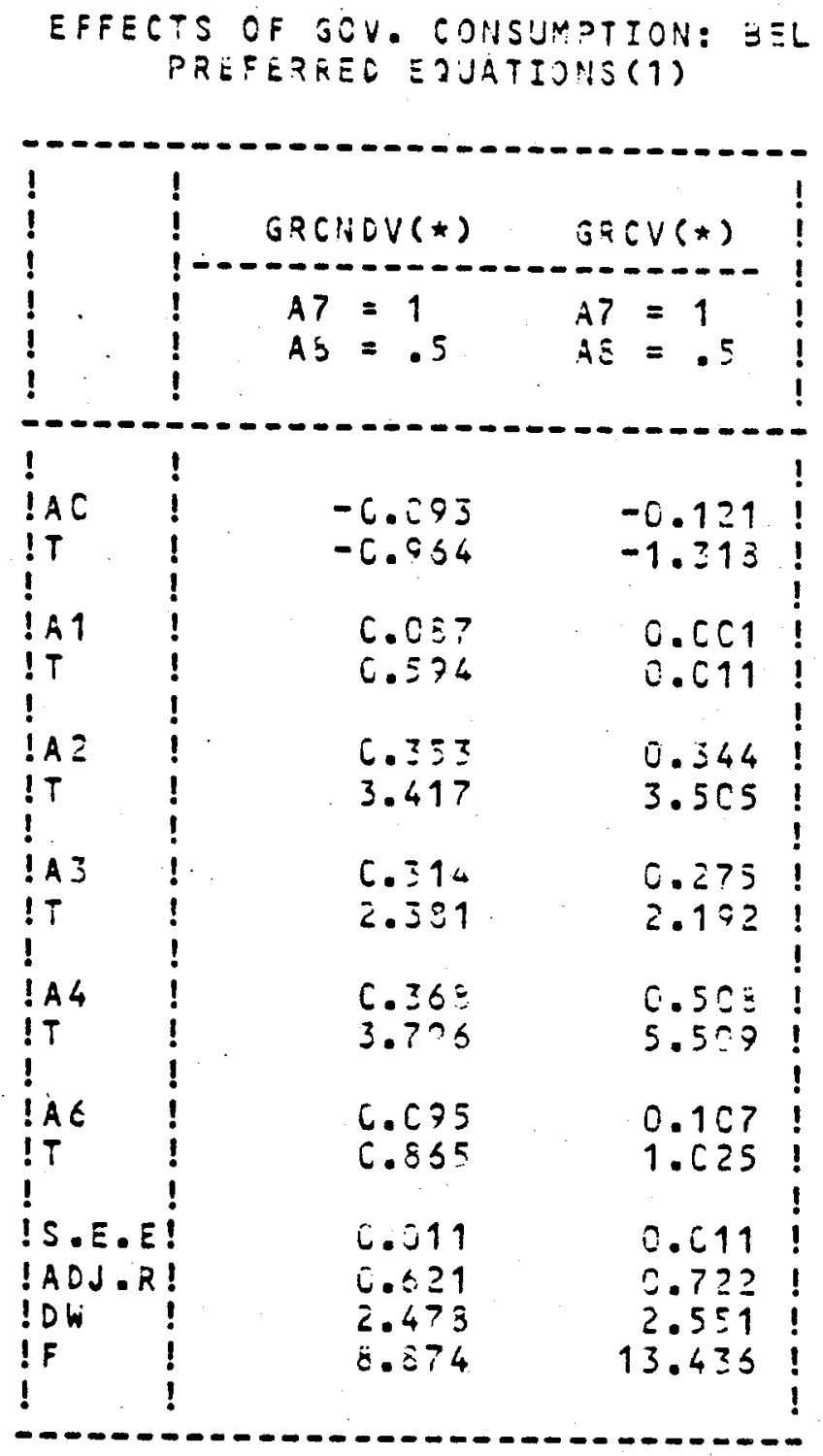

(*) SEE NOTES TO TABLE 4 .

(1) CETAINED BY SCAINIING OVER THE SJUARE $[(0,1),(0,1)]$. 

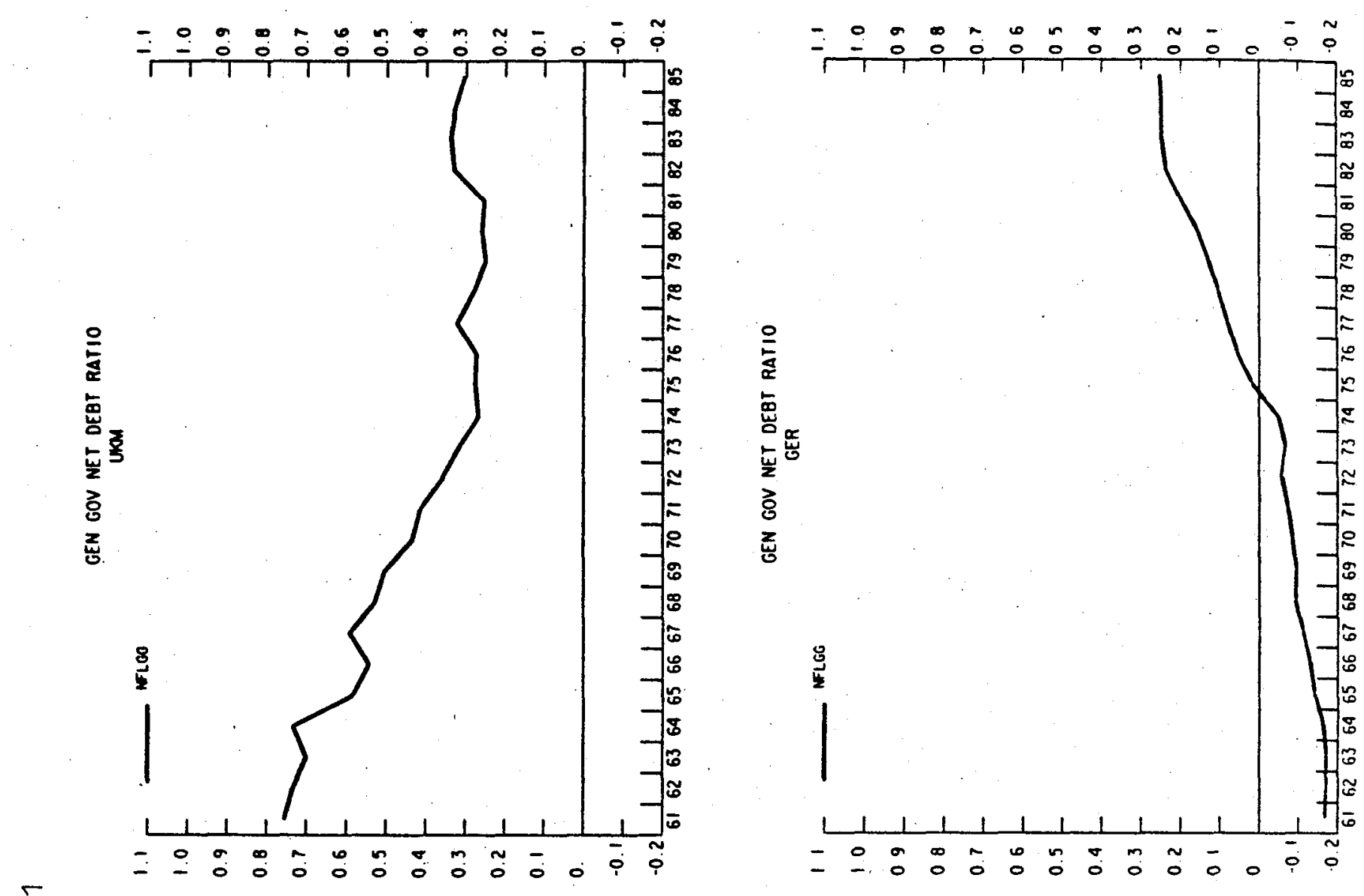

岕
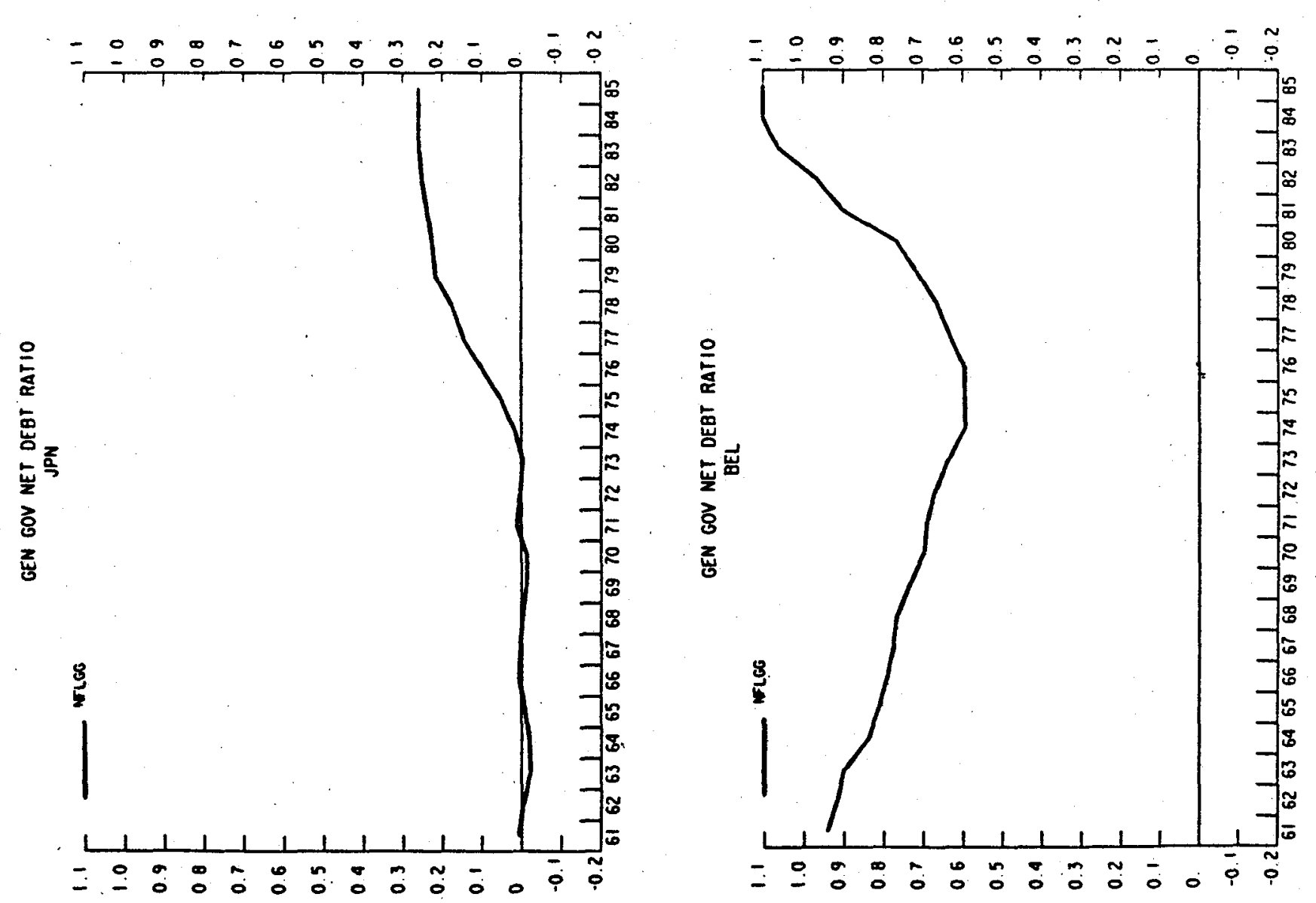

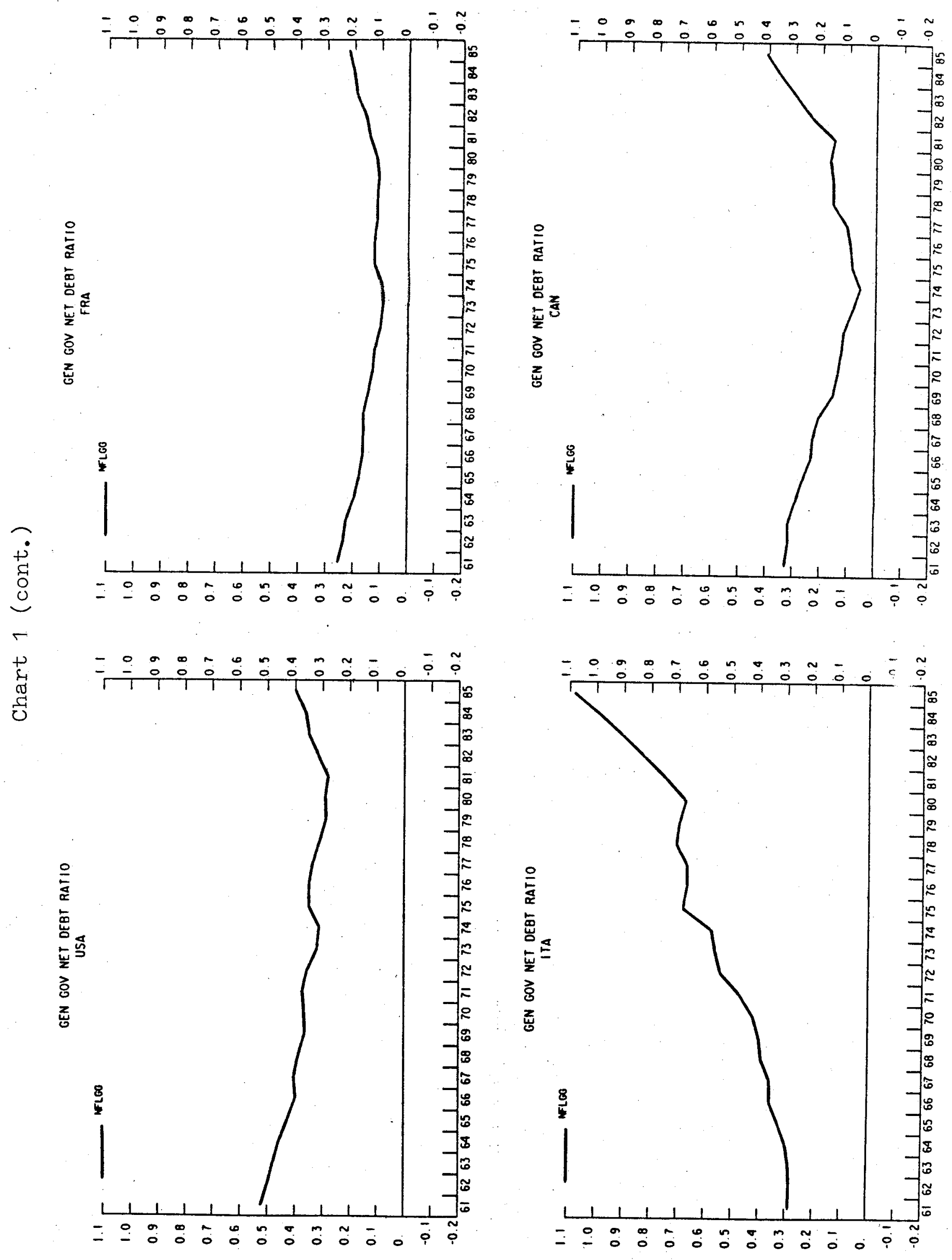

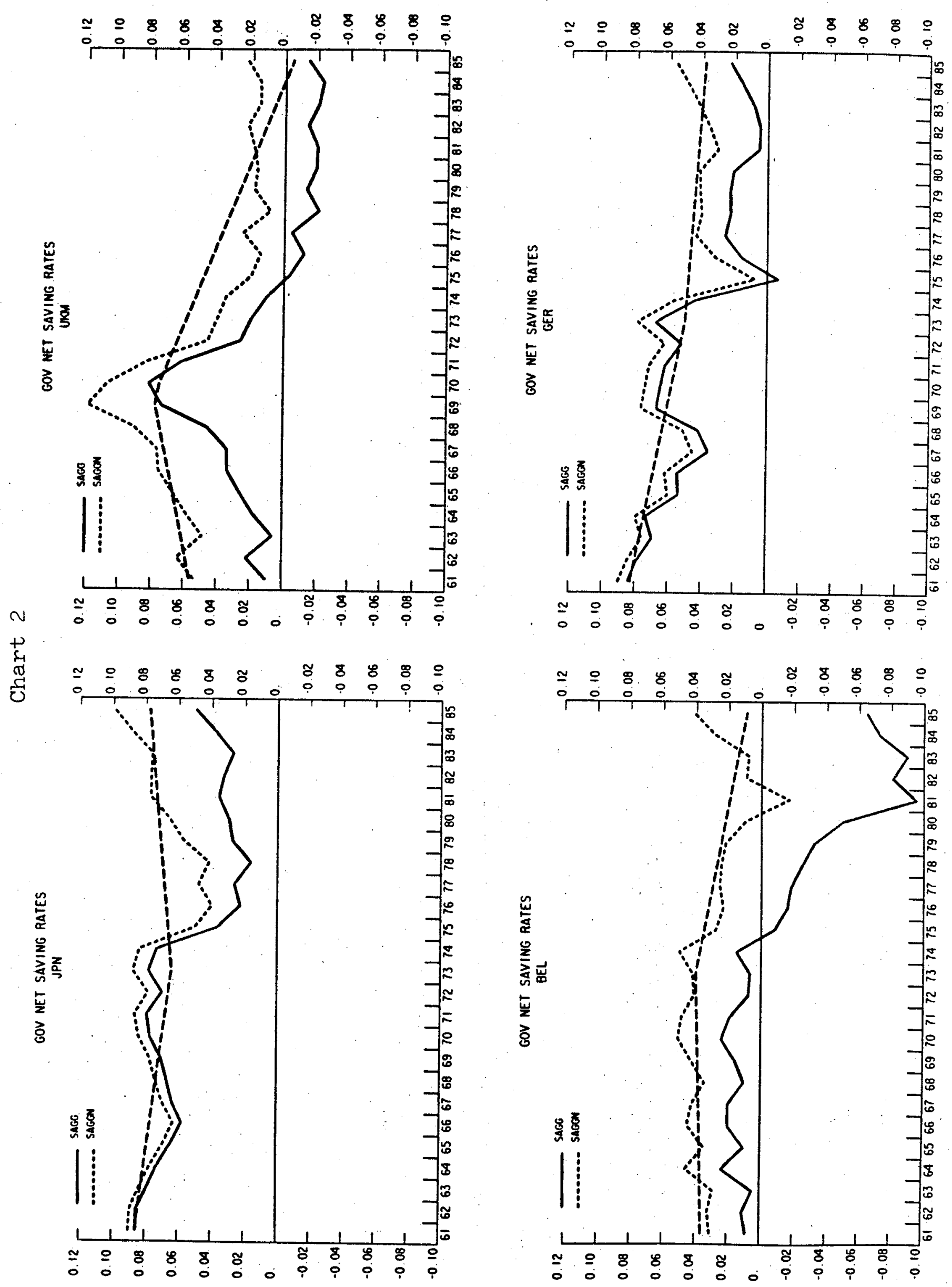

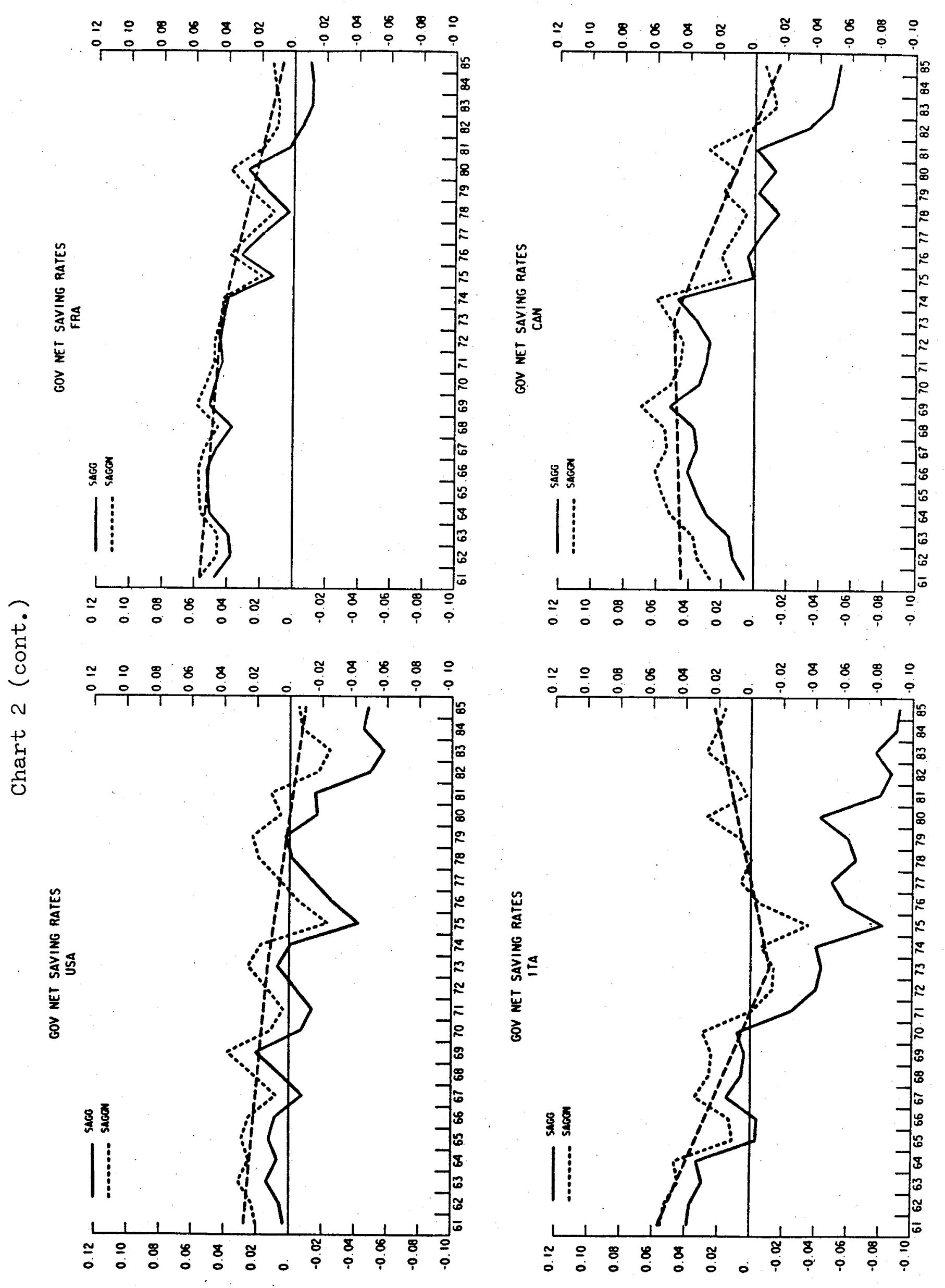

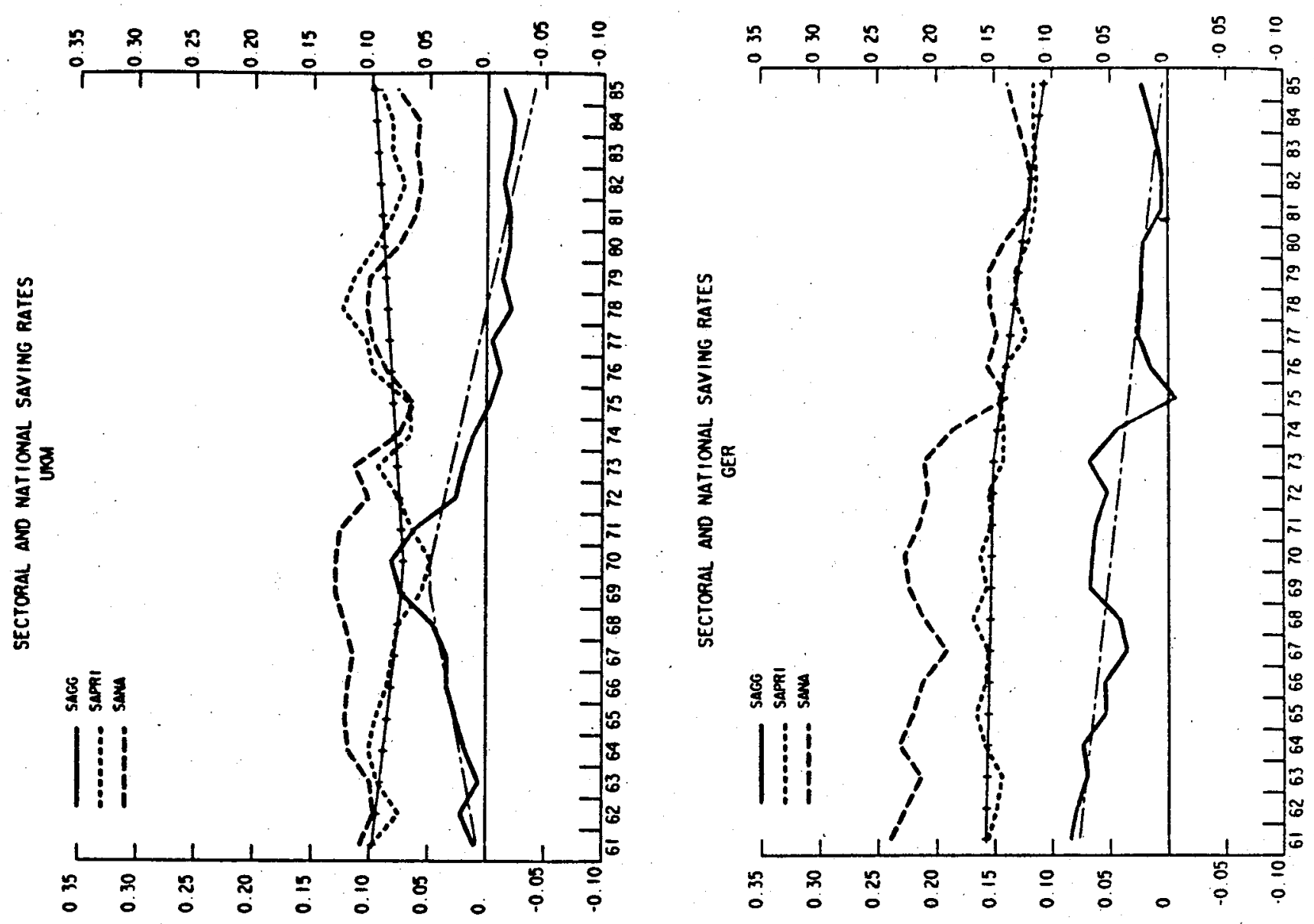

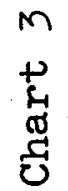
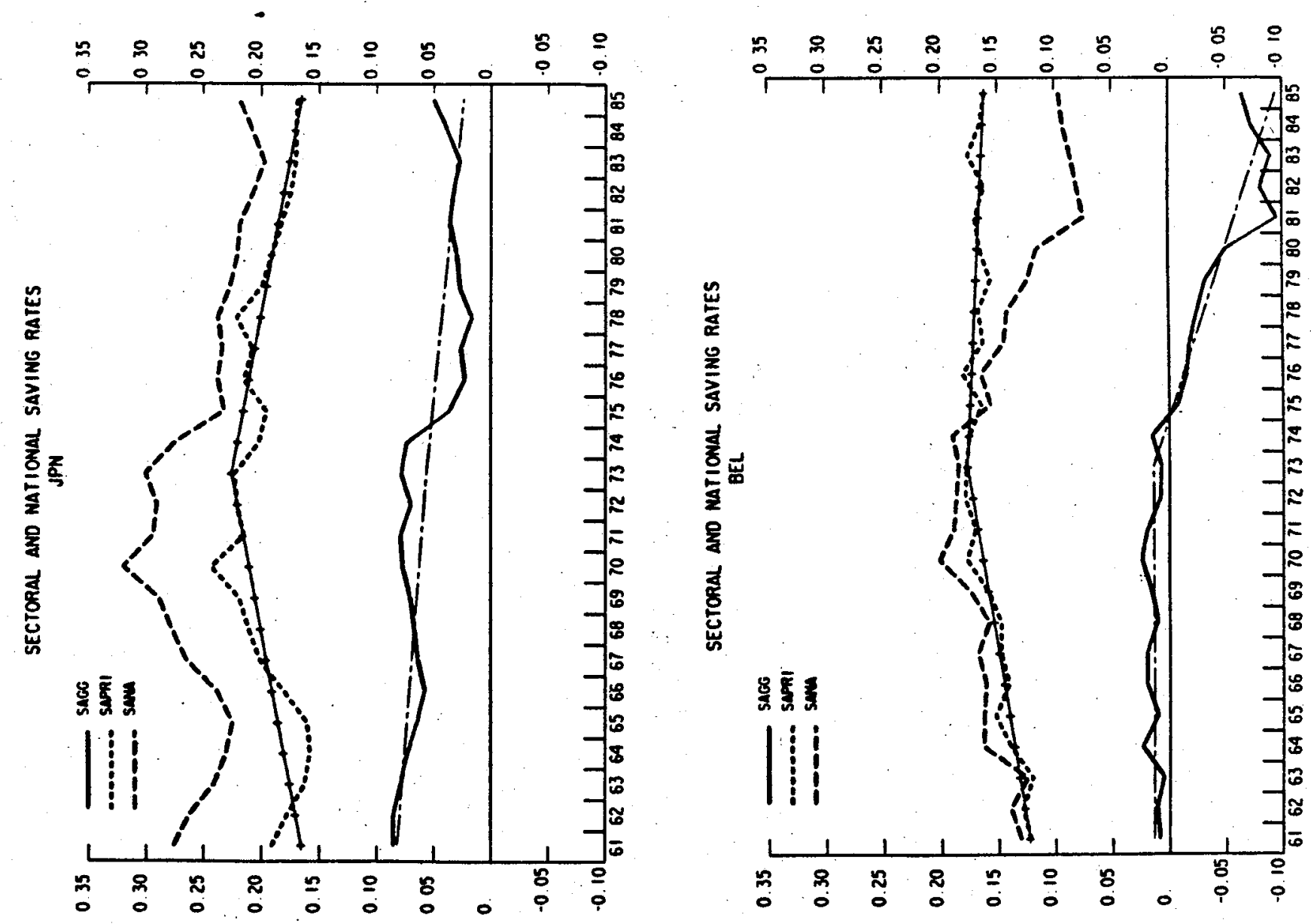

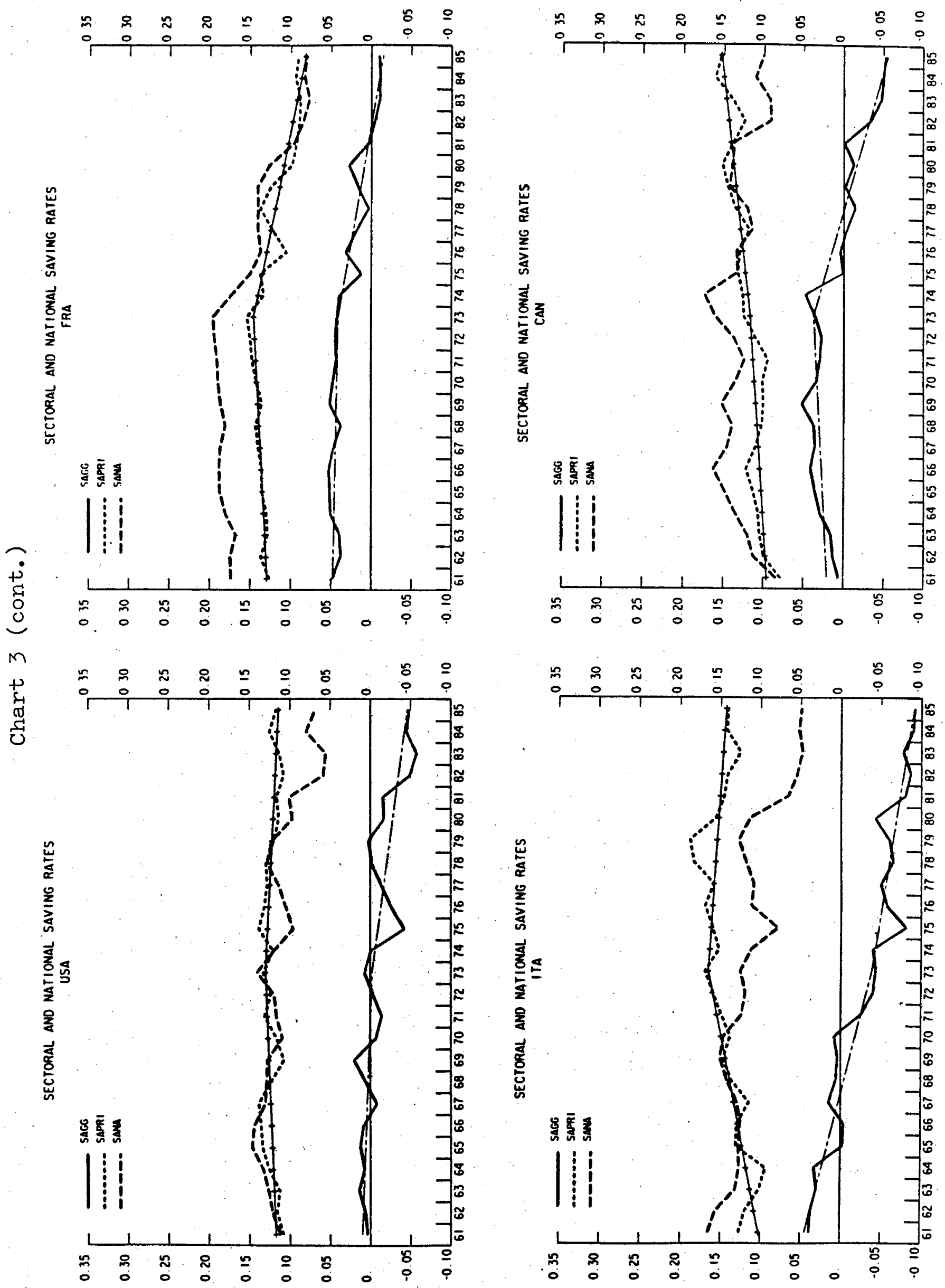

$m$
है
है

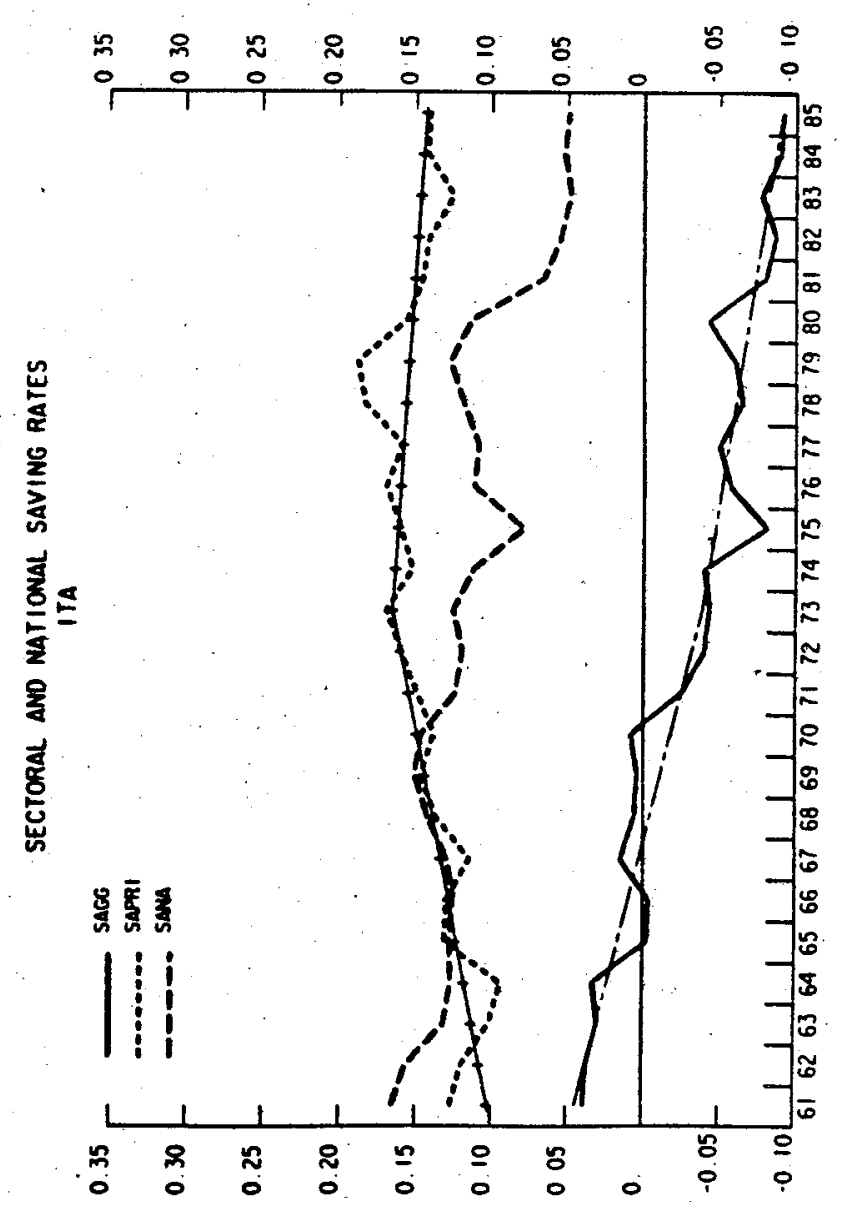




\section{REFERENCES}

Aschauer, D.A. (1985), "Fiscal Policy and Aggregate Demand", American Economic Review, March, pp.117-127.

Attfield, C.L.F. \&.M.J. Browning (1985), "A Differential Demand System, Rational Expectations and the Life-Cycle Hypothesis", Econometrica, Vol.53, No.1, January, pp.31-48.

Bailey, M. (1962), National Income and the Price Level, New York: McGraw Hill.

Barnett, W.A. (1979), "Theoretical Foundations for the Rotterdam Model", The Review of Economic Studies, pp.109-130.

Barro, R. (1974), "Are Government Bonds Net Wealth?", Journal of Political Economy, Vol.82, No.6, November/December, pp.1095-1117.

Barro, R. (1984), Macroeconomics, Wiley.

Becker, G. (1974), "A Theory of Social Interactions", Journal of Political Economy, Vol.82, No.6, November/December, pp.1063-1093.

Bernheim, B.D. (1987), "Ricardian Equivalence: an Evaluation of Theory and Evidence", NBER Working Paper No.2330, July.

Blanchard, 0. (1985), "Debt, Deficits and Finite Horizons", Journal of Political Economy, Vol.93, April, pp.223-247.

Blinder, A. \& A. Deaton (1986), "The Time Series Consumption Function Revisited", Brookings Papers on Economic Activity No.1, pp.465-511.

Boskin, M.J. \& L.J. Kotlikoff (1985), "Public Debt and U.S. Saving: A New Test of the Neutrality Hypothesis", National Bureau of Economic Research, Working Paper No.1646, June.

Buiter, W. (1977), "Crowding Out and the Effectivenss of Fiscal Policy" Journal of Public Economics, Vol.7, June, pp.309-328.

Buiter, W. \& J. Tobin (1980), "Debt Neutrality, a Brief Review of Doctrine and Evidence", in G. Von Furstenberg (ed.), Social Security versus Private Saving in Post Industrial Societies, Series on Capital Investment and Saving, Vol.I (Cambridge, Mass., Ballinger Publishing Co.).

Carmichael, J. (1987), "Pitfalls in Testing the Ricardian Equivalence Theorem", mimeo.

Chan-Lee, J.H. (1986), "Pure Profit Rates and Tobin's $q$ in Nine OECD Countries", OECD Economic Studies, No.7, Autumn, 205-232.

Chouraqui, J.C., B. Jones \& R.B. Montador (1986); "Public Debt in a Medium-Term Perspective", OECD Economic Studies, No.7, Autumn, 103-153. 
David, P.A. \& J.L. Scadding (1974), "Private Savings: Ultrarationality, Aggregation and Denison's 'Law", Journal of Political Economy, Vol.82 I, March/April, 225-249.

Davidson, J.E.H., D.F. Hendry, F. Srba \& S. Yeo (1978), "Econometric Modelling of the Aggregate Time-Series Relationship between Consumers' Expenditure and Income in the U.K.", The Economic Journal, Vol.88, December, 661-692.

Davidson, R. \& J.G. Mackinnon (1981), "Several Tests for Model Specification in the Presence of Alternative Hypotheses", Econometrica, Vol.49, No.3, $781-793$.

Deaton, A. (1977), "Involuntary Saving Through Unanticipated Inflation", American Economic Review, Vol.67, December, pp.899-910.

Deaton, A. (1986), "Life-Cycle Models of Consumption: Is the Evidence Consistent with the Theory?", NBER Working Paper No.1910, April.

Diewert, W.E. (1974), "Intertemporal Consumer Theory and the Demand for Durables", Econometrica, Vol.42 No.3, May.

Feldstein, M. (1982), "Government Deficits and Aggregate Demand", Journal of Monetary Economics, Vol.9, pp.1-20.

Flavin, M.A. (1981), "The Adjustment of Consumption to Changing Expectations about Future Income", Journal of Political Economy, Vol.89, pp.974-1009.

Flavin, M.A. (1985), "Excess Sensitivity of Consumption to Future Income: Liquidity Constraints or Myopia?", The Canadian Journal of Economics, Vol.18, pp.117-136.

Hall, R.E. (1978), "Stochastic Implications of the Life Cycle-Permanent Income Hypothesis: Theory and Evidence", Journal of Political Economy, Vol.86, pp.971-987.

Hall, R.E. (1985), "Real Interest and Consumption", NBER Working Paper No.1694, August.

Hansen, L.P. \& K. Singleton (1983), "Stochastic Consumption, Risk Aversion, and the Temporal Behavior of Asset Returns", Journal of Political Economy, Vol.91, March, pp.249-2.65.

Hayashi, F. (1985), "Tests for Liquidity Constraints: a Critical Survey", NBER Working Paper No.1720, October.

Hendry, D.F. \& T. Von Ungern-Sternberg (1981), "Liquidity and Inflation Effects on Consumers' Behavior" in A. Deaton (ed.) Essays in the Theory and Measurement of Consumers' Behaviour, Cambridge University Press.

Hubbard, R.G. \& K.L. Judd (1986), "Liquidity Constraints, Fiscal Policy and Consumption", Brookings Papers on Economic Activity, No.1, pp.1-50.

Jappelli, T. \& M. Pagano (1987), "Liquidity Constraints and Capital Market Imperfections: an International Comparison", Working Paper Consiglio Nazionale delle Ricerche, June, Proget to Finalizzato Economia, Roma. 
Jump, G.V. (1980); "Interest Rate, Inflation Expectations, and Spurious Elements in Measured Real Income and Saving", American Economic Review, Vol.70, No.5, 990-1004.

Kessler, D.,. S. Perelman and P. Pestieau (1986), "L'hypothèse d'équivalence entre impôt et emprunt: un test sur les pays de l'OCDE", Annales d'économie et de statistique, No.3, juillet/septembre, pp.141-149.

Kmenta, J. (1971), Elements of Econometrics, McMillan, New York.

Kochin, L.A. (1974), "Are Future Taxes Anticipated by Consumers?", Journal of Money, Credit and Banking, Vol.VI, No.3, August, pp.385-394.

Kormendi, R.C. (1983), "Government Debt, Government Spending and Private Sector Behavior", American Economic Review, Vol.73, pp.994-1010.

Koskela, E. \& M. Virèn (1983), "National Debt Neutrality: Some International evidence", Kyklos, Vol.36, No.4, pp.575-588.

Lecaldano Sasso La Terza, E., G. Marotta \& R. Masera (1984), "Consumo, risparmio e tasso d'interesse: la correzione per l'inflazione", in Moneta ed Economia Nazionale, Cassa di Risparmio di Torino.

Leiderman, L. \& A. Razin (1987), "Testing Ricardian Neutrality with an Intertemporal Stochastic Model", NBER Working Paper No.2258, May.

Mankiw, G.N. (1981); "The Permanent Income Hypothesis and the Real Interest Rate", Economics Letters, V.ol.7, pp.307-311.

Mankiw, G.N. (1985), "Consumer Durables and the Real Interest Rate", Review of Economics and Statistics, Vol.LXVII No.3, August, pp.353-362.

Marotta, G. (1984), "Un'indagine econometrica sui consumi nazionali (7201-8104)", in Ricerche quantitative per la politica economica, Vol.II, Roma, Bank of Italy.

Marotta, G. (1983), "Un'indagine econometrica sui consumi privati in Italia (7102-8004)", in Ricerche sui modelli per la politica economica, Vol.I, Roma, Bank of Italy.

McCallum, B. (1984), "Are Bond Financed Deficits Inflationary? A Ricardian Analysis", Journal of Political Economy, Vol.92, February, pp.123-135.

Miller, M. \& C. Upton (1974), Macroeconomics: A Neoclassical Introduction, Homewood, Illinois.

Modigliani, F. (1961), "Long Run Implications of Alternative Fiscal Policies and the Burden of the National Debt." The Economic Journal, Vol.71, December, pp. 207-210.

Modigliani, F. (1986), "Life-Cycle, Individual Thrift and the Wealth of Nations", American Economic Review, vol.76, No.3, 297-313. 
Modigliani, F. \& A, Ando (1963), "The 'Life-Cycle' Hypothesis of Saving: Aggregate Implications and Tests", American Economic Review, Vol. 53, March, pp.55-83.

Modigliani, F. \& A. Sterling (1986), "Government Debt, Government Spending and Private Sector Behavior: Comment", American Economic Review, Vol.76, December, pp.1168-1179.

Modigliani, F. \& T. Jappelli (1986), "Fiscal policy and saving in Italy since 1860", paper presented at the International Conference on "Private Saving and Public Debt, Alghero.

Modigliani, F., T. Jappelli \& M. Pagano (1985), "L'impatto della politica fiscale e dell'inflazione sul risparmio nazionale:il caso italiano", Moneta e Credito, pp.123-162.

Muellbauer, J. (1986), "Habits, Rationality and Myopia in the Life-Cycle Consumption Function", CEPR Discussion Paper No.112, June.

Nicoletti, G. (1987), "Empirical Tests of the Tax-Discounting Hypothesis: Models and Results", OECD, mimeo.

0'Driscoll, G.P. Jr. (1977), "The Ricardian Nonequivalence Theorem", Journal of Political Economy, Vol.85, No.1, February, pp.208-209.

Pesaran, M.H. \& R.A. Evans (1984), "Inflation, Capital Gains and U.K. Personal Savings: 1953-1981", The Economic Journal, vol.94, June, 237-257.

Poole, W. (1972), "The role of Interest Rates and Inflation in the Consumption Function", Brookings Papers on Economic Activity, No.1, pp.211-219.

Poterba, J.M. \& L.H. Summers (1987), "Recent U.S. Evidence on Budget Deficits and National Savings", NBER Working Paper No.2144, February.

Rossi, N. (1986), "Spesa pubblica, tasso d'interesse reale e risparmio delle famiglie", Working Paper Consiglio Nationale delle Ricerche, Progetto Finalizzato Economia.

Rossi, N. and F. Schiantarelli (1985), "Error-Correction, "Surprise" Models and the Differential Approach to the Consumption Function", mimeo.

Rossi, N. \& F. Schiantarelli (1982), "Modelling Consumer Expenditure in Italy 1965-77", European Economic Review, Vol.17, No.3, March, pp.371-391.

Seater, J.J. (1982), "Are Future Taxes Discounted?", Journal of Money, Credit and Banking, Vol.14, No.3, August, pp.376-389.

Seater, J.J. (1985), "Does Government Debt Matter? A Review", Journal of Monetary Economics, vol.16, No.1, July, pp.121-131.

Seater, J.J. \& R.S. Mariano (1985), "New Tests of the Life Cycle and Tax Discounting Hypotheses"; Journal of Monetary Economics, Vol.15, No.2, March, pp.195-215. 
Summers, L. (1984), "The After-Tax Rate of Return Affects Private Savings", American Economic Review Papers and Proceedings, Vol.74, May, pp.249-253

Tanner, E.J. (1978), "Fiscal Policy and Consumer Behavior", The Review of Economics and Statistics, Vol.61, pp.317-321.

Tanner, E.J. (1979), "An Empirical Investigation of Tax Discounting", Journal of Money, Credit and Banking, Vol.XI, No.2, May, pp.214-218.

Theil, H. (1975), Theory and Measurement of Consumer Demand, Vol.1, Amsterdam: North Holland, pp. 205-207.

Theil, H. (1980), The System Wide Approach to Microeconomics, Basil Blackwell, Oxford.

Yawitz, J.B. \& L.H. Meyer (1976), "An Empirical Investigation of the Extent of Tax Discounting", Journal of Money, Credit and Banking, Vol.VIII, No.1, May, pp. 247-254.

Yotsuzuka, T. (1986), "Ricardian Equivalence in the Presence of Capital Market Imperfections", mimeo, MIT.

von Ungern-Sternberg, T. (1981), "Inflation and Savings: International Evidence on Inflation Induced Losses", The Economic Journal, Vol.91, December, 961-976.

von Ungern-Sternberg, T. (1987), "Inflation and the Consumption Function", Weltwirschaftliches Archiv, pp.741-744.

Wickens, M.R. \& H. Molana (1983), "Stochastic Life-Cycle Theory with Varying Interest Rates and Prices", The Economic Journal, pp.133-147. 
